Seminario de Bibliotecología, Información y Sociedad

\title{
Derecho a la información, bien público y bien privado: acceso comunitario y acceso individual
}

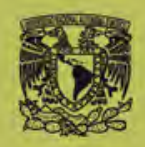


La presente obra está bajo una licencia de:

http://creativecommons.org/licenses/by-ncsa/3.0/deed.es MX

\section{(c) creative}

Eres libre de:

(15)

copiar, distribuir y comunicar públicamente la obra

(D)

hacer obras derivadas

Bajo las condiciones siguientes:

(1)

Atribución - Debes reconocer la autoria de la obra en los têrminos

especificados por el propio autor o licenciante.

No comercial - No puedes utilizar esta obra para fines comerciales.

Licenciamiento Reciproco - Si alteras, transformas o creas una obra a

partir de esta obra, solo podrás distribuir la obra resultante bajo una licencia igual a ésta.

Esto es un resumen fácilmente legible del: texto legal (de la licencia completa)

\section{En los casos que sea usada la presente obra, deben respetarse los términos especificados en esta licencia.}
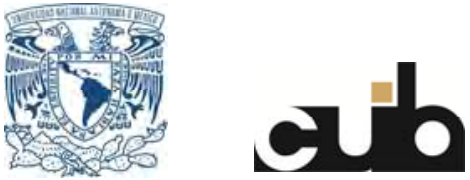
Seminario de Bibliotecología, Información y Sociedad

Derecho a la información, bien público y bien privado: acceso comunitario $y$ acceso individual 

COLECCIÓN

Seminarios de investigación, 16

Centro Universitario de Investigaciones Bibliotecológicas 

Seminario de Bibliotecología, Información y Sociedad

Derecho a la información, bien público y bien privado: acceso comunitario y acceso individual

\author{
Coordinación
}

Estela Morales Campos

Universidad Nacional Autónoma de México 2011 


\begin{tabular}{|c|c|}
\hline $\begin{array}{l}\text { JC598 } \\
\text { S46D4 }\end{array}$ & $\begin{array}{l}\text { Seminario de Bibliotecología, Información y Sociedad } \\
\text { (2010 : México / Costa Rica) } \\
\text { Derecho a la información, bien público y bien privado : } \\
\text { acceso comunitario y acceso } \\
\text { Individual, } 2 \text { al } 5 \text { de noviembre de } 2010 \text { / coordinadora, } \\
\text { Estela Morales Campos.-México : UNAM, Centro Uni- } \\
\text { versitario de Investigaciones Bibliotecológicas, } 2011 \\
\text { xii, 233p. - (Seminarios de investigación 16) } \\
\text { Este seminario se llevó a cabo en el marco del XII Con- } \\
\text { greso de la Sociedad Latinoamericana de Estudios sobre } \\
\text { América Latina y el Caribe (SOLAR) } \\
\text { ISBN: 978-607-02-2146-0 } \\
\text { Colección Seminarios de Investigación antes } \\
\text { Cuadernos de Investigación } \\
\text { 1. Libertad de Información - Conferencias } 2 \text {. Dere- } \\
\text { cho a la información - Conferencias } 3 \text {. Acceso a la } \\
\text { información-Conferencias I. Morales Campos, Estela, } \\
\text { coordinadora II. t. III. ser }\end{array}$ \\
\hline
\end{tabular}

Diseño de portada: Cristopher Barrueta Álvarez.

\author{
Primera Edición 2011 \\ DR (c) UNIVERSIDAD NACIONAL AUTÓNOMA DE MÉXICO \\ Ciudad Universitaria, 04510, México D.F. \\ Impreso y hecho en México \\ Seminarios de investigación16, \\ antes Cuadernos de investigación.
}




\section{Contenido}

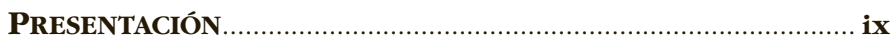

Estela Morales Campos

El derecho a la información como constructo de la reali-

dad social. Discurso de la información e imaginario ............1

Héctor Guillermo Alfaro López

Información y derechos humanos de las mujeres

en América Latina

Beatriz Casa Tirao

Los repositorios de acceso abierto:

una vía para la democratización de la información

y el conocimiento

Saray Córdoba González

Conceptuación de las bibliotecas y otros recursos de información como bienes comunes

Hugo Alberto Figueroa Alcántara

Propiedad intelectual: la información como bien público y bien privado 81

Jesús Francisco García Pérez

Información: un derecho y factor de desarrollo .97

José de Jesús Hernández Flores

El derecho a la información como eje fundamental en las sociedades democráticas.

Rosa María Martínez Rider

La alfabetización informacional en la sociedad de los saberes compartidos 
Apoyo bibliográfico que ofrecen las bibliotecas

de la UNAM a sus estudiantes indígenas.

Gabriela Olguín Martínez

La universidad pública y su compromiso social

en la producción del conocimiento 163

Estela Morales Campos

La información como bien público:

la responsabilidad social del bibliotecólogo 175

Jaime Ríos Ortega

Gestión de la información en pueblos indígenas:

una contextualización desde la experiencia. 187

Florybeth Sánchez Espinoza

El derecho a la información desde la perspectiva costarricense: un bien de carácter público 207

Rosario Solano Murillo y José Pablo Meza Pérez 


\section{Presentación}

G $\mathrm{n}$ el marco del XII Congreso de la Sociedad Latinoamericana de Estudios sobre América Latina y el Caribe (SOLAR), efectuado a inicios de noviembre de 2010 en la ciudad de Heredia, Costa Rica, el Seminario permanente de "Bibliotecología, Información y Sociedad" participó con la realización del simposio "Derecho a la información, bien público y bien privado: acceso comunitario y acceso individual".

Nuestro seminario, en efecto, ha sido invitado a formar parte de los congresos de la SOLAR desde el año 2008 (en dicha ocasión, en la ciudad de Bahía Blanca, Argentina), con lo cual se comenzó a consolidar la meta de sumar la colaboración de especialistas de otros países que estuvieran interesados en la orientación social de nuestra disciplina y, en general, de la información. Por ello, además de los colegas mexicanos que han formado parte del seminario desde su creación y 
Derecho a la información, bien público y bien privado:...

de invitados nacionales, se contó con la valiosa participación de investigadores costarricenses de distintas entidades académicas locales.

El propósito de la temática convocada buscó explicar la importancia cada vez más visible del derecho a la información, teniendo en cuenta cuatro enfoques contrastados pero, sin duda, complementarios: la información como un bien público o como un bien privado, y su correspondiente acceso comunitario o individual. A partir de ese objetivo, el seminario tuvo la oportunidad de enriquecer su quehacer, vislumbrando nuevos entornos, rutas y políticas, susceptibles de promover y fortalecer una amplia serie de bienes comunes en el contexto de la investigación bibliotecológica.

De acuerdo con esas bases, los participantes plantearon y debatieron asuntos vinculados con el derecho a la información, ya sea desde el punto de vista costarricense (en su carácter de bien público) y como factor esencial en los sistemas democráticos, o bien, examinado como construcción de las realidades sociales. De igual modo, se abordaron temas relacionados con las responsabilidades sociales de los bibliotecólogos, en su esfuerzo para que la información sea un satisfactor de carácter público; con la naturaleza de los repositorios de acceso abierto como vías de la democratización del conocimiento; y con el deber social de las universidades públicas para que el conocimiento esté al alcance de todos.

Asimismo, se expusieron ponencias en torno a la información considerada como un derecho y un elemento de desarrollo; la propiedad intelectual, estudiada en 
relación con el derecho a la información; la alfabetización informacional en una sociedad de saberes compartidos; así como la conceptuación de las bibliotecas públicas y su compromiso hacia la población.

Finalmente se plantearon perspectivas relacionadas con sectores sociales específicos: la información y los derechos humanos en las mujeres en el contexto de la región latinoamericana, el apoyo bibliográfico que ofrecen las bibliotecas de la UNAM a usuarios indígenas mexicanos, y la gestión de la información en pueblos indígenas costarricenses.

En ese entorno, el seminario consideró fundamental examinar nociones esenciales para entender los rasgos de un bien común de información, delineando sus características más notables. Uno de los hallazgos más sobresalientes al respecto develó que los bienes comunes de información constituyen un sistema en el cual el uso común y colectivo de la información, si bien es un aspecto controversial, es esencial en nuestros tiempos al abarcar la generación, el uso, la diseminación y la preservación de ese bien. La información como un bien común requiere de marcos teóricos bien estructurados para establecer su defensa y para alentar su uso colectivo. El auge de las tecnologías digitales y la Internet, con todo su acervo de nuevos perfiles culturales, hacen crecer exponencialmente las discusiones en torno a la información considerada como un bien común, privado, colectivo o individual.

El seminario de "Bibliotecología, Información y Sociedad" aún tiene muchas labores por realizar; no obstante, son palpables sus logros al continuar ampliando 
Derecho a la información, bien público y bien privado:...

la participación de colegas de distintos países latinoamericanos, en este caso de académicos costarricenses; se trata de un diálogo que se vislumbra cada vez más enriquecedor que nos impulsa a seguir explorando ese camino para continuar creciendo como grupo de estudio.

Estela Morales Campos,

Coordinadora de Humanidades, UNAM/

Coordinadora del Seminario de "Bibliotecología, Información y Sociedad" 


\title{
El derecho a la información como constructo de la realidad social. Discurso de la información e imaginario
}

\author{
Héctor Guillermo Alfaro López \\ Centro Universitario de Investigaciones Bibliotecológicas \\ Universidad Nacional Autónoma de México \\ galfaro@cuib.unam.mx
}

\begin{abstract}
Con la instauración de la denominada "sociedad de la información" se reconstituyeron las maneras en cómo se desenvolvía e implementaba la información. Al grado de convertirse en un bien central que permitía otra forma de articular las estructuras sociales, economía, política, cultura, etcétera, empezaron a reconstituirse a partir de los expansivos procesos informacionales. Asimismo este uso intenso y extenso en gran escala de la información redundó en la necesidad de conocer más a fondo tal fenómeno, por lo que no se hizo esperar la aparición de las llamadas ciencias de la información, las cuales a su vez venían a empalmar con ciencias que ya de antiguo trataban sobre la información, como es el paradigmático caso de la Bibliotecología. Este amplio espectro de las ciencias de la información estudia desde múltiples ángulos y enfoques los diversos escorzos que exhibe la información en su cambiante desenvolvimiento. Es por ello que se ha lle-
\end{abstract}


Derecho a la información, bien público y bien privado:...

gado a un conocimiento muy particularizado de cada detalle y problema que presenta la información. Así, problemas como el derecho a la información son objeto de amplia indagación, máxime si este aspecto del fenómeno informativo responde a problemáticas sociales y políticas tan actuales como las de la democracia.

Pero esa especificidad cada vez más acotada de conocimiento de los varios aspectos del fenómeno puede redundar en que se deje de lado una visión conjunta del mismo. Por lo que una alternativa, que podríamos caracterizar como conciliadora, debería aunar el vasto capital de conocimientos particulares sobre la información con una concepción englobadora del fenómeno. Lo que nos puede permitir engarzar el tema específico del derecho a la información con el amplio proceso de construcción de la realidad social: esta correlación, a su vez, nos plantea el problema sobre los procesos que se llevan a cabo para que puedan incidir el derecho a la información y la construcción de la realidad social. Procesos que de antemano enuncio como: la construcción del discurso y la conformación del imaginario social.

De manera intuitiva podemos avizorar las diferencias que existen entre las sociedades en que se encuentra restringido el acceso a la información y aquellas sociedades en las que se establece el derecho a la información. En cuanto a la primera queda de manifiesto que la limitación informativa redunda en el acotamiento de las libertades sociales y el control que se lleva a cabo sobre los individuos. Mientras que en las segundas se amplía el marco de la actividad social y por ende 
El derecho a la información como constructo de la realidad social. ...

de las libertades, lo que favorece, en términos de Jürgen Habermas, la acción comunicativa; serían sociedades de carácter democrático, en las que el derecho a la información es una de sus principales expresiones, la cual a su vez contribuye a la sustentación democrática. Pero esto último puede comprenderse mejor si nos ubicamos en una de las manifestaciones del ámbito social: el espacio público.

En las sociedades democráticas hay tres columnas que le brindan su unidad y fortaleza: la esfera de lo político, la de lo civil y la de los medios. Entre las tres esferas se da una interacción por medio de la cual se busca el desenvolvimiento de cada una de ellas, así como un mutuo equilibrio. Aunque es de acotarse que tal equilibrio es difícil de alcanzar, porque suele haber, en términos reales, un desbalance entre tales esferas. Pero tal desbalance no llega al extremo de las sociedades en las que se encuentra restringido el acceso a la información, en las que la esfera política absorbe a las otras dos esferas. Y es precisamente el derecho a la información en las sociedades democráticas el que puede permitir el equilibrio entre las esferas de lo político, lo civil y los medios. Lo que por otra parte implica el proceso de construcción de la realidad social. Así, el derecho a la información contribuye notoriamente a la construcción de la realidad social o, más específicamente hablando, a esa forma de realidad social que es la sociedad democrática. Lo que lleva a plantear la cuestión de ¿cómo intervienen en la señalada construcción social del discurso de la información y lo imaginario social? 
Derecho a la información, bien público y bien privado:...

El espacio público no es una organización social abstracta. Muy por el contrario, es una realidad gestada y articulada por individuos concretos. Hombres de "carne y hueso", como diría el filósofo Unamuno. De ahí que el punto de partida para emprender una indagación que correlaciona fenómenos en apariencia no tan explícitamente cercanos como el derecho a la información y la construcción social, ha de ser el sencillo núcleo del proceso informacional: la relación comunicativa entre dos individuos; sin embargo, tal relación ha de comprenderse a partir de una visión compleja (como lo es la realidad concreta), lo que implica la explicitación de los múltiples procesos internos de la relación comunicacional entre los sujetos, como de su correlación con los procesos externos a ella. Por lo mismo, la limitada y empírica definición de comunicación de la información que especifica que ésta consiste en la posesión de un saber que es transmitido por vía del lenguaje por un individuo a otro que, se supone, no lo tiene, es una relación que entraña un cambio de estado cognitivo entre quien tiene un saber y lo comunica para sacar de su ignorancia a quien no lo posee. Acto comunicativo que en su simpleza altruista oculta la extrema complejidad que hace de tal relación un campo surcado de minas, por lo que hay que cruzarlo con mucho cuidado y ojo avizor, sin dar nada por sentado. Una concepción tan simplificada de la relación informativa entre los individuos soslaya totalmente los procesos internos que cada uno de ellos despliega en el acto comunicacional. Procesos que pueden estar signados por 
El derecho a la información como constructo de la realidad social. ...

la opacidad psíquica de egoísmos, ocultamientos, engaños e intereses antagónicos. Es el ruido que recorre el hilo comunicacional, el cual, incluso, puede redundar en incomunicación bajo la apariencia de altruismo comunicativo. A lo que también contribuye la presión de las fuerzas del contexto social. Por tal razón una concepción tan esquemática, digamos unidimensional, del acto comunicacional entre los individuos no resulta operativa para explicar cómo en ese acto se construye la realidad social.

Sigamos la senda de la complejidad: un individuo, en cualquier calle y en el momento que sea, habla con otro individuo. Con lo que entre ellos el mundo se comenta y se comparte; es decir, el mundo se describe y estructura. Pero más aún, en tal conversación al manifestar el mundo igualmente se manifiesta una relación comunicacional: hablar del mundo implica remitirse a aquellos que lo hablan, para saber qué pasa en ese simple y cotidiano acto de transmisión de la información entre dos individuos.

El saber que se busca trasmitir a través del acto de informar es el de describir, con lo que se identifica y califican los hechos; contar qué implica narrar los acontecimientos, y explicar qué significa proporcionar los motivos de esos hechos y acontecimientos. Naturalmente que entre mayor sea la cantidad de información con que cuenten los individuos que dialogan cotidianamente, mejor podrán llevar a cabo las fases del describir, contar y explicar. Que es lo que acontece sobre todo en sociedades donde hay una mayor cobertura 
Derecho a la información, bien público y bien privado:...

de generación y circulación informativa: derecho de información. Más para llevar a cabo tal transmisión informativa se requiere como conditio sine qua non del lenguaje. El vehículo por antonomasia de la información es el lenguaje que, en cuanto tal, es el sistema de signos interno de una lengua. El lenguaje es la correa de transmisión que además permite las transacciones informativas en las intersubjetividades.

La información no sólo se despliega, enuncia, como un saber a través de la organización de los signos de una lengua y que son comunicados por un lenguaje. De hecho este es el basamento sobre el que se levanta la construcción del discurso, dentro del cual a su vez se desenvuelve el imaginario social. Dos individuos dialogan en algún recodo del un camino y a la par de comunicarse un saber, información, por medio del correspondiente lenguaje, del que ambos comparten el mismo código que organiza los signos, van más allá de ese nivel para acceder al sistema del valor de uso de los signos del lenguaje: lo que viene a ser la esfera del discurso. Una definición desde el enfoque del análisis del discurso señala que el discurso: “... designa menos un campo de investigación delimitado que cierto modo de percepción del lenguaje: éste no es considerado como una estructura arbitraria sino como la actividad de sujetos inscritos en contextos determinados. En este empleo discurso no puede tener plural: se dice 'el discurso', 'el dominio del discurso', etc.”

1 Dominique Maingueneau, Términos clave del análisis del discurso, Buenos Aires, Nueva Visión, 2008. 
El derecho a la información como constructo de la realidad social. ...

Lo que es de subrayar, en tal definición, es que el discurso es una actividad que emprenden los individuos ubicados en contextos específicos. Lo que por otra parte nos conduce a señalar que el discurso, primariamente, depende del ámbito de conocimientos de que trata, al que hace referencia, pero también del dispositivo en que circula y que lo despliega en la transmisión comunicativa entre los individuos. Y al decir ámbito de conocimientos se trata de la especificidad de aquello de lo que se habla, que obviamente cambia en cada caso de comunicación entre los individuos. Si, por ejemplo, los individuos que entablan diálogo son científicos y lo llevan a cabo en un laboratorio, la información que transmiten puede encontrarse acotada al ámbito de conocimientos de su respectiva ciencia. Como puede suponerse la especificidad de una plática callejera. En cuanto al dispositivo es aquel que puede vehiculizar el lenguaje como, por ejemplo, los medios electrónicos o simplemente el habla. Y todo esto se lleva a cabo en contextos determinados; por lo que el contexto, como veremos, juega un papel fundamental en el despliegue de lo imaginario.

Lo que es de suma importancia remarcar son los atributos del discurso: en primera instancia da cuenta de la forma en cómo se organiza la circulación de las palabras en una colectividad para producir sentido. En segunda instancia, implica que los discursos son portadores de descripciones del mundo y de los valores con que se dota el grupo. A partir de tales descripciones se construye la estructuración mental del espacio social 
Derecho a la información, bien público y bien privado:...

y, por lo tanto, del espacio público. Mientras el lenguaje vehiculiza el saber de la información, el discurso la convierte en producción de sentido, el cual brinda una imagen del mundo que, de manera particular, articula una visión del espacio público en el que interactúan comunicativamente los individuos. Ahora bien, como se desprende de la explicitación de los atributos del discurso, se puede observar que nos conducen hacia las dos esferas a través de las cuales se despliega el discurso: factores intradiscursivos y condiciones extradiscursivas. En cuanto a las primeras, se trata de los elementos que estructuran la organización del discurso como son: la polisemia, que consiste en la diversidad de valores que puede tener un enunciado (lo que entraña la polidiscursividad); referencialidad, que es la descripción de un estado del mundo; enunciación, que es la transmisión de algo sobre la identidad y la intención de los interlocutores; y las creencias, que expresan los juicios sociales emitidos sobre los seres y los hechos del mundo.

Mientras que con las condiciones extradiscursivas nos ubicamos, como se apuntó con anterioridad, en el terreno del contexto social, espacio a través del cual se desenvuelve la circulación de las palabras. Así, el contexto viene a significarse inicialmente como ese lugar o momento (espacio-tiempo) en y desde el que se habla. Pero el contexto adquiere mayor complejidad porque entraña la identidad de los que hablan. Los individuos llegan a ser lo que son en gran medida por "la presión de las circunstancias". Hablar con el otro conlleva, a la 
El derecho a la información como constructo de la realidad social. ...

par de proyectar su identidad, establecer una relación de intencionalidad que los vincula comunicativamente. Por último, el contexto también adquiere especial significación porque implica la corporeidad de los individuos. Así, el contexto es la ubicación, pero asimismo la multiplicidad de los escorzos que integran a los individuos tanto interna como externamente. Todo ello hace que se encuentre en insoslayable y permanente interacción lo intradiscursivo con lo extradiscursivo: el uno remite al otro y viceversa, lo que confluye en la gestación de, como ya se indicó líneas atrás, una imagen del mundo entre los pliegues de la comunicación intersubjetiva. Tal imagen que se desprende del discurso por consiguiente, hace referencia a esa fuerza que emerge de los procesos intelectivos y psíquicos de la acción comunicativa entre los individuos, como es el imaginario social. El filósofo Charles Taylor nos da una definición personal de imaginario social:

Por imaginario social entiendo algo mucho más amplio y profundo que las construcciones intelectuales que puedan elaborar las personas cuando reflexionan sobre la realidad social de un modo distanciado. Pienso más bien en el modo en que imaginan su existencia social, el tipo de relaciones que mantienen unas con otras, el tipo de cosas que ocurren entre ellas, las expectativas que se cumplen habitualmente y las imágenes e ideas normativas más profundas que subyacen a estas expectativas. ${ }^{2}$

2 Ch. Taylor, Imaginarios sociales modernos, España, Paidós, 2006, p. 37. 
Derecho a la información, bien público y bien privado:...

Puede decirse que todo ese conjunto de cosas que, como señala Taylor, conforman el imaginario social es lo que viene estatuir una forma de representación de la realidad. De hecho un imaginario también puede caracterizarse como un conjunto de representaciones que un grupo o individuo construyen sobre el mundo. Ahora bien, en cuanto representación ésta tiene entre sus diversas funciones organizar y estructurar conocimientos y valores así como orientar a los individuos en su desenvolvimiento en el mundo. El imaginario social al conformar representaciones del mundo articula los conocimientos: a toda esa gama de elementos como son imágenes, pasiones, expectativas, etcétera, para que los individuos configuren constructos de la realidad, lo que, a su vez, les permite guiarse en ella. Es de acotar que en conjunto ese entramado de elementos se encuentra cruzado por un fuerte impulso hacia la ficcionalización de la realidad. La realidad social no sólo es un universo de elementos materiales (seres y objetos) sino que está integrado por un conglomerado de factores intangibles, como por ejemplo los símbolos, los cuales son privilegiadamente generados y vehiculizados por el lenguaje: que hace de esa manera que la información se convierta en factor primordial en la construcción de la realidad social. La información nimbada de simbolismo, y demás entidades intangibles, estructura el entorno colectivo. Mas esa estructuración tiene un componente de ficción para dar forma a la realidad, construida así a la medida de las posibilidades humanas de cada época histórica. Pero es de aclarar 
que la ficción no debe ser entendida de manera simplificada como una distorsión o negación de la realidad, muy por el contrario, es un factor que nos remite de una forma peculiar a la realidad, de ahí su fuerza constructiva de la realidad bajo sus propias cualidades. Lucien Sfez a mostrado esta complejidad de la ficción y cómo actúa dentro del discurso, así es como caracteriza a la ficción:

Si la ficción se aleja de la realidad, si toma distancias de la descripción de las cosas como son, es porque se coloca en un plano que no es de la verdad (adecuación de lo que es enunciado con el objeto de la enunciación), sino el de lo verosímil, es decir, una semejanza con los objetos y las situaciones reales. En efecto, lo verosímil no es lo contrario de lo verdadero, sino su casi semejante. En ese "casi" se encuentra la seducción, así como las trampas de la ficción. En efecto, se trata de que la ficción encuentre el reconocimiento, por parte del público, de su "vero-similitud". La producción ficcional debe satisfacer los criterios de credibilidad; dicho de otro modo, debe obedecer las reglas de lo verosímil: para funcionar, debe ser aceptada como posible, entrar en lo "imaginable" de una época, es decir, en lo que puede ser imaginado sin contravenir los principios fundamentales de una creencia común. ${ }^{3}$

El impacto de la ficción se juega en el terreno de lo verosímil, entra en lo imaginable. Lo imaginario construye la realidad social haciéndola verosímil "casi" ver-

3 L. Sfez, Técnica e ideología. Un juego de poder, México, Siglo XXI, 2005, p. 196. 
Derecho a la información, bien público y bien privado:...

dadera; así es como actúa la producción de sentido que brinda todo ese universo de entidades intangibles, que hace que la información transfigurada por el discurso y lo imaginario, den forma a ese mundo signado por lo humano. El impacto de la ficción se juega en el terreno de lo verosímil, entra en lo imaginable: lo imaginario construye la realidad social. Haciéndola verosímil "casi” verdadera, así es como actúa la producción de sentido que brinda todo ese universo de entidades intangibles, que hace que la información transfigurada por el discurso y lo imaginario, den forma a ese mundo signado por lo humano. El mismo Lucien Sfez da un preclaro ejemplo de cómo actúa, la información modulada por el discurso y concretizada por la ficción (y su fuerza motriz que es lo imaginario) para construir la realidad social, tal es la tecnología.

Dos individuos, en una tienda de artículos electrónicos, hablan sobre los artefactos que se encuentran a la venta, así como sobre las propiedades de los que han adquirido. La conversación oscila constantemente entre las propiedades inherentes del artefacto (conjunto de partes y funciones) y todos aquellos factores externos a él que lo ofrecen a la conciencia, como por ejemplo la publicidad que apela a cualidades psicológicas y sociales: la plática acaba por decantarse hacia ésta dimensión del artefacto tecnológico. Dimensión que es la que da consistencia al artefacto en la conciencia de los individuos; conciencia a partir de la cual se dirigen al artefacto en cuanto a su percepción, concepción y manejo. Todo lo cual viene a ser parte de la construc- 
El derecho a la información como constructo de la realidad social. ...

ción de la realidad social. Cabe agregar, siguiendo el ejemplo, que lo que actúa como mediador del uso de la tecnología es el discurso que al proyectar el imaginario hace un uso ficcional del artefacto. El uso del artefacto no sólo se da en función de sus cualidades tecnológicas sino también en relación a lo que sobre el hemos configurado en nuestra mente, como ilusiones, expectativas, pulsiones, etcétera, que lo hacen verosímil como realidad. Incluso puede ser más importante, para el poseedor de un artefacto electrónico, toda esas representaciones que constelan su imaginario, que el objeto real per se. Caso paradigmático es la Internet, cuyo discurso publicitario la presenta como una revolución de la información y la comunicación, que por lo mismo está en consonancia con los valores democráticos. Con esto se apela para hacerla creíble a factores que trascienden sus cualidades tecnológicas toda esta información referente a tal entidad tecnológica, a su vez, es transfigurada en discurso (que se despliega intra y extra discursivamente) por aquellos que hablan sobre ella para configurar una serie de representaciones (imaginario social), que la hacen verosímil (ficción) para ser utilizada en la realidad inmediata. Con lo que la información que entra en juego en la transacción comunicativa, pasa simultáneamente por todos los procesos explicitados entre individuos que discurren continuamente sobre diversos temas en el espacio público se convierte en factor de construcción de la realidad.

En la medida que en las sociedades se avala el derecho a la información, ésta puede más amplia y fluida- 
mente transitar por las fases simultáneas aquí descritas para desembocar en la construcción de la realidad social sustentada democráticamente, plasmada más específicamente en el espacio público. Lo que por otra parte no debe velar el hecho de que este proceso comunicativo que acompaña al derecho a la información también es seguido muy de cerca por la tentación del poder. La ecuación está dibujada: acceso amplio y democrático a la información dispara en relación directamente proporcional los resortes del poder para monopolizar y controlar la información. Lo que redunda en cortes, fragmentaciones en el proceso comunicativo, como ha sido aquí descrito, que conduce a la construcción de la realidad social. Tal tensión entre derecho a la información y la limitación de ésta es parte inherente a la condición humana. 


\title{
Información y derechos humanos de las mujeres en América Latina
}

\author{
Beatriz Casa Tirao \\ Colegio de Bibliotecología y Estudios de la Información \\ / Facultad de Filosofía y Letras \\ Universidad Nacional Autónoma de México \\ becati@servidor.unam.mx
}

\section{Introducción}

$\mathrm{Z}^{1}$ antiguo tema de la situación de las mujeres en Egeneral, especialmente relacionado con la discriminación que el género ha experimentado y sigue experimentando aún en muchos sectores, es una cuestión que ha ocupado la atención de muchas autoras y algunos autores desde hace tiempo. Desde los escritos vanguardistas en su momento y hoy clásicos de Simone de Beauvoir hasta las modernas investigaciones feministas, como las de la mexicana Graciela Hierro que presentan un criterio más integrador y complejo, se ha resaltado la situación marginada de las mujeres. Me inclino a pensar que, en realidad, en muchos casos, la marginación de las mujeres se da dentro de una marginación mayor que es la de los numerosos grupos sociales, cada vez más amplios, que no participan de los beneficios del desarrollo económico y social y que 
Derecho a la información, bien público y bien privado:...

constituyen las "sociedades grises" o "sociedades invisibles," como hoy se las denomina. A partir de lo anterior podemos hablar de una discriminación dentro de la discriminación.

La lucha de las mujeres por sus derechos es, en realidad, la lucha por sus derechos humanos. Este tema supone la necesidad de que las mujeres puedan ubicarse en el aquí y en el ahora, que sean capaces de comprender, además de su propia situación, la del entorno al que pertenecen, que su lucha no se transforme en un enfrentamiento de géneros sino, por el contrario, que sea el resultado de un impulso hacia un crecimiento de los géneros que los lleve al entendimiento imprescindible que los humanos estamos reclamando, independientemente del género. Esto supone el cono cimiento de diversas instancias que deben tenerse en cuenta en situaciones como las que se tratan en este capítulo, entre ellas las formas de relación entre los individuos y los grupos, los valores, la dinámica de la convivencia, las necesidades sociales e individuales, los distintos rasgos culturales, e integrados a lo anterior, los derechos humanos de las mujeres.

\section{Los derechos humanos de las mujeres}

Los derechos humanos en general son innatos pues corresponden al respeto, hacia la persona propia y el otro y, además, son universales pues su vigencia es exigible en todo momento y en todo lugar. También son derechos cuyo cumplimiento no se puede eludir ya que 
son necesarios por estar relacionados con la naturaleza misma del ser humano. Los derechos humanos son inalienables e inviolables, ya que no es posible que alguien actúe en contra de ellos sin atentar contra principios éticos. Ésta es, por lo menos, la teoría en lo que respecta a los derechos humanos en general. Sobre la base de lo anterior surge el concepto de los derechos humanos de las mujeres.

Ahora bien, ¿por qué plantear los derechos de las mujeres como una cuestión particular? Desde el relato bíblico, la mujer fue relegada a un lugar secundario, cosa que se ha ido repitiendo a través del tiempo, lo que ha creado la figura de marginación de las mujeres. Esto ha determinado, por otra parte, una dinámica positiva respecto del tema ya que las mujeres, a través de las distintas épocas, han ido desarrollando intensos esfuerzos de reflexión y acción para lograr el reconocimiento social que por derecho les corresponde. Según lo que históricamente se conoce, a partir del siglo XVI comenzó la producción de materiales de información acerca del tema. En ellos se trataban temas que iban desde la igualdad de derechos entre los géneros hasta el planteamiento de los verdaderos y más grandes intereses de las mujeres, como en esas obras se mencionaba. La autoría generalmente correspondía a mujeres.

Esta inquietud por producir escritos destinados especialmente a sensibilizar a las mujeres, tenía sin duda un segundo objetivo: difundir en la sociedad, para su conocimiento y comprensión, los datos acerca de la verdadera situación de las mujeres. Con el correr del 
Derecho a la información, bien público y bien privado:...

tiempo, y sin dejar de lado la producción bibliográfica, algunas mujeres comprendieron la importancia de la colaboración entre mujeres y comenzaron entonces los primeros movimientos feministas, que en sus inicios debieron enfrentarse en muchas ocasiones con el rechazo social. Actualmente los movimientos feministas son más vigorosos y han estado al frente del esfuerzo por hacer valer los derechos humanos de las mujeres que no dejan de estar amenazados. ¿Y cuáles son esos derechos? Algunos de ellos no presentan diferencia alguna por razones de género sino que coinciden con los de todos los miembros de la sociedad; los otros son los que se refieren, precisamente, con la calidad del ser mujer. En ese sentido, el primer derecho fundamental es el de decidir sobre su propia vida, su persona, su cuerpo. El derecho a trabajar en iguales condiciones laborales que lo hacen los hombres, es decir a igual trabajo, igual remuneración, es parte de la forma de vida a que las mujeres tienen derecho.

La educación, que durante largo tiempo fue derecho de los hombres, corresponde, sin la menor duda, también a las mujeres y para poder ejercerlo deben tener libre acceso a los centros donde les será posible desarrollar sus capacidades. La autonomía económica y una vida libre de violencia se encuentran también entre los derechos de las mujeres así como el afianzamiento de su personalidad política para participar de manera activa y paritaria con los hombres en las decisiones de su comunidad y de su país, juntamente con la garantía de elección para ocupar puestos guberna- 
mentales, desde los más modestos hasta los más importantes en esa escala.

Podrían ser mencionados otros derechos humanos de las mujeres, pero los ya vistos parecen ser los fundamentales que, por otra parte, se ligan con otros derechos complementaros.

\section{La condición de las mujeres latinoamericanas}

La condición de las mujeres está constituida por el conjunto de relaciones, de producción y por todas las demás relaciones vitales en que están inmersas las mujeres, independientemente de su voluntad y de su conciencia acerca de las formas en que participan en ellas; por las instituciones políticas y jurídicas que las contienen y las norman; y por las concepciones del mundo que las definen y las interpretan. Por esta razón son categorías intercambiables condición de la mujer, condición histórica, condición social y cultural y condición genérica.

En Latinoamérica, nuestra patria grande tan dolida en muchos aspectos, las mujeres no han sido ajenas a los problemas de género, ya como protagonistas, ya como integradas en la lucha por la superación de los mismos. Información actualiza acerca de la situación general de las mujeres en nuestro continente la ofrecen las consideraciones y acuerdos de la XI Conferencia Regional sobre la Mujer de América Latina y el Caribe que, con el auspicio de las Naciones Unidas y de la CEPAL, 
Derecho a la información, bien público y bien privado:...

se llevó a cabo del 13 al 16 de julio de 2010. El trabajo de esta reunión tiene como antecedente el de algunas anteriores tales como, por ejemplo, la Conferencia Mundial sobre la Mujer de Beijing, 1995.

Los temas que permanecen sobre la mesa de discusiones en relación con la situación de las mujeres en América Latina son varios y diversos, pero todos tienen su origen en la cuestión de género. Uno de ellos, grave sin duda, es el de la violencia contra las mujeres, violencia que no sólo se da en el ámbito familiar sino también más allá, desde la marginación en distintas instancias hasta la violación y el feminicidio que conforman el grado más severo de la agresión. Entre los extremos mencionados se encierra una gama de otras formas de violencia que tienen que ver con el tráfico de personas, la prostitución, la explotación laboral, etc.

La cuestión económica representa una forma de sojuzgamiento ya que cuando las mujeres no pueden alcanzar su autonomía en este terreno, terminan dependiendo de otros (padre, pareja, hermanos) y en este mismo sentido, se impone lo ya mencionado: la importancia de que el trabajo de las mujeres sea evaluado con los mismos criterios que el de de los hombres y remunerado de manera equivalente.

La ciudadanía de las mujeres es todavía una asignatura pendiente y para completarla es necesario promover políticas de Estado que garanticen los derechos humanos de las mujeres, de todas las edades y condiciones, como base sustantiva de los procesos democráticos. La ciudadanía de las mujeres tiene relación no 
sólo con el ejercicio de sus derechos políticos y civiles sino, además, con la estructuración de la personalidad para integrarse en la comunidad como individuo con iguales derechos y obligaciones que el resto de los miembros, independientemente del género. El que las mujeres puedan asumir su ciudadanía hace posible que tengan participación en la toma de decisiones y en el ejercicio del poder, lo que permitirá crear espacios de participación igualitaria. En este punto vale la pena una reflexión acerca del tardío acceso de las mujeres al voto en el caso de América Latina ya que las fechas oscilan entre 1929 para Ecuador y 1964 para Bahamas.

Un tema fundamental en este enfoque acerca de la situación de las mujeres es el de la educación. La escolarización de las mujeres en América Latina presenta problemas aun hoy. Cierto es que no resulta posible generalizar porque la diferencia se aprecia tanto en el porcentaje de población escolarizada en cada región y en las distintas edades, como en que las proporciones comparadas de hombres y mujeres son desiguales por países y presentan un panorama de contrastes. Hay un grupo de países que tienen una amplia cobertura de la educación básica que supera el 90\% de la población con la edad correspondiente, y son los mismos que alcanzan más del 50 \% en la cobertua de la educación secundaria (Argentina, Chile, Cuba, Panamá, Uruguay). Costa Rica y Perú les siguen con porcentajes algo inferiores. El promedio de participación de las mujeres en la educación superior en la región, oscila entre el 49\% y el $51 \%$ lo cual parece una cifra satisfactoria, no obs- 
Derecho a la información, bien público y bien privado:...

tante hay que tener en cuenta que grandes grupos de mujeres no participan en este nivel.

Es evidente que la educación es la puerta que se abre al conocimiento $\mathrm{y}$, por lo tanto, a la capacidad para el ejercicio de los derechos de los individuos; al conocimiento se llega a través de la información que es el soporte que permite al conocimiento llegar hasta quienes lo demandan. En la actualidad, las tecnologías de la información y de la comunicación facilitan el encuentro con la información y constituyen parte de su soporte. Es cierto que no sólo las mujeres sino también grandes grupos de población de nuestros países, no participan de la fiesta del conocimiento y mucho menos de los recursos de la tecnología. Hay exclusión, no cabe duda. No obstante, en este empeño por el ejercicio de los derechos humanos de las mujeres, quienes tienen la responsabilidad habrán de reconocer que en el ejercicio de su derecho a la educación las mujeres tienen como un derecho complementario y fundamental el acceso a las nuevas tecnologías de la información. Con el acceso viene la necesidad del aprendizaje para el empleo de los nuevos recursos, el cual habrá de partir de las propias necesidades de las mujeres, ya sea en el orden familiar, laboral, doméstico, etc. A medida que el aprendizaje avance irán apareciendo otros puntos de interés que llevarán a la mujeres a hacer un uso cada vez más provechoso del resultado de su aprendizaje. Por otro lado, es necesario también promover el acceso de las mujeres indígenas a los medios masivos de comunicación para, al mismo tiempo, estimular el 
interés de las niñas y las jóvenes por los conocimientos científicos y tecnológicos y que puedan tener acceso al pensamiento humanístico integrador.

\section{La información como instrumento para el desarrollo y aplicación de los derechos humanos de las mujeres}

La información es a la vez, y paradójicamente, un derecho y una obligación. Es decir, tenemos todo el derecho a poseer los recursos necesarios para informarnos y así llegar al conocimiento de las cosas y de los hechos pero, de igual manera, cuando poseemos esos recursos, tenemos la obligación de emplearlos para entrar en el campo de la información y, por ende, llegar al conocimiento. Los recursos no son sólo tecnológicos sino que el punto de partida es, en todo caso, lo más elemental, la posibilidad de utilizar en toda su amplitud, poder leerlo y escribirlo y, sobre todo, entender lo que se lee y escribe. La educación permanente, la que es un proceso que dura toda la vida de las mujeres y de los hombres, tiene en estas acciones un fuerte aliado. Hay que recordar que a medida que la gente se educa adquiere mayores conocimientos y también más seguridad con respecto a su posición en la vida y a la defensa de sus derechos. En el caso de las mujeres corresponde a ellas posicionarse en el mundo y en la vida y para ello tendrán que entender su valor como seres humanos y como mujeres. ¿Cómo relacionar lo anterior con la información? A través de entender a ésta como 
Derecho a la información, bien público y bien privado:...

un instrumento que conecta con el conocimiento el cual, a su vez, permite entender las propias circunstancias a través de la reflexión. Entre las ventajas que el camino de la información hacia el conocimiento ofrece, deben integrarse a los programas educativos para mujeres, capaces de fortalecerlas en las cuestiones más sensibles que afectan a las mujeres. Estos mismos temas deberán ser difundidos en la sociedad ya que sólo con el conocimiento y la comprensión comunitaria se lograrán soluciones.

Cuando se habla de la educación de las mujeres la referencia no supone necesariamente un proceso escolarizado, supletorio o remedial. Se piensa más bien en una enseñanza de vida, en un aprendizaje que permita a las mujeres superar su marginación de género. Deberán ser las propias mujeres las que decidan qué quieren aprender en función de qué problemas a resolver y también qué recursos emplearán. Entre éstos se encuentra la lectura, medio irremplazable en cualquier acción educativa.

La relación entre la lectura y la condición de las mujeres presenta dos vertientes: una que tiene que ver con la función de información, es decir proporcionarles los elementos que les permitan dilucidar quiénes son y su valor como seres humanos y como género. La otra vertiente tiene que ver con la propia formación de las mujeres para realizar el proceso de apropiación o empoderamiento de sus vidas, de sus pensamientos y de sus decisiones, con la posibilidad de asumir con provecho su proyecto de vida. 
La búsqueda de conocimiento a través de la información por parte de las mujeres demanda acciones que, además, cohesionen a los grupos comunitarios. En este momento en que hay una revaloración de lo local por sobre lo global, es la demanda la de reunir y afianzar los lazos de interacción entre los individuos y entre los grupos para que, a su vez, sean una fuerza que impulse la acción local de las instituciones. Y en este punto es donde tiene un rol la biblioteca, especialmente la pública, como parte integradora de un fenómeno que cada vez irá adquiriendo mayor fuerza en la interacción de todas las instituciones locales para constituir un centro transdisciplinario de desarrollo local. Allí, precisamente, será donde puedan cristalizarse las perspectivas de género de las mujeres en cuanto a su acceso a la información y el conocimiento. Habrá que tener en cuenta que nuestras instituciones, las que se nos dieron hace mucho tiempo, parecen haber llegado al límite de su capacidad dentro de su actual estructura académica y operativa y a este respecto se mencionan la escuela, la universidad con su diseño napoleónico, los diversos servicios públicos, ¿por qué entonces no poner en tela de juicio los servicios bibliotecarios y a la biblioteca como agente para empujar cambios que deben nacer de la mente y el espíritu de quienes tenemos la capacidad técnica y profesional para hacerlo y también de la voluntad política de los organismos gubernamentales?

En esta ocasión el tema se dirige a las mujeres, no obstante ellas, nosotras, somos parte de un conglomerado social que no puede ignorar a ninguna de sus par- 
Derecho a la información, bien público y bien privado:...

tes y en ese sentido todos debemos ser partícipes de un proyecto que no es una utopía y, en todo caso, si lo fuera, hay que recordar que las utopías, en gran medida, han movido al mundo. Esto resultará en un acercamiento real de la biblioteca al sentir social, lo cual es una responsabilidad que debemos asumir todos los profesionales de la información para cumplir nuestro compromiso social a través de de acciones como las que se proponen y ello será un impulsor del movimiento hacia una sociedad más igualitaria y más justa.

\section{Bibliografía}

Amorós, Celia. Feminismo, igualdad, y diferencia. México, UNAM, Coordinación de Humanidades, 1994 (Libros del Programa Universitario de Estudios de Género)

Beauvoir, Simone de. El segundo sexo. Santiago de Chile, Siglo XXI, 1967

Casa Tirao, Beatriz. "Familia, educación y democracia”, en: Filosofía de la educación y género, comp. Graciela Hierro. México, UNAM, Facultad de Filosofía y Letras, 1997. p. 49-58.

Freire, Paulo. La importancia de leer y el proceso de liberación. 18.ed. México, Siglo XXI Edit., 2006

Freire, Paulo La educación como práctica de la libertad.2. ed. México, Siglo XXI, 1972. 
Hierro, Graciela. De la domesticación a la educación de las mexicanas. México, Fuego nuevo, 1981.

Lagarde, Marcela. Los cautiverios de las mujeres: madresposas, monjas, putas, presas y locas. México, UNAM, 1997.

Violencia sexista: algunas claves para la comprensión de los feminicidios en Ciudad Juárez. Comp. Griselda Gutiérrez C. México, UNAM, Facultad de Filosofía y Letras, Programa Universitario de Estudios de Género, 2004.

Staff, Wilson. Mujer y derechos humanos (1998) .http/www.derecoñs.org/koaga/xiii/staff.html

Bonder, Gloria. Las nuevas tecnologías de la información y las mujeres: reflexiones necesarias. Santiago de Chile, CEPAL, 2002. (Mujer y desarro1lo, 39)

Brown, Mark. Presentación del Informe Mundial sobre Desarrollo bumano. Manila, PNUD, 2002.

Masolo, Alejandra. El espacio local: oportunidades y desafíos para el empoderamiento de las mujeres. Una visión latinoamericana. En: Desarrollo Humano e institucional en América Latina. 10 de junio de 2003. http/www.igiv.redorg/nial/?p=42-05 
Derecho a la información, bien público y bien privado:...

CEPAL. Informe de la Cuadragésima Tercera Reunión de la Mesa Directiva de la Conferencia Regional sobre la Mujer en América Latina y el Caribe. Puerto España, 7 y 8 de julio de 2009

Jiménez Guardiola, Ivette y Luis Orlando Aguilera García. Red para la formación de gestores de la ciencia, la tecnología y la innovación para el desarrollo local. 2008, Publicación electrónica.

XI Conferencia Regional sobre la Mujer de América Latina y el Caribe, Brasilia, 13-16 jul. 2010. CEPAL, 16 jul. 2010 


\title{
Los repositorios de acceso abierto: una vía para la democratización de la información y el conocimiento
}

\author{
Saray Córdoba González \\ Proyecto Latindex. Vicerrectoría de Investigación \\ Universidad de Costa Rica \\ saraycg@gmail.com
}

\section{Introducción}

T a necesidad de que el acceso a la información fue-

$\checkmark$ ra abierto se comenzó a plantear en lo que luego fue el "Movimiento de Acceso Abierto" (OAM), cuando el 1 de julio de 1999 se da la Declaración de Budapest y el 1 de diciembre del 2001 nace el movimiento Open Access con una declaración de la Budapest Open Access Iniciative (BOAI). Este movimiento fue inspirado por la situación que durante muchos años mantuvieron las revistas científicas en el mundo, como un negocio muy rentable para los servicios de índices, bases de datos, hemerotecas virtuales y otros que las incluyen y que empezaron a lucrar con base en las instituciones académicas que fueron, y siguen siendo, las principales consumidoras de la información que contienen. Posteriormente, con Internet se fortaleció el negocio, pues la red facilitó los mecanismos para comunicar y 
Derecho a la información, bien público y bien privado:...

comercializar ampliamente muchos de estos servicios, pero a la vez, también la Internet ofrece la posibilidad de democratizar el acceso a la información, con servicios alternativos que no cobran por su uso.

Hasta ese momento, este grado de comercialización se convirtió en un abuso, llegando a tal punto que realmente no había acceso a ningún servicio si no era por medio del aporte de una buena suma de dinero, y además, poderosas empresas y agencias editoriales acaparaban el mercado, combatiendo con las armas mercantiles a aquellos que se atrevieran a hacerles la competencia. Así, muchas bibliotecas tuvieron que renunciar o restringir sus suscripciones, porque sus presupuestos no alcanzaban a satisfacer la exigencia del costo (Rodríguez, 2008). Para obtener una idea precisa sobre esto, se puede establece el siguiente cálculo: El precio promedio de una revista científica es de $€ 1500$, si se toma en cuenta que actualmente se publican unas 24.000 revistas que sacan a la luz unos 2.500.000 artículos al año, se calcula un negocio de unos $€ 10.000 \mathrm{mi}-$ llones al año, con un margen de beneficio aproximado de un $30 \%$.

Si tomamos en cuenta que el producto de ese negocio queda en muy pocas manos, pues existe un monopolio muy marcado; tal situación es preocupante porque restringe en vez de democratizar el acceso a la información. Pero es aún más grave, porque la mayoría del conocimiento que circula en esas publicaciones es generado por científicos que trabajan en instituciones públicas, costeadas por los impuestos que pagan los 
ciudadanos. Las bibliotecas de estas instituciones, a su vez, son los principales clientes de las empresas editoriales, por lo que las empresas reciben dos veces el costo de la inversión. En el caso de Costa Rica, al igual que muchos otros países menos desarrollados, la información científica que se produce se financia con fondos públicos; ésta, a su vez, es comprada a las editoriales a precios onerosos, y por ello resulta poco accesible aun para los mismos investigadores, hasta tal punto que ni siquiera pueden adquirir en forma gratuita sus propios trabajos, a pesar de que son ellos quienes ofrecen la materia prima que genera tal negocio. No obstante, también los países ricos sufren esta situación, y por ello han llevado la batuta en este campo. Un ejemplo son los numerosos mandatos y declaraciones que se han emitido en estos años, como el más reciente de Arcadia Fund en el Reino Unido (2011).

En consecuencia, gracias al avance de las tecnologías de la información y la comunicación, el uso de la Internet para reforzar la comercialización de la información científica ha abierto una gama mayor de posibilidades a estas empresas, pues les permite restringir aún más que antes - léase, la era del papel- el acceso y dominio del conocimiento. Según lo denunció la Asociación Norteamericana de Bibliotecas Universitarias y de Investigación (ACRL, por sus siglas en inglés) como parte de la Iniciativa ACRL para reformar la comunicación erudita:

A medida que las revistas pasan de la forma impresa a la electrónica, el marco legal sobre su uso cambia de la 
Derecho a la información, bien público y bien privado:...

ley de propiedad intelectual (copyright) hacia la ley contractual. Este último marco gobierna los acuerdos de licenciamiento del publicador, que a menudo incluyen barreras indeseables sobre el uso, eliminando formas de acceso que habrían sido permitidas en el entorno de impresión en papel, bajo los principios del uso justo (ACRL, 2003a).

Estas empresas establecen una serie de restricciones a la consulta y descarga de documentos, que son determinadas por el tipo de licencia que se adquiere, pero también se establecen restricciones en lo que se refiere a la preservación de la información a largo plazo y al acceso a la misma. Las bibliotecas, en realidad, ni almacenan, ni son dueñas del contenido de las revistas que suscriben en forma electrónica. En la Internet, cada empresa dispone de sus propias regulaciones a la información que hace disponible, pues ésta no tiene un tiempo ilimitado para su consulta.

Por todas esas razones se presenta la Declaración de Budapest y el 1 de diciembre del 2001 nace el OAM, que se propone...

que los usuarios puedan leer, descargar, copiar, distribuir, imprimir, buscar, o enlazar los textos completos de los artículos científicos, y usarlos con cualquier otro propósito legítimo, sin otras barreras financieras, legales o técnicas más que las que suponga Internet en sí misma. Es decir, sin coste alguno (Budapest, 2002). 
Para ello establecen como única condición que se garantice a los autores el control sobre la integridad de su trabajo y el derecho a ser adecuadamente reconocidos y citados. Así, se abre una ventana de esperanza a un movimiento que lleva ya nueve años de existencia y que ha crecido hasta llegar a fortalecer significativamente el acceso a la información.

En este trabajo nos proponemos demostrar con algunos datos y situaciones generadas en Costa Rica, cómo este movimiento ha abierto las posibilidades hacia la búsqueda y acceso de información y generado nuevos productos para los usuarios, como una verdadera vía hacia la democratización del conocimiento; sin trabas de tipo económico ni legal y por el contrario, bajo los principios de la solidaridad, la equidad, el carácter público de la ciencia, la cooperación y la excelencia. Incluimos la situación existente en Costa Rica de una forma descriptiva, como un caso que evidencia que esta interrelación es aún incipiente y que es necesario afianzar aún más los esfuerzos que se han realizado hasta ahora.

\section{Unos pocos apuntes sobre la democracia}

Si estamos hablando de democracia es importante definirla en su justa dimensión. Este es un fenómeno en construcción dinámico y expansivo, (Carpizo, 2007) y por ello, para ofrecer una sola definición correríamos el riesgo de caer en un simplismo peligroso. Las variaciones del concepto en las últimas décadas del mundo 
Derecho a la información, bien público y bien privado:...

occidental, nos conducen a establecer más las características de un país democrático, comparado con otro que lo es menos. Pero ¿cuáles son esas características? Dahl et al. (1999) aducen que la democracia ha adquirido un matiz cada vez más fuerte, como la posibilidad de participar en la toma de decisiones pero paradójicamente, este control está cada vez más lejos de la ciudadanía:

Desde la perspectiva de la teoría democrática, el problema no reside sólo en constatar que, efectivamente, cada vez nos vemos más afectados por decisiones y procesos que eluden nuestro control político directo; la cuestión que se suscita es si disponemos de los medios adecuados para compensar los déficit democráticos derivados de esta nueva "desterritorialización" de los espacios políticos, que va acompañada de un nuevo desplazamiento de las fronteras de la acción política (p. 4).

Asumimos aquí aquella concepción de democracia como la viabilidad de los ciudadanos en la toma de decisiones, cuya vida es relativamente reciente y está estrechamente relacionada con el concepto de participación ciudadana. Dentro de este marco, es muy importante el acceso a la información, no sólo para ejercer el control político, sino también para poder romper las fronteras que teóricamente dejaron de existir con la globalización. Esta condición se vuelve clave, pero además da muestras del grado de evolución que una sociedad tiene en este campo. Por ello se han tratado de es- 
tablecer índices que midan ese grado, aunque sabemos que éstos tienen carácter relativo y, en consecuencia, deben leerse con cuidado.

Costa Rica es un país que se ha distinguido por ser una sociedad democrática, por el modo que aplica para elegir a sus gobernantes desde hace muchas décadas. No obstante, si tomamos en cuenta el índice de distribución de su riqueza, esa característica se transforma pues la inversión sigue siendo escasa. Dado que ha invertido en educación y salud comparativamente más que otros países de la región en los últimos 60 años, esto le ha valido para mantener un índice de desarrollo humano aceptable $(0,725)$, que ocupa el $6^{\circ}$ lugar en América Latina y el $62^{\circ}$ en el mundo (PNUD, 2010). Asimismo, en el campo de la democracia, se puede confirmar que ocupa el $3^{\circ}$ lugar en América Latina (DDLat, 2010), después de Chile y Uruguay, con un puntaje de 9,252 de 10,000 que tiene Chile.

De esta manera, pensamos que la democracia debe ser observada desde sus múltiples facetas, en la conformación de un Estado libre y solidario, y no sólo en lo referente a la elección de los gobernantes.

\section{El Movimiento de Acceso Abierto (OAM)}

Posterior a la Declaración de Budapest se desató una oleada de iniciativas que han llamado la atención del mundo entero sobre la necesidad de seguir estos principios. Así nació la Declaración de Berlín de Acceso Abierto en Octubre del 2003 (Más sobre... 2003), que 
Derecho a la información, bien público y bien privado:...

ha sido firmada hasta el momento (marzo 2011) por más de 297 organizaciones científicas de todo el mundo, entre las que se encuentran universidades, centros de investigación, organizaciones gubernamentales, agencias financiadoras de la investigación, fundaciones, bibliotecas, museos, archivos, sociedades científicas y profesionales. Estos son algunos de los principios que sostienen al movimiento:

-Que el conocimiento generado con fondos públicos debe ser de acceso público, dado que en determinado momento se volvió insostenible, porque la publicación la realizan empresas privadas que sólo permiten la difusión de la ciencia mediante el pago de costosas suscripciones. Así, la campaña a favor del acceso abierto "se centra en la literatura que los autores ponen a disposición de todos sin esperar un pago a cambio" (Suber, 2006).

-Que la comunidad científica está basada en el intercambio de opiniones y su fortaleza deviene de la calidad de ese intercambio, por ello, el juicio individual o colectivo es fundamental para el desarrollo de la disciplina y de la calidad de ese juicio, se deriva el prestigio de la publicación.

-Que la publicación científica revela el grado de madurez del sistema de investigación y desarrollo; el tipo de información que incluye es el reflejo de lo que se ha investigado y además, facilita el intercambio del conocimiento que se genera en diferentes ámbitos. Por ello, ésta se convierte en el 
principal medio para comunicar los avances científicos logrados.

Ahora bien, esta justificación muestra que de la publicación electrónica en acceso abierto debe ser ampliamente difundida y que las tecnologías ofrecen esa posibilidad sin restricción. Para demostrarlo, se han desarrollado numerosas investigaciones alrededor del mundo, que abarcan:

1.La visibilidad mundial para la producción y sus autores en forma inmediata. Harnad (2007) insiste en que sólo cuando los 24000 títulos de revistas que existen en el mundo y sus 2500000 artículos estén en acceso abierto, la navegación y la recuperación será tan eficiente como aquellos repositorios y sistemas abiertos que utilizan metadatos y resúmenes, que actualmente son los sistemas más visibles en la Web y por ello los buscadores los encuentran para aparecer en los primeros lugares de la lista de resultados.

2.Fácil aprovechamiento por parte de los investigadores, estudiantes y otros lectores. Dado que la recuperación de estos sistemas y bases de datos es más fácil y eficiente, y se multiplican las citaciones, como se verá más adelante.

3.Su diseño y mantenimiento exige una inversión inicial que luego se disminuye notablemente. Se ha comprobado que los costos de publicación disminuyen en un 30\% (Montgomery \& King, 2002; Bot 
Derecho a la información, bien público y bien privado:...

et al. (1998), El ahorro económico proviene fundamentalmente de los gastos de impresión, difusión y envío, no de su calidad.

4.Máxima rapidez en la edición de las publicaciones. El hecho de que éstas no deban pasar por la imprenta, ni tengan que ser enviadas por el correo postal, agiliza su proceso divulgación y recuperación.

Doyle et al. aclaran que el propósito del acceso abierto es "hacer accesible inmediatamente la literatura arbitrada, que pueda ser buscada y reutilizada para cualquier persona en el mundo con conexión a Internet". Este es el único medio común y directo - según reconocen- para lograr una serie de objetivos que son comunes a la mayoría de las asociaciones académicas y de promover los diversos intereses de sus asociados (Doyle, Gass \& Kennison, 2004). Esta posición indica que el acceso abierto también tiene grandes posibilidades para las sociedades científicas, tal como lo ha demostrado recientemente la decisión de la ACRL (Branin, 2011, p. 108) de convertir su importante revista College and Research Libraries en acceso abierto.

Adicionalmente, en octubre del 2000 nace la Public Library of Science (PLoS) http://www.plos.org por iniciativa de los científicos Harold E. Varmus, Patrick O. Brown, y Michael B. Eisen. Su objetivo inicial fue hacer accesible la literatura científica a través de la Internet, en forma gratuita. Para ello hizo circular una carta que fue firmada por 34,000 científicos de 180 países, pero 
las respuestas de los publicadores fueron muy débiles ante las políticas que el proyecto defendía. No obstante, el proyecto continuó y en 2003, PLoS se convirtió en una editorial científica, sin fines de lucro, con el ánimo de ofrecer varias revistas de alta calidad y bajo el modelo de acceso abierto. Actualmente ofrece siete revistas diferentes en diversos campos de las ciencias biomédicas, arbitradas y con una calidad indiscutible en el contenido de sus artículos. Éstas se enmarcan en el modelo de la vía dorada del acceso abierto, como se explicará posteriormente.

Otra decisión importante en este sentido, fue la que tomó la American Library Association (ALA) el 24 de junio de 2003 (ACRL, 2003a), donde se genera la Iniciativa ACRL para reformar la comunicación erudita, la cual define una estrategia y recomienda a sus afiliados seguir los siguientes lineamientos, entre otros:

- El desarrollo de revistas competitivas, inclusive la creación de revistas de bajo costo y acceso abierto, como alternativa directa a los títulos comerciales caros.

- Mayor control por los consejos editoriales a las prácticas comerciales de sus revistas, lo cual puede incluir el negociar reducción de precios de suscripción, la conversión a modelos comerciales de acceso abierto, o reubicar las revistas con publicistas (sic) sin ánimo de lucro, tales como las prensas (sic) universitarias, en aquellos casos donde la publicación comercial continuada no sirvan las necesidades de sus comunidades eruditas. 
Derecho a la información, bien público y bien privado:...

- El desarrollo de revistas arbitradas por pares y de acceso abierto, basadas en modelos comerciales que obvien la necesidad de suscripciones u otras restricciones económica al acceso.

- El desarrollo de repositorios institucionales (definidos como sitios de acceso abierto que captan el producto investigativo de una institución dada), creados de manera individualizada por instituciones o por grupos de instituciones que trabajan dentro de un marco cooperante (ACRL, 2003b).

Tal decisión estuvo motivada por los mismos argumentos ya citados pero con un tono contundente y definitorio. Esto es importante si se toma en cuenta que la ACRL es una organización que tiene más de 12,000 miembros, incluyendo a las bibliotecas universitarias y académicas más grandes de Estados Unidos, y que ha sobrevivido durante 65 años como la mayor división de la Asociación Norteamericana de Bibliotecas (ALA).

Por otro lado, existen muchas otras organizaciones que son parte de este movimiento mundial, entre las que se encuentran varios sistemas de información sobre revistas científicas en Iberoamérica y el Caribe. Algunas son: LATINDEX http://www.latindex.org, SciELO http://www.scielo.org, REDALyC http://www. redalyc.org, DOAJ www.doaj.org fundado por el Open Society Institute (OSI, con sede en Budapest), que consiste en el directorio más amplio existente en Internet de revistas de acceso abierto. Reside en las bibliotecas de la Universidad de Lund (Suecia) y está finan- 
ciado por la coalición SPARC (The Scholarly Publishing and Academic Resources Coalition). También la OSI creó más tarde el DOAR (Directorio de Repositorios de Acceso Abierto) www.doar.org con la intención de dar a conocer las respuestas existentes a la creación de repositorios y bases de datos especializadas. Asimismo, muchas universidades cuentan con sus repositorios de acceso abierto, en los que se pueden encontrar no sólo sus revistas científicas, sino también las tesis de grado y posgrado, pre y post-prints, monografías, documentos oficiales, y todo tipo de publicaciones valiosas para la comunidad científica mundial.

Dentro de este marco, Harnad (2007) define dos vías para el acceso abierto: la vía verde y la vía dorada. Se denomina vía dorada al método de publicación de artículos en revistas de acceso abierto; algunas de estas cobran a los autores por publicar, como una forma para sostener la publicación, lo cual ha sido cuestionado por algunos promotores del OA (Harnad, 2010). La vía verde, por su parte, propone que aunque siga publicando en revistas de acceso restringido, el autor autodeposite sus artículos arbitrados en el repositorio institucional de acceso abierto de su organización. Ambas formas han sido aceptadas por la comunidad científica y aplicadas hasta tal punto que se considera que un $20 \%$ de las revistas del mundo han optado por la vía dorada.

\section{Impacto del acceso abierto}

Un aspecto importante que merece destacarse, son los estudios recientes que se han realizado en los que se 
Derecho a la información, bien público y bien privado:...

demuestra que los artículos publicados en el acceso abierto son más visibles, y en consecuencia más citados, y que este comportamiento tiene una tendencia creciente. Así, Eysenback (2006) publicó un estudio en PLoS Biology, en el que concluye que los artículos publicados en una misma revista (PNAS: Proceedings of the National Academy of Sciences) en acceso abierto, son citados más a menudo y más pronto. Gargouri et al. (2010) comprobaron que el autoarchivo tiene muchas ventajas, y entre ellas, que los usuarios tienen la posibilidad de seleccionar los artículos de mayor calidad para usarlos y citarlos. Consecuentemente, los autores prefieren los artículos de alta calidad y en acceso abierto, en oposición a aquellos que restringen el acceso con suscripciones. El estudio se realizó con 27.197 artículos en línea, de 1.984 revistas publicadas entre 2002-2006. Björk et al. (2009) comprobaron también que el acceso abierto tiene un alto impacto en la disponibilidad de artículos para la investigación científica, aunque ello varía entre las diferentes disciplinas. Por ejemplo, química presentó el porcentaje más bajo (13\%) para compartir el conocimiento, contra las ciencias de la tierra que tuvo el más alto (33\%).

Harnad \& Brody (2004) tomaron una muestra de 14 millones de artículos provenientes de 7000 revistas del ISI-Thomson. La ventaja de citación de los artículos en acceso abierto va desde el $233 \%$ hasta el $557 \%$. Por su parte, el estudio elaborado en el 2009 por Houghton (2011) y financiado por el The Joint Information Systems Committee (JISC) establece una comparación 
entre los costos y beneficios de las 3 modalidades existentes: las revistas en acceso abierto, las revistas por suscripción y el autoarchivo. Así, da cuenta de los beneficios del acceso abierto y aclara algunas diferencias para estas modalidades: los resultados serán más visibles a largo plazo, dado que nos encontramos en un periodo de transición, en el que aún falta mayor toma de conciencia por parte de los investigadores para reconocer que la inversión que se hace en la investigación y el desarrollo pueda ser recuperada más rápida y eficazmente por medio del acceso abierto.

Estos estudios demuestran que el impacto de las publicaciones en acceso abierto es significativamente mayor, en relación con las publicaciones restringidas por el pago de una suscripción. Por ello se nota la necesidad de crear conciencia en las instituciones de investigación sobre las ventajas del acceso abierto, para luego promover la emisión de políticas en esas instituciones, con tal de fomentar el acceso a sus resultados y que a la vez, estos se reproduzcan en mayor conocimiento http://www.sherpa.ac.uk/juliet/. Estas políticas se concretan en mandatos que se han ido produciendo en el mundo, y que van creciendo para lograr que los países y sus organizaciones de investigación cada vez amplíen más el acceso a la información que producen y así aportar a la democratización del conocimiento. Algunos de los mandatos más famosos que existen en el mundo son los siguientes:

- PLoS open letter firmada por 34000 científicos de 180 países, 2000. En el 2001 aparece su primera revista www.plos.org 
-National Institute of Health (NIH): En octubre de 2007 el Senado de los Estados Unidos aprobó la FY2008 Labor, HHS, and Education Appropriations Bill (S.1710), que exige al NIH fortalecer la Política de Acceso Público (Suber, 2010). Bajo este mandato, los investigadores financiados por el NIH (la agencia más grande del mundo), se deben depositar copias de los manuscritos elegibles en las bases de datos en línea de la National Library of Medicine, PubMed Central. Los artículos estarán disponibles al público, no más de 12 meses después de su publicación en revistas arbitradas http://publicaccess.nih.gov/policy.htm.

-European Research Council: En el 2007 se emite este mandato (ERC, 2007) y exige a sus beneficiarios depositar sus artículos arbitrados, al menos seis meses después de haberse publicado, así como los datos de la investigación después de haber sido depositado el artículo, en bases de datos relevantes.

- Harvard Faculty of Arts and Sciences, Faculty of Law y cuatro más: Comenzaron en el año 2008 y han seguido creciendo en esa Universidad, según lo informa su Office for Scholarly Communication http://osc.hul.harvard.edu/. En el primer caso, cada académico está obligado a entregar una copia digital de su artículo para que la Oficina lo deposite en un repositorio (Office, 2010). 


\section{Repositorios de acceso abierto (Vía verde)}

Son archivos digitales que pretenden recoger toda la producción científica de un país, una institución o una región en un sitio web que esté a disposición de los usuarios en forma gratuita y sin restricciones. Deben cumplir con cuatro requisitos, según lo establece Suber (2006, 16): "es digital, en línea, sin cargo y está libre de la mayoría de las restricciones en términos de derechos de autor y licencias". Pero también deben ser interoperables para que la información contenida pueda ser intercambiable entre las diferentes colecciones existentes en una misma institución, país o región. Éstos son compatibles con la revisión o arbitraje, con los derechos de autor, o con la rentabilidad de la producción. Además, según Tissera (2008, p.4) se caracterizan por su naturaleza institucional, su carácter científico, acumulativo y perpetuo. El acceso abierto a la producción científica de una institución es una forma de amortizar la inversión de investigación de un país al poner a disposición de los usuarios el libre acceso a la documentación derivada de la misma (http://www. accesoabierto.net/node/8).

\section{Estudio de un caso: Costa Rica}

En Costa Rica existen algunos intentos que responden a esta corriente y podríamos afirmar que esto da muestra de sus avances en el campo de la inversión en ciencia y tecnología y de los rasgos democráticos que tradi- 
Derecho a la información, bien público y bien privado:...

cionalmente se le señalan. Si se compara este país con el resto de la región centroamericana, los avances en este sentido han sido destacables. No obstante, podemos observar que éstos no son suficientes porque presentan las siguientes características:

1.Se concentran principalmente en las universidades y algunas entidades públicas que tienen colecciones en línea, pero no llegan a ser repositorios: en general, no son interoperables, no son de autoarchivo, no tienen visibles sus políticas sobre contenido, formas de envío o preservación, ni tampoco aclaran una política explícita para el uso de metadatos, y pocos tienen carácter científico.

2.Un $99 \%$ de sus revistas científicas son de acceso abierto, sin ninguna restricción para los autores ni para los lectores. No obstante, la visibilidad de estas publicaciones aún presenta pocos avances, su ubicación en la Web es dispersa pues existen pocos repositorios. Aun dentro de una misma universidad, su localización es difícil pues no existen sitios especiales para ellas y sólo el directorio de Latindex www.latindex.org las reúne en un solo sitio.

Los directorios de repositorios en el mundo Open $D O A R$ http://www.opendoar.org/ y $R O A R$ http://roar. eprints.org/, D-Space List http://www.dspace.org/index indican para Costa Rica hasta cinco repositorios, variando la lista de acuerdo con criterios desconoci- 
Los repositorios de acceso abierto: una vía para la democratización...

dos. Estos coinciden en sólo 2 de estos que son: ITCR y SciELO, aunque no sean los más importantes, según mostramos en el cuadro 1. De esta manera, podría afirmarse que estos directorios no son una guía confiable para la búsqueda de repositorios por país.

CUADRO 1.- Repositorios y colecciones digitales más importantes en Costa Rica, según una búsqueda realizada en la Web, 2010

\begin{tabular}{|l|l|l|l|}
\hline Institución & Dirección & Contenido & Software \\
\hline ITCR $^{*}$ & $\begin{array}{l}\text { Repositorio institucional: } \\
\text { http://bibliodigital.itcr.ac.cr:8080/ } \\
\text { dspace/ }\end{array}$ & $\begin{array}{l}525 \\
\text { documentos }\end{array}$ & D-Space \\
\hline UCR & $\begin{array}{l}\text { Repositorio del Centro de } \\
\text { Investigación en Identidad y Cultura } \\
\text { Latinoamericanas (CIICLA): http:// } \\
\text { www.ciicla.ucr.ac.cr/circa.htm }\end{array}$ & $\begin{array}{l}171 \\
\text { documentos }\end{array}$ & D-Space \\
\hline UCR & $\begin{array}{l}\text { Repositorio institucional de la } \\
\text { Vicerrectoría de Investigación: http:// } \\
\text { www.kerwa.ucr.ac.cr }\end{array}$ & $\begin{array}{l}120 \\
\text { documentos }\end{array}$ & D-Space \\
\hline UCR & $\begin{array}{l}\text { Repositorio de sus revistas científicas: } \\
\text { http://www.latindex.ucr.ac.cr }\end{array}$ & $\begin{array}{l}45 \text { títulos } \\
3500 \text { artículos }\end{array}$ & HTML, PDF \\
\hline UCR & $\begin{array}{l}\text { Biblioteca digital de la Escuela de } \\
\text { Trabajo Social: http://www.ts.ucr.ac.cr/ } \\
\text { bv/documentos.php }\end{array}$ & $\begin{array}{l}3000 \\
\text { documentos }\end{array}$ & PDF \\
\hline CONARE & $\begin{array}{l}\text { Biblioteca digital: } \\
\text { http://163.178.80.12/catalogos/ } \\
\text { doctextcomp/index.htm }\end{array}$ & $\begin{array}{l}99 \\
\text { documentos }\end{array}$ & PDF \\
\hline BINASSS & $\begin{array}{l}\text { Colección SciEL0 de revistas: http:// } \\
\text { www.scielo.sa.cr/scielo.php?Ing=pt }\end{array}$ & $\begin{array}{l}11 \text { títulos de } \\
\text { revistas, 246 } \\
\text { fascículos, } \\
3511 \text { doc. }\end{array}$ & $\begin{array}{l}\text { Metodología } \\
\text { SciELO }\end{array}$ \\
\hline
\end{tabular}


Derecho a la información, bien público y bien privado:...

\begin{tabular}{|l|l|l|l|}
\hline $\begin{array}{l}\text { Centro } \\
\text { Agronómico } \\
\text { Tropical de } \\
\text { Investigación y } \\
\text { Enseñanza }\end{array}$ & $\begin{array}{l}\text { Biblioteca digital: http://orton.catie. } \\
\text { ac.cr/cgi-bin/wxis.exe }\end{array}$ & $\begin{array}{l}1539 \\
\text { documentos }\end{array}$ & CDS-ISIS \\
\hline $\begin{array}{l}\text { Ministerios de } \\
\text { Gobierno }\end{array}$ & $\begin{array}{l}\text { 50\% tienen colecciones en línea, } \\
\text { algunas son: MEIC (http://información. } \\
\text { meic.go.cr), SINABI (http://información. } \\
\text { meic.go.cr), COMEX www.comex.go.cr, } \\
\text { MIDEPLAN http://www.mideplan.go.cr/ } \\
\text { component/option,com_docman/ }\end{array}$ & $\begin{array}{l}\text { Pequeñas sin } \\
\text { calcular }\end{array}$ & CDS-ISIS \\
\hline Nacional & $\begin{array}{l}\text { Algunas colecciones en línea: } \\
\text { Investigaciones del Observatorio } \\
\text { Vulcanológico y Sismológico de } \\
\text { Costa Rica (OVSICORI) http://www. } \\
\text { ovsicori.una.ac.cr/sismologia/ } \\
\text { investigaciones.htm }\end{array}$ & $\begin{array}{l}\text { Pequeñas sin } \\
\text { calcular }\end{array}$ & PDF \\
\hline $\begin{array}{l}\text { Colección electrónica de la Facultad } \\
\text { de Filosofía y Letras: http://www. } \\
\text { bibliografia.una.ac.cr/index.htm } \\
\text { Mapoteca Virtual de la Escuela } \\
\text { de Ciencias Geográficas de la } \\
\text { Universidad Nacional: http://www. } \\
\text { mapoteca.geo.una.ac.cr Contiene } \\
\text { una cantidad de mapas de Costa } \\
\text { Rica elaborados por los académicos } \\
\text { y estudiantes de la UNA. Los } \\
\text { usuarios pueden depositar los mapas } \\
\text { elaborados por ellos. }\end{array}$ & $\begin{array}{l}\text { Re-UNED, Repositorio institucional: } \\
\text { www.uned.ac.cr }\end{array}$ & 146 & \\
\hline UNED & documentos & D-Space & \\
\hline
\end{tabular}

* Significado de las siglas: ITCR: Instituto Tecnológico de Costa Rica, UCR: Universidad de Costa Rica, CONARE: Consejo Nacional de Rectores, BINASSS: Biblioteca Nacional de Salud y Seguridad Social, UNA: Universidad Nacional Autónoma, UNED: Universidad Estatal a Distancia. 


\section{Conclusiones}

A pesar de los esfuerzos realizados en los últimos años, los avances logrados en el acceso abierto a la información no son suficientes. La siguiente síntesis nos puede servir como corolario:

- No existe en Costa Rica ningún mandato que obligue a los académicos a depositar sus producciones en los repositorios existentes, ni invitaciones que inciten al autoarchivo de la producción en determinadas instituciones. Excepto uno de los repositorios que es de autoarchivo, los demás son construidos por las bibliotecas institucionales y depositados por su personal.

- La mayoría de las iniciativas existentes tienden a recopilar textos, y por ello todos los repositorios encontrados contienen pocos documentos, son de formación reciente, no incluyen normas para compartir los metadatos o lograr su interoperabilidad y pueden considerarse incompletos.

- Existe una buena cantidad de intentos para organizar repositorios - sobre todo en las universidades públicas - y el tema es objeto de discusión en los últimos meses. No obstante, de las cinco universidades públicas que existen en el país, sólo tres tienen un repositorio institucional y ninguno sobrepasa los 500 documentos.

-Existe una confusión entre biblioteca virtual y repositorio; algunos que se denominan repositorios 
son solo BD y otras bibliotecas virtuales podrían ser repositorios. Algunas colecciones digitales son gestionadas $\mathrm{u}$ ofrecidas por las bibliotecas, pero otras iniciativas han salido de los investigadores. Algunos denominados repositorios institucionales incluyen la digitalización de documentos que son ajenos a la entidad y, en consecuencia, no son un producto científico.

- Los prejuicios, la falta de claridad conceptual y la falta de creatividad han impedido que éstos se desarrollen adecuadamente. El conocimiento sobre el acceso abierto y las vías para hacerlo efectivo apenas se empieza a extender entre las universidades, principalmente.

- La ausencia de políticas institucionales - sin pensar siquiera en la posibilidad de una política nacional- limitan el desarrollo de los repositorios. Pareciera que se requiere un cambio drástico en la mentalidad de las personas para lograr que el autodepósito sea una práctica común y que se aclaren los prejuicios relacionados con los derechos de los autores.

-La sostenibilidad de estos esfuerzos es dudosa, muchas de las iniciativas que se observan en la Web son de creación reciente y otras, que datan de varios años atrás, se quedaron en el tiempo sin actualizarse.

- Se evidencia la necesidad de divulgar los alcances y bondades de los repositorios, pues en varios estudios (Córdoba y Sequeira, 2010; Córdoba, 2009) 
se pudo captar el desconocimiento existente relacionado con el uso del término, su contenido y la aplicación de estándares internacionales.

Si deseamos democratizar el acceso a la información, es fundamental alimentar la Web con la propia producción nacional; para ello, se deben generar políticas que promuevan el acceso abierto y la creación de repositorios institucionales y especializados. No hay duda en que el acceso abierto contribuye a la democratización de la información y el conocimiento, pero pareciera que al igual que otras formas de asegurar la democracia, el acceso abierto tiene sus retractores que solapadamente lo debilitan, principalmente con la ausencia de definiciones claras. En consecuencia, queda patente la necesidad de promover el acceso abierto aún más en los países como Costa Rica, para poder llegar a una apertura tal que la inversión en $\mathrm{I}+\mathrm{D}$ se recupere y multiplique.

\section{Referencias}

Arcadia Fund (2011). Academic Knowledge, Open Access and Democracy: Synopsis. Disponible en: http://www.arcadiafund.org.uk/sites/default/ files/arcadia_open_access_academic_knowledge_and_democracy_with_signatories_11_ march_2011.pdf, (consultado el 12 marzo 2011). 
ACRL, Scholarly Communication Committee (2003a). Principles and Strategies for the Reform of Scholarly Communication. Document approved at the ALA Annual Conference in Toronto. Disponible en: http://www.ala.org/ala/mgrps/divs/acrl/publications/whitepapers/principlesstrategies.cfm (Consultado el 1 marzo 2011.

ACRL, (2003b). Iniciativa ACRL para reformar la comunicación erudita. Geotrópico [on line], v. 1, n. 2:155-159. Disponible en: http://www.geotropico.org/1_2_Documentos_ACRL_Principios.html (Consultado el 2 marzo 2011).

Berlin Declaration on Open Access to Knowledge in the Sciences and Humanities (2003). Disponible en: http://www.zim.mpg.de/openaccessberlin/berlin_declaration.pdf (Consultado el 2 marzo 2011).

Björk, B-C; Welling, P; Laakso, M; Majlender, P; Hedlund, T.; Guðnason, G. (2010) Open Access to the Scientific Journal Literature: Situation 2009. PLoS ONE v. 5, n. 6: e11273. Disponible en: http://www.plosone.org/article/ info\%3Adoi\%2F10.1371\%2Fjournal.pone.0011273 (Consultado el 13 febrero 2011).

Bot, M., Burgemeester, J., Roes, H. (Nov., 1998). The Cost of Publishing an Electronic Journal: A general model and a case study. D-Lib Magazine, v.4, n. 11. Disponible en: http://www.dlib.org/dlib/ 
Los repositorios de acceso abierto: una vía para la democratización...

november98/11roes.html (Consultado el 23 febrero 2011).

Branin, J. (2011). Editorial. College and Research Libraries Goes Fully Open Access. College and Research Libraries [en linea], v. 72, n. 2:108-109. Disponible en: http://crl.acrl.org/content/72/2/108.full.pdf + html (Consultado el 17 marzo 2011).

Budapest Open Access Iniciative (2002). [Declaration]. Disponible en: http://www.soros.org/openaccess, (Consultado el 28 febrero 2011).

Carpizo, J. (Mayo-ago., 2007). "Concepto de democracia y sistema de gobierno en América Latina" Boletín Mexicano de Derecho Comparado, v. 11, n. 119, pp. 325-384.

Córdoba, S. (Jul.-Dic., 2009). "Los repositorios institucionales y de acceso abierto en Costa Rica". Hélice (Venezuela), v. 1, n. 2. Disponible en: http:// www.cidtec.luz.edu.ve/helice/page.php?module $=$ htmlToPdf $\&$ task $=$ magazine $\& i d=92 \& v o l=1 \&$ nu $\mathrm{m}=2$ (Consultado el 23 febrero 2011).

Córdoba, S., Sequeira, Z. (2010). e-Bibliotecas en Costa Rica. En: Informe de PROSIC 2009: Hacia la Sociedad de la Información y el Conocimiento en Costa Rica [en línea], pp. 201-234. Disponible en: http://www.prosic.ucr.ac.cr/prosic09/ cap7.pdf, (Consultado el 2 noviembre 2010). 
Dahl, R; Sartori, G; Vallespín, F. (Nov., 1999). El Futuro de la democracia. Claves de razón práctica, n. 97:4-9.

DDLat 2010. Índice de desarrollo democrático de América Latina. Fundación Konrad Adenauer. Disponible en: http://www.idd-lat.org/index.php

Doyle H, Gass A, Kennison R (2004) Open Access and Scientific Societies. PLoS Biol 2(5): e156. Disponible en: http://www.plosbiology.org/article/ info:doi/10.1371/journal.pbio.0020156, (Consultado el 28 febrero 2011).

ERC Scientific Council Guidelines for Open Access (2007). Disponible en: http://erc.europa.eu/pdf/ ScC_Guidelines_Open_Access_revised_Dec07_ FINAL.pdf, consultado el 14 marzo 2011.

Eysenbach, G. (2006). Citation Advantage of Open Access Articles. PLoS Biology, v. 4 n. 5: e157. Disponible en: http://www.plosbiology.org/article/ info\%3Adoi\%2F10.1371\%2Fjournal.pbio.0040157, (Consultado el 13 febrero 2011).

Gargouri, Y.; Hajjem, C.; Larivière, V.; Gingrass, Y.; Carr, L.; Brody, T.; Harnad, S. (Oct. 2010). Self-Selected or Mandated, Open Access Increases Citation Impact for Higher Quality Research. PLoS ONE, v. 5, n. 10: e13636. Disponible en: http://www.plosone.org/article/info\%3Adoi\%2F10.1371\%2Fjournal. pone.0013636, (Consultado el 13 febrero 2011). 
Los repositorios de acceso abierto: una vía para la democratización...

Harnad, S. (2007). The Green Road to Open Access: A Leveraged Transition. In: Anna Gacs (ed.). The Culture of Periodicals from the Perspective of the Electronic Age. L'Harmattan. 99-106. Disponible en: http://eprints.ecs.soton.ac.uk/15753/1/ greenroad.html, (Consultado el 23 febrero 2011).

Harnad, S. (2010) The Immediate Practical Implication of the Houghton Report: Provide Green Open Access Now. Prometheus, v. 28, n. 1: 55-59. Disponible en: http://eprints.ecs.soton.ac.uk/18514/, (Consultado el 18 marzo 2011).

Houghton, J.W. (2011). "The costs and potential benefits of alternative scholarly publishing models". Information Research, 16(1) paper 469. Disponible en: http://InformationR.net/ir/16-1/ paper469.html, (Consultado el 18 marzo 2011).

Más sobre acceso abierto (2003). Geotrópico [on line], v.1. n. 2:152-154. Disponible en: http://www. geotropico.org/Berlin-I-2.pdf, (Consultado el 2 marzo 2011).

Montgomery, C., King, D. (Oct., 2002). Comparing Library and User Related Costs of Print and Electronic Journal Collections: First Step Towards a Comprehensive Analysis. D-Lib Magazine, v. 8, n. 10. Disponible en: http://www.dlib.org/dlib/ october02/montgomery/10montgomery.html, (Consultado el 23 febrero 2011). 
Derecho a la información, bien público y bien privado:...

Odlyzko, A. (1997). The Economics of Electronic Journals, First Monday, v. 2, n. 8. Disponible en: http://firstmonday.org/htbin/cgiwrap/bin/ojs/index.php/fm/article/view/542/463, (Consultado el 2 marzo 2011).

PNUD (2010). Informe sobre desarrollo humano 2010: La verdadera riqueza de las naciones. Caminos al desarrollo humano. México, D.F.: Ed. Mundi-Prensa. Disponible en: http://hdr.undp.org/en/media/HDR_2010_ES_Complete.pdf, (Consultado el 23 febrero 2011).

Rodríguez Gallardo, A. (2008). Elementos que fundamentan el acceso abierto. Investigación Bibliotecológica, v. 22, n. 44: 161-182.

Suber, P. (2010). The Mandates of October 2010. SPARC Open Access Newsletter. n. 151. Disponible en: http://www.earlham.edu/ peters/ fos/newsletter/11-02-10.htm\#mandates, (Consultado el 14 marzo 2011).

Tissera, M. (2008). Repositorios institucionales en bibliotecas académicas. Ponencia inédita. Disponible en: http://eprints.rclis.org/handle/10760/13064, (Consultada el 2 febrero 2011).

University of Harvard, Office for Scholarly Communication (2010). Harvard Faculty of Arts and Sciences Open Access Policy. Voted February 12, 2008. Disponible en: http://osc.hul.harvard. edu/hfaspolicy, (Consultado el 14 marzo 2011). 


\title{
Conceptuación de las bibliotecas y otros recursos de información como bienes comunes
}

\author{
Hugo Alberto Figueroa Alcántara \\ Colegio de Bibliotecología y Estudios de la Información \\ / Facultad de Filosofía y Letras \\ Universidad Nacional Autónoma de México \\ bugof@servidor.unam.mx
}

\section{Introducción}

T a finalidad esencial de este capítulo es explicar la Ltrascendencia de los bienes comunes de información; conceptuar las bibliotecas, la información, el conocimiento y los medios digitales como bienes comunes de información; promover la construcción de nuevos enfoques, políticas e investigación para fortalecer estos bienes comunes de información en nuestro entorno bibliotecológico.

Esta perspectiva conceptual, basada en la idea de bienes comunes de información, permite la integración de áreas de estudio, investigación, servicios y activismo que han estado normalmente separadas; por ejemplo, derechos de propiedad intelectual, bienes comunes creativos, cultura hacker, ética de la información, bibliotecas, software libre, sistemas para colaborar y compartir en línea, ciencia colaborativa, ciu- 
Derecho a la información, bien público y bien privado:...

dadanía y procesos democráticos, identidad y acción colectiva, economía de la información, etcétera. Además, este enfoque ofrece nuevas perspectivas que nos permiten concebir la información y el conocimiento como bienes compartidos, así como el acceso libre al conocimiento como un tema central en nuestra sociedad actual (Hess, 2007, pp. 3-6).

\section{Conceptuación de las bibliotecas y otros recursos de información como bienes comunes}

Cotidianamente, en la esfera pública de la sociedad y la cultura, surgen y se desarrollan conflictos y tensiones críticos, derivados de los heterogéneos intereses que tienen diferentes entidades y comunidades en relación con los bienes de consumo, sociales, culturales, científicos, de información, etcétera.

En tal sentido, varias corporaciones, entre ellas las vinculadas con la información y los medios de comunicación, pugnan por la privatización y el lucro de diferentes tipos de bienes comunes, mientras que otros grupos sociales, entre ellos distintas comunidades bibliotecarias, activistas del acceso libre a la información y el conocimiento, y defensores del interés público y comunal, protagonizan arduas batallas para defender y promover el uso común de los bienes, entre los cuales son fundamentales los bienes de información (Kranich, 2004). 
De acuerdo con este contexto, resulta primordial profundizar en los fundamentos conceptuales de los bienes comunes de información, explicar sus características principales e integrar en un marco común distintos tipos de bienes comunes de información, así como sus rasgos sobresalientes.

La idea de bienes comunes de información tiene sus raíces en el concepto de bienes comunes, término que se emplea para referirse a un conjunto de bienes de uso colectivo y común, como por ejemplo las tierras comunales, los océanos, la atmósfera, las plazas públicas, etcétera.

Derivado de lo anterior, entendemos que un bien común de información es un sistema de información donde se considera primordial el uso común y colectivo, así como la producción, difusión y preservación comunal para las generaciones actuales y futuras. Es un término genérico que alude a un recurso de información compartido por una comunidad. Considerar la información como bien común sugiere, por lo tanto, que un elemento unificador en todos los recursos comunes es que ellos se utilizan conjuntamente y son administrados por la propia comunidad, en grupos de intereses y tamaños diversos.

Aunque el concepto de bien común es antiguo, no ocurre así con el de bien común de información, cuya acuñación se remonta a la década de los noventa. Este detalle es importante de resaltar porque manifiesta la necesidad perentoria de crear nuevos modelos teóricos y pragmáticos para defender y promover el uso común 
Derecho a la información, bien público y bien privado:...

de la información. Tal tendencia, a su vez, está íntimamente vinculada con la cada vez mayor producción, difusión, etcétera, de información digital, disponible a través de Internet, así como con las dinámicas sociales y culturales - como por ejemplo colaborar y compartir en red- que la plataforma tecnológica y comunicacional que es en la actualidad Internet, posibilita exponencialmente. Sin duda Internet se ha convertido en un elemento cardinal del tejido social y cultural de nuestras vidas. Una de las cualidades más sobresalientes del paradigma en que se basa Internet es su capacidad para conectar todo con todo (Berners-Lee, 2000) y distribuir el poder de la información por todos los espacios de la actividad humana, convirtiéndose así en la plataforma tecnológica y de comunicación del modelo de organización que caracteriza a la sociedad actual: la red (Castells, 2001, p. 15).

De esta manera, la búsqueda de nuevas formas de vivencia y convivencia en la sociedad red requiere de un marco teórico, ideológico, social, cultural, económico, político, legal, etcétera, que permita el libre flujo de datos, información, ideas, conocimiento, etcétera, para generar y difundir, entre otros rubros, nuevas ideas, obras, invenciones, descubrimientos científicos, educación, creaciones de todo tipo, entre otros aspectos, y con todo ello contribuir al progreso de la humanidad.

En tal contexto, los bienes comunes de información tienen una importancia crucial porque representan una respuesta y alternativa viable y sustentable a los modelos cada vez más restrictivos y asfixiantes de 
derechos de autor, propiedad intelectual, apropiación abusiva de espacios y bienes públicos, etcétera, visibles en el sistema capitalista vigente, a la vez que permite reunir bajo un concepto general, una gama muy amplia y heterogénea de iniciativas que en el universo de la información no se circunscriben solamente al entorno de las bibliotecas, sino que su ámbito es más integral y multifacético.

Los bienes comunes de información tienen cualidades intrínsecas, entre las que destacan que necesitan acciones colectivas contundentes y mecanismos de autogobierno o autoorganización, así como un alto grado de capital social e intelectual. La autoorganización está sustentada en acciones colectivas, combinadas con conocimiento, soporte y acuerdos grupales o institucionales. El capital social e intelectual implica los grados de partipación y las funciones a desempeñar, de manera voluntaria, por diferentes personas, según sus conocimientos expertos, así como los motivos e intereses que los impulsan a hacer cosas para otras personas, como actos de reciprocidad, altruismo, generosidad, estar convencidos de la importancia del bienestar común, etcétera. Estos tres elementos: acción colectiva, autogobierno y capital social e intelectual son elementos de gran importancia para el desarrollo y preservación de los bienes comunes de información.

Por otra parte, todo sistema de bienes comunes de información debe considerar tres factores esenciales para su evolución, permanencia y trascendencia social y cultural: equidad, eficiencia y sostenibilidad. La equi- 
Derecho a la información, bien público y bien privado:...

dad involucra aspectos relativos al uso justo o igualitario de los recursos de información, así como las contribuciones de cada integrante de la comunidad para el mantenimiento de esos recursos. La eficiencia tiene que ver con la producción, manejo y uso óptimo de los recursos. A su vez, la sostenibilidad implica el manteniento y desarrollo de los recursos de información por largo tiempo, de manera perdurable y sin que los bienes comunes de información tiendan a extinguirse.

Otra característica trascendental de los bienes comunes de información es que son colaborativos e interactivos y aprovechan el entorno de red, a través de medios digitales basados en la web, para consolidar comunidades de información. Así, se benefician de una de las cualidades más interesantes de los sistemas en red: mientras mayor es la participación, los recursos de información se vuelven más valiosos y el sistema crece $y$ se fortalece (Kranich, 2004, pp. 1-3).

\section{Ejemplos de bienes comunes de información}

A continuación se explican algunas de las tendencias más representativas que promueven la creación, desarrollo y mantenimiento de bienes comunes de información, las cuales también ejemplifican los aspectos conceptuales, cualidades y características previamente explicados:

Software libre. Desde los últimos años de la década de los cincuenta del siglo XX, surgieron comunida- 
des hackers que impregnadas por una cultura y ética muy definidas promovieron desde sus inicios la libre circulación de la información, la colaboración y el intercambio de conocimientos, códigos de programación, etcétera. Pero junto con el desarrollo de las computadoras surgió también una industria del software muy poderosa y con grandes ganancias económicas que paulatinamente se alejó del paradigma de la cultura hacker, basándose sobre todo en modelos de software propietario, sujeto a propiedad intelectual, copyright y con restricciones totales para acceder al código fuente (Mochi Alemán, 2002, pp. 73-89). Como respuesta opuesta a esta tendencia, en 1984 nació el movimiento de software libre, inspirado por Richard Stallman, quien hasta la fecha sigue siendo uno de sus principales promotores (Stallman, 2002b).

En esta corriente, aunque el concepto libre lo podemos asociar con la idea de gratuito, no necesariamente es el único sentido y por lo tanto no tiene que ver, en todos los casos, con que un producto o servicio sea gratuito o comercial, sino que ante todo se fundamenta en un sentido ético-filosófico de libertad. Bajo esta perspectiva libertaria, Stallman definió desde un principio las cuatro libertades primordiales que todo software libre debe tener:

- Libertad para utilizar el software sin restricciones y sin importar cuál sea el propósito o aplicación que el usuario le dé. 
Derecho a la información, bien público y bien privado:...

- Libertad para examinar el funcionamiento del software en su sentido más profundo, con en propósito de descubrir nuevas aplicaciones, adaptarlo a necesidades específicas, etcétera, por lo que el acceso al código fuente es condición necesaria.

- Libertad para redistribuir copias o versiones del software para beneficio de toda la comunidad.

-Libertad para mejorar el software y publicar y difundir estas modificaciones, para el bien de la comunidad en su conjunto, por lo que el acceso, manipulación y modificación del código es también condición necesaria (Stallman, 2002a, pp. 43-45).

Como acertadamente afirma Lessig (2002): cada generación tiene su filósofo. Una persona que a través de sus ideales y sus acciones plasma el espíritu e imaginación de una época. En el caso de los nuevos movimientos sociales a favor de una sociedad y cultura libres y el acceso libre al conocimiento (Krikorian, 2010), su filosofía intrínseca, basada en el principio de creación de bienes comunes de información, está representada por la teoría y praxis de Stallman. En este contexto, el movimiento de software libre ha permeado su ideología y articulaciones teórico-pragmáticas a los otros movimientos que tienen propósitos afines (Kelty, 2008). Un ejemplo muy claro de ello es la persistencia en todos ellos, en menor o mayor medida o con diferentes modalidades, de las cuatro libertades fundamentales previamente explicadas. 
Ahora bien, ¿cómo articular en los planos teórico, ideológico, cultural, social, jurídico, etcétera, estas libertades? Tal interrogante ha sido crucial para el movimiento de software libre y sus propuestas al respecto nos brindan un excelente ejemplo de imaginación, creatividad, ingenio, muy buen sentido del humor e idealismo teórico-pragmático (Stallman, 2002, pp. 93-95).

En tal perspectiva, por ejemplo, ante las restricciones cada vez más abusivas de las leyes relacionadas con el copyright, que en su sentido más radical implica: todos los derechos reservados, el proyecto promovido por Stallman inventó el concepto de copyleft (como un juego de palabras que se opone humorísticamente a copyright), que en su vertiente más fundamental implica: ningún derecho reservado.

Copyleft. Aunque el copyleft nació y se desarrolló originalmente en el entorno del software libre, muy pronto se convirtió en un poderoso artilugio aplicable a todos los campos de la producción intelectual de contenidos: textos, imágenes, música, videos, filmes, etcétera. El marco jurídico conceptual del copyleft garantiza ante todo la copia, distribución, uso y modificación, etcétera, de todo tipo de obras sin restricciones o con pocas restricciones, pero obliga a que todas las copias, versiones modificadas, obras derivadas, etcétera, contengan las mismas propiedades de copia, distribución, uso, modificación, etcétera que la versión original de la obra (Stallman, 2002c, pp. 91-94). Este método asegura cabalmente que nadie pueda apropiarse de un 
Derecho a la información, bien público y bien privado:...

bien común de información libre ni de sus obras derivadas, a la vez que promueve la libre circulación de la información, el conocimiento, la ideas y, con todo ello, el trabajo común, la compartición de recursos y la cooperación y colaboración en proyectos comunes para beneficio social y cultural colectivo (Malina Torrent, 2006, pp. 159-191).

El copyleft se instrumenta a través de licencias que se aplican en la actualidad en todos los ámbitos de la creación intelectual cultural, científica, tecnológica, etcétera. Un ejemplo destacado de licencia copyleft es la licencia pública general (GPL), una de las más conocidas y utilizada en miles de proyectos de software libre como GNU/Linux, Open Office, Firefox, etcétera (González Barahona, 2006, p. 29). Otra licencia copyleft muy frecuentemente aplicada es la licencia de documentación libre, aplicable a diversos tipos de documentos en versión física o digital, como es el caso del contenido disponible en Wikipedia, entre muchos otros ejemplos.

Además de otras muchas variedades de licencias copyleft, el movimiento de software libre, como ya se explicó, ha inspirado o está vinculado con una gama amplia de nuevos movimientos sociales que comparten el ideal de la sociedad y cultura libres, así como el acceso libre al conocimiento. A continuación se explican algunos de los más significativos.

Bienes comunes creativos (creative commons). La idea de los bienes creativos comunes está inspirada en el movimiento de software libre. El creador de esta 
iniciativa es Lawrence Lessig (especialista en ciberderecho), quien además es uno de los principales ideólogos del movimiento de acceso libre al conocimiento, a través de sus libros como Code and other laws of cyberspace (1999), The future of ideas: the fate of the commons in a connected world (2001) y Free culture (2004). Para operacionalizar su idea fundó en 2002 la Creative Commons, organización no gubernamental que tiene como propósito principal crear un sistema legal y tecnológico alternativo al copyright tradicional para promover la creatividad mediante el principio común de compartir (Helfrich, 2008, p. 265). Para ello se han creado un conjunto de licencias, llamadas también creative commons, la cuales, según su modalidad, permiten compartir atributos de una obra en menor o mayor grado. El grado de libertad para compartir lo establece el propio autor de la obra, de acuerdo con la combinación de las siguientes condiciones fundamentales:

- Reconocimiento/atribución: Otras personas pueden distribuir, copiar, exhibir, etcétera, por cualquier medio una obra pero están obligadas a indicar con precisión los créditos de autoría.

- No comercial: Otras personas pueden distribuir, copiar, exhibir, etcétera, por cualquier medio una obra pero sin fines comerciales.

- Sin obra derivada: Otras personas pueden distribuir, copiar, exhibir, etcétera, por cualquier medio una obra pero no derivar obras de ella. 
Derecho a la información, bien público y bien privado:...

- Compartir igual/Licenciamiento recíproco: Permite derivar otras obras de una obra específica, siempre y cuando cumplan con los mismos atributos de libertades que la precedente (Vercelli, 2009, pp. 138-142).

Si por ejemplo un autor incluye en su obra un licencia creative commons que incluya todos los rubros, se facilita mucho compartir obras y mediante ello se libera la creación cultural, además de que se crea un efecto exponencial viral porque las obras derivadas beredan las mismas propiedades que sus precedentes (Bollier, 2008).

Acceso abierto (Open Access). El movimiento de acceso abierto nace formalmente en 2001, a raíz de la reunión convocada en Budapest por el Instituto para una Sociedad Abierta (Open Society Institute). El resultado fue la Iniciativa de Budapest para el Acceso Abierto, que se sustenta en el principio fundamental de integrar, por un lado, la añeja tradición científica y académica de difundir públicamente los resultados de investigación, concebidos como bienes comunes y, por el otro, el medio tecnológico idóneo que permita el acceso público, abierto, gratuito y sin restricciones a distintos tipos de obras académicas y científicas, a través de la web (Open Society Institute, 2010). Es tan trascendente este movimiento y sus repercusiones sociales para el libre flujo de la información y el conocimiento son tan importantes que, por ejemplo, en Estados Unidos está vigente desde 2006 la Federal research public 
access act, que obliga a que todas las publicaciones que son resultado de investigaciones financiadas con recursos federales, estén disponibles mediante acceso público en línea.

Para cumplir su cometido, el movimiento de acceso abierto se basa en dos estrategias principales:

- Revistas académicas y científicas de acceso abierto. Son publicaciones en serie disponibles gratuitamente y sin restricciones por medio de la Web, que cumplen con los mismos criterios de calidad, arbitraje, normas de publicación, etcétera, que aquellas que no son de acceso abierto. El hecho de que no haya restricciones en su acceso, no quiere decir que la producción sea libre de costos, por lo que normalmente la institución responsable de la publicación asume los gastos. Otra opción es que la venta de los ejemplares de la versión impresa permita sufragar los gastos operativos de la versión digital en línea (Suber, 2007). Por ejemplo el Directory of Open Access Journals (2010) reúne hasta la fecha 4868 revistas académicas y científicas que contienen más de 3,79875 artículos.

-Archivos o repositorios de acceso abierto. Pueden estar organizados por disciplina (por ejemplo ArXiv (2010) para física) o por institución (por ejemplo eScholarship repository (University of California, 2010)). En esta modalidad la estrategia que se sigue es que los propios autores, o bien la propia 
Derecho a la información, bien público y bien privado:...

institución suben a los repositorios sus libros, artículos, ponencias, tesis, etcétera. Aunque normalmente se suben a este tipo de sitios web obras previamente publicadas en otro medio, en ocasiones puede no ser así, por lo que la revisión entre pares y por lo tanto la calidad rigurosa de todos los recursos de información no siempre está garantizada (Suber, 2007).

Recursos educativos abiertos (open educational resources). Igual que en la esfera de las actividades académicas y científicas, también en el ámbito de la educación cobra cada vez mayor relevancia el movimiento de recursos educativos abiertos. El concepto de recursos educativos abiertos fue adoptado por primera vez en 2002 por la Unesco y hace alusión a materiales y recursos educativos abiertos y reutilizables ofrecidos libre, gratuitamente y sin restricciones a través de la Web o de otros medios para que cualquiera los pueda utilizar, modificar, reusar, etcétera, en distintos escenarios educativos, con el propósito de apoyar y mejorar los procesos de enseñanza aprendizaje, coadyuvar en el aprendizaje autónomo, reforzar los materiales de apoyo para la educación en línea y a distancia, así como contribuir a que la cultura y el conocimiento sean libres (OECD, Centro para la Investigación y la Innovación Educativas, 2008).

El espectro de recursos es muy amplio y puede abarcar, entre otros: cursos completos, materiales para los cursos, apuntes del profesor, objetos de aprendizaje, 
software para la gestión de contenidos de aprendizaje abierto, adaptación local de contenido, empleo de licencias abiertas tipo creative commons que promuevan el acceso y uso irrestricto de materiales educativos, etcétera. Ejemplos notables de estos proyectos son, entre otros: el Open course ware del Instituto Tecnológico de Massachusetts (MIT, 2010), que hasta la fecha incluye recursos educativos abiertos de más de 1900 cursos del MIT, así como, en nuestro entorno universitario, el Repositorio universitario de la Facultad de Filosofía y Letras de la UNAM, (UNAM, 2010), que tiene la virtud de ser el primer repositorio de estas características en nuestra Universidad.

Comunidades de aprendizaje e información. En los últimos años en diversos campos universitarios se han creado, dentro de las bibliotecas o asociados con ellas, centros digitales integrados de aprendizaje, concebidos como comunidades de aprendizaje e información. Las bibliotecas han establecido estos centros en colaboración con otros colegas académicos, como por ejemplo profesores, pedagogos, ingenieros, expertos en tecnologías de la información, multimedia, etcétera, quienes desarrollan ambientes colaborativos de enseñanza y aprendizaje. Algunos de estos espacios son llamados bienes comunes de información, porque recursos de información muy heterogéneos son reunidos por bibliotecólogos y otros colegas académicos para apoyar nuevas formas de aprendizaje y de trabajo colaborativo. En otros casos el concepto que se utiliza es el de bienes comunes de aprendizaje, porque los 
Derecho a la información, bien público y bien privado:...

estudiantes, que trabajan juntos y no de manera aislada, comparten información, tareas de aprendizaje y se ayudan unos a otros, es decir, trabajan y aprenden de manera colaborativa y comparten abiertamente bienes comunes de información. Lo que distingue esencialmente a estos novedosos espacios de información y aprendizaje de los más tradicionales laboratorios de cómputo es que ellos no se centran en la búsqueda y recuperación de la información, sino en facilitar el aprendizaje colaborativo utilizando todo tipos de medios y contenidos impresos y digitales. El cambio de paradigma fundamental es asegurar que estos bienes comunes de aprendizaje sean conceptualmente apropiados por los estudiantes. Por ejemplo, diversos modelos de esta naturaleza se basan en seminarios especiales o en comunidades de aprendizaje, coordinados por un equipo colaborativo de bibliotecólogos, cuerpo docente, personal especializado, etcétera, quienes inculcan en los estudiantes habilidades de pensamiento crítico, la importancia de colaborar y compartir información, etcétera, aspectos que refuerzan las experiencias de aprendizaje de los estudiantes (Kranich, 2007, pp. 100-101).

\section{Conclusiones}

El panorama previamente ofrecido nos invita a reflexionar sobre la manera en que podemos expandir nuestro papel dentro de la sociedad en torno de la información y el conocimiento como bien común. Por siglos, los bibliotecarios hemos jugado un papel muy importante 
como responsables de seleccionar información, organizarla, difundirla y preservarla, así como en nuestras posiciones respecto a principios fundamentales tales como la libertad intelectual, el acceso a la información equitativo, la diversidad, la participación democrática para forjar políticas y prácticas sociales y culturales que sirvan al bien común, etcétera.

Pero para fortalecer e irradiar nuestra participación social y cultural a favor del bien común en materia de información, resulta primordial que conceptualizemos $\mathrm{y}$ articulemos a las bibliotecas como bienes comunes de información y como instituciones sociales y culturales basadas en la acción colectiva, que no sólo protegen información, ideas y conocimientos, sino que facilitan su creación, intercambio, preservación y sostenibilidad. Uno de nuestros mayores desafíos es convencer a todo tipo de personas y entidades acerca de los beneficios de los bienes comunes de información y del acceso abierto al conocimiento.

Debemos promover en nuestras comunidades mecanismos para constituir, desarrollar y mantener sistemas de bienes comunes de información, diseñados como alternativas al mercado de las industrias de información prevalecientes, además de consolidarnos como actores relevantes en el universo de la información.

Es necesario aprender a actuar colectivamente, a favor del bien común, para resolver multitud de problemas relacionados con la información, así como para defender la idea de los bienes comunes de información y los intereses de las comunidades en diferentes temas 
Derecho a la información, bien público y bien privado:...

cruciales, como es el caso de los derechos de autor, la propiedad intelectual, las patentes, etcétera. Pero no podemos actuar solos o en el vacío, por lo que necesitamos extender nuestras redes de colaboración mutua más allá de las bibliotecas, incluyendo el espectro completo de creadores, gestores y usuarios de recursos de información.

Es imprescindible explorar nuevas modalidades para compartir información mediante nuestra participación activa y relevante en iniciativas como acceso abierto; bienes creativos comunes; repositorios digitales; creación, desarrollo, organización, difusión y preservación de información basada en la comunidad; comunidades de aprendizaje e información, etcétera, así como involucrar a las partes interesadas en el diseño, creación y manejo de estos sistemas de bienes comunes de información.

Asimismo es crucial que participemos en los debates jurídicos y en el discurso político para promover el valor y beneficios de los bienes comunes de información, asi como alertar de los peligros de las restricciones al respecto (Kranich, 2007, pp. 104-105).

Finalmente, es primordial crear nuestras propias comunidades de aprendizaje para mantenernos al día sobre las nuevas tendencias respecto a los bienes comunes de información y comunicar sus implicaciones al público para fomentar el diálogo, la participación y la colaboración; y de esta manera contribuir, por lo tanto, al fortalecimiento de la sociedad y cultura libres y democráticas. 


\section{Referencias}

ArXiv (2010). Sitio web en línea. Recuperado el 29 de octubre, 2010 de: http://arxiv.org/.

Berners-Lee, Tim (2000). Tejiendo la red. Madrid: Siglo XXI.

Bollier, David (2008). Viral spiral: bow the commoners built a digital republic of their own. New York: The New Press.

Castells, Manuel (2001). La galaxia internet: reflexiones sobre internet: empresa y sociedad. Barcelona: Areté.

Directory of Open Access Journals. (2010). Sitio web en línea. Recuperado el 29 de octubre, 2010 de: http://www.doaj.org/.

Estados Unidos. Congress. Senate (2006). Federal research public access act. Recuperado el 6 de enero, 2010 de: http://cornyn.senate.gov/doc_archive/05-02-2006_COE06461_xml.pdf.

González Barahona, Jesús M. (2006). Guía del software libre. En Copyleft: manual de uso (pp. 1940). Madrid: Traficantes de Sueños.

Helfrich, Silke. (2008). Creative commons: la pasión por compartir. En Silke Helfrich (Compiladora), Genes, bytes y emisiones: bienes comunes y ciu- 
Derecho a la información, bien público y bien privado:...

dadanía (pp. 265-266). San Salvador: Fundación Heinrich Böll.

Hess, Charlotte y Ostrom, Elinor (2007). Introduction: an overview of the knowledge commons. En Charlotte Hess and Elinor Ostrom (Editors), Understanding knowledge as a commons: from theory to practice (pp. 3-26). Cambridge, Massachusetts: The MIT Press.

Kelty, Christopher M. (2008). Two bits: the cultural significance of free software. Durham: Duke University Press.

Kranich, Nancy (2004). The information commons: a public policy report. New York: Brenan Center for Justice at NYU School of Law.

Kranich, Nancy (2007). Countering enclosure: reclaiming the knowledge commons. En Charlotte Hess and Elinor Ostrom (Editors), Understanding knowledge as a commons: from theory to practice (pp. 85-122). Cambridge, Massachusetts: The MIT Press.

Krikorian, Gaëlle y Kapczynski, Amy (Editors) (2010). Access to knowledge in the age of intellectual property. New York: Zone Books.

Lessig, Lawrence (1999). Code and other laws of cyberspace: how will the architecture of cyberspace change the Constitution. New York: Basic Books. 
Existe traducción al español: Lessig, Lawrence (1999). El código y otras leyes del ciberespacio. Madrid: Santillana.

Lessig, Lawrence (2001). The future of ideas: the fate of the commons in a connected world. New York: Random House.

Lessig, Lawrence (2002). Introduction. En Stallman, Richard M. Free software, free society: selected essays of Richard M. Stallman (pp. 11-14). Boston, Massachusetts: GNU Press.

Lessig, Lawrence (2004). Free culture: how big media uses technology and the law to lock down culture and control creativity. New York: Penguin Press. Libro en texto completo. Recuperado el 29 de octubre, 2010 de: http://www.free-culture.cc/freeculture.pdf. Existe traducción al español: Lessig, Lawrence (2004). Cultura libre: cómo los grandes medios usan la tecnología y las leyes para encerrar la cultura y controlar la creatividad. Libro en texto completo. Recuperado el 29 de octubre, 2010 de: http://cyber.law.harvard. edu/blogs/gems/ion/Culturalibre.pdf.

Malina Torrent, Teresa (2006). Activismo copyleft: liberar los códigos de la producción tecnopolítica. En Copyleft: manual de uso (pp. 159-191). Madrid: Traficantes de Sueños. 
Derecho a la información, bien público y bien privado:...

Massachusetts Technology Institute (2010). Open course ware. Sitio web en línea. Recuperado el 29 de octubre, 2010 de: http://ocw.mit.edu/ OcwWeb/web/home/home/index.htm.

Mochi Alemán, Prudencio Óscar (2002). El movimiento de software libre. Revista Mexicana de Ciencias Políticas y Sociales, 45 (185), 73-89.

Open Society Institute (2001). Iniciativa de Budapest para el Acceso Abierto. Recuperado el 29 de octubre, 2010 de: http://www.soros.org/openaccess/esp/read.shtml.

Organización para la Cooperación y Desarrollo Económicos. Centro para la Investigación y la Innovación Educativas (2008). El conocimiento libre y los recursos educativos abiertos. Mérida: OECD: Junta de Extremadura, Dirección General de Telecomunicaciones y Sociedad de la Información.

Stallman, Richard M. (2002). Copyleft: pragmatic idealism. En Stallman, Richard M. Free software, free society: selected essays of Richard M.Stallman (pp. 93-95). Boston, Massachusetts: GNU Press.

Stallman, Richard M. (2002a). Free software definition. En Stallman, Richard M. Free software, free society: selected essays of Richard M.Stallman (pp. 43-45). Boston, Massachusetts: GNU Press. 
Stallman, Richard M. (2002b). Free software, free society: selected essays of Richard M.Stallman. Boston, Massachusetts: GNU Press. Existe traducción al español: Stallman, Richard M. (2004). Software libre para una sociedad libre. Madrid: Traficantes de Sueños.

Stallman, Richard M. (2002c). What is copyleft? En Stallman, Richard M. Free software, free society: selected essays of Richard M.Stallman (pp. 9194). Boston, Massachusetts: GNU Press.

Suber, Peter (2007). Open access overview. Recuperado el 29 de octubre, 2010 de: http://www.earlham.edu/ peters/fos/overview.htm.

Universidad Nacional Autónoma de México. Facultad de Filosofía y Letras (2010). Repositorio universitario de la Facultad de Filosofía y Letras. Sitio web en línea. Recuperado el 29 de octubre, 2010 de: http://ru.ffyl.unam.mx:8080/jspui/.

University of California. (2010). eScholarship repository. Sitio web en línea. Recuperado el 29 de octubre, 2010 de: http://repositories.cdlib.org/escholarship/.

Vercelli, Ariel (2009). Repensando los bienes intelectuales comunes: análisis socio-técnico sobre el proceso de co-construcción entre las regulaciones de derecho de autor, derecho de copia y las tecnologías digitales para su gestión. Tesis, Doc- 
Derecho a la información, bien público y bien privado:...

torado en Ciencias Sociales y Humanas, Universidad Nacional de Quilmes, Argentina, Instituto de Estudios Sociales de la Ciencia y Tecnología. Tesis en texto completo. Recuperado el 29 de octubre, 2010 de: http://www.arielvercelli.org/rlbic.pdf. 


\title{
Propiedad intelectual: la información como bien público y bien privado
}

\author{
Jesús Francisco García Pérez \\ Instituto de Investigaciones Sociales \\ Universidad Nacional Autónoma de México \\ garper@servidor.unam.mx
}

\section{Introducción}

Tnmersos en un mundo globalizado, la propiedad inItelectual y la información han experimentado un aumento en las capacidades para procesar, almacenar, transformar y transmitir la información, tanto en su forma tradicional - papel- como en los formatos electrónicos y digitales.

A la propiedad intelectual se le concibe como el conjunto de normas jurídicas que regula todo lo concerniente a las patentes, marcas y derechos de autor, por mencionar algunos. En este sentido, se considera como la noción amplia que abarca no sólo los derechos de autor, sino los derechos que integran a la propiedad industrial. A la información se le concibe como un conjunto de datos con un significado, que reduce la incertidumbre o que aumenta el conocimiento de algo. La información es un mensaje con significado en un de- 
Derecho a la información, bien público y bien privado:...

terminado contexto, disponible para uso inmediato y que proporciona orientación a las acciones por el hecho de reducir el margen de incertidumbre con respecto a nuestras decisiones.

Ante la globalización cada vez más inminente de los mercados, la información se convierte en un bien público o en un bien privado por la generalización del acceso a ésta; la organización y prestación de servicios en la red; el crecimiento exponencial de la misma; la necesidad de crear y recrear conocimiento y la globalización a nivel mundial de las economías.

\section{Propiedad intelectual}

La propiedad intelectual (P.I.) se refiere a las creaciones de la mente: las invenciones, las obras literarias y artísticas, los símbolos, los nombres, las imágenes, los dibujos y los modelos utilizados en el comercio.

Así, el término propiedad intelectual se refiere al derecho de pertenencia sobre una creación, se asemeja a cualquier otro derecho de propiedad permitiendo al creador o al titular de una patente, marca o derecho de autor, beneficiarse de su obra o inversión.

Para Battisti la propiedad intelectual "ha sido interpretada en diversas vertientes en Europa". ${ }^{1}$ Pone de manifiesto como prototipo de estas vertientes a Inglaterra, donde utilizan el término Copyright, teniendo como

1 B. Michele, The future of copyright management. European perspective. En IFLA Journal 27(2): 82, 2001. 
antecedente el siglo XVIII, con la incorporación del Estatuto de la Reina Ana. "Actualmente se base en la idea de contratos entre el autor y la sociedad, sustentándose en la base económica por el trabajo del autor". ${ }^{2}$

La propiedad intelectual se divide en dos categorías:

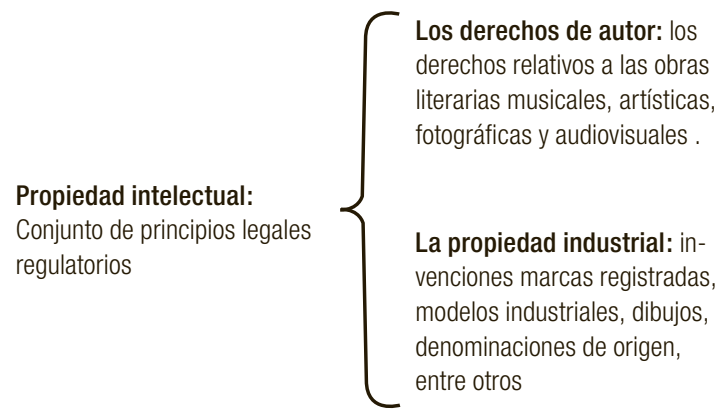

La importancia de la propiedad intelectual tiene sus antecedentes en el Convenio de París para la Protección de la Propiedad Industrial de 1883 y en el Convenio de Berna para la Protección de las Obras Literarias y Artísticas de 1886. La Organización Mundial de la Propiedad Intelectual (OMPI) administra ambos tratados.

La OMPI fue establecida para velar por la protección de los derechos de los creadores y los titulares de propiedad intelectual a nivel mundial y contribuir a que se reconozca y se recompense el ingenio de los invento-

2 Ibídem. 
Derecho a la información, bien público y bien privado:...

res, autores y artistas. La protección internacional estimula la creatividad humana, ensancha las fronteras de la ciencia y la tecnología y enriquece el mundo de la literatura y de las artes. Al crear un marco estable para la comercialización de los productos de la propiedad intelectual, también facilita el comercio internacional.

En 1996, la OMPI amplió sus funciones y demostró todavía más la importancia de los derechos de propiedad intelectual en la reglamentación del comercio mundial al concertar un acuerdo de cooperación con la Organización Mundial del Comercio (OMC).

La OMPI, administra hoy 24 tratados, dentro de los más importantes encontramos:

\begin{tabular}{|l|l|}
\hline Tratado & Generalidades \\
\hline $\begin{array}{l}\text { Convenio de París para } \\
\text { la Protección de la } \\
\text { Propiedad Industrial. }\end{array}$ & $\begin{array}{l}\text { La protección de la propiedad industrial tiene por objeto las } \\
\text { patentes de invención, los modelos de utilidad, los dibujos o } \\
\text { modelos industriales, las marcas de fábrica o de comercio, las } \\
\text { marcas de servicio, el nombre comercial, las indicaciones de } \\
\text { procedencia o denominaciones de origen, así como la represión } \\
\text { de la competencia desleal. }\end{array}$ \\
\hline $\begin{array}{l}\text { Convenio de Berna } \\
\text { para la Protección de } \\
\text { las Obras Literarias y } \\
\text { Artísticas }\end{array}$ & $\begin{array}{l}\text { Las obras literarias y artísticas comprenden todas las } \\
\text { producciones en el campo literario, científico y artístico, } \\
\text { cualquiera que sea el modo o forma de expresión, tales como } \\
\text { los libros, folletos y otros escritos; las conferencias, alocuciones, } \\
\text { sermones y otras obras de la misma naturaleza; las obras } \\
\text { dramáticas 0 dramático-musicales; las obras coreográficas y } \\
\text { las pantomimas; las composiciones musicales con o sin letra; } \\
\text { las obras cinematográficas, a las cuales se asimilan las obras } \\
\text { expresadas por procedimiento análogo a la cinematografía; } \\
\text { las obras de dibujo, pintura, arquitectura, escultura, grabado, } \\
\text { litografía; las obras fotográficas a las cuales se asimilan las } \\
\text { expresadas por procedimiento análogo a la fotografía; las obras } \\
\text { de artes aplicadas; las ilustraciones, mapas, planos, croquis } \\
\text { y obras plásticas relativos a la geografía, a la topografía, a la } \\
\text { arquitectura o a las ciencias. }\end{array}$ \\
\hline
\end{tabular}


Propiedad intelectual: la información como bien público...

\begin{tabular}{|c|c|}
\hline $\begin{array}{l}\text { Arreglo de Madrid } \\
\text { relativo a la represión } \\
\text { de las indicaciones } \\
\text { de procedencia falsas } \\
\text { o engañosas en los } \\
\text { productos }\end{array}$ & $\begin{array}{l}\text { Todos los productos que lleven una indicación falsa o engañosa } \\
\text { en virtud de la cual resulten indicados directa o indirectamente, } \\
\text { como país o como lugar de origen alguno de los países a los } \\
\text { cuales se aplica el presente Arreglo, o un lugar situado en alguno } \\
\text { de ellos, serán embargados al ser importados en cada uno de } \\
\text { los dichos países. }\end{array}$ \\
\hline $\begin{array}{l}\text { Convención de Roma } \\
\text { sobre la protección de } \\
\text { los artistas intérpretes } \\
\text { o ejecutantes, los } \\
\text { productores de } \\
\text { fonogramas y los } \\
\text { organismos de } \\
\text { radiodifusión }\end{array}$ & $\begin{array}{l}\text { La protección prevista por la presente Convención en favor de } \\
\text { los artistas intérpretes o ejecutantes comprenderá la facultad } \\
\text { de impedir: la radiodifusión y la comunicación al público de sus } \\
\text { interpretaciones o ejecuciones para las que no hubieren dado } \\
\text { su consentimiento, excepto cuando la interpretación o ejecución } \\
\text { utilizada en la radiodifusión o comunicación al público constituya } \\
\text { por sí misma una ejecución radiodifundida o se haga a partir } \\
\text { de una fijación; la fijación sobre una base material, sin su } \\
\text { consentimiento, de su ejecución no fijada; la reproducción, sin } \\
\text { su consentimiento, de la fijación de su ejecución. }\end{array}$ \\
\hline $\begin{array}{l}\text { Convenio de Ginebra } \\
\text { para la protección de } \\
\text { los productores de } \\
\text { fonogramas contra } \\
\text { la reproducción no } \\
\text { autorizada de sus } \\
\text { fonogramas }\end{array}$ & $\begin{array}{l}\text { Preocupados por la extensión e incremento de la reproducción } \\
\text { no autorizada de fonogramas y por el perjuicio resultante } \\
\text { para los intereses de los autores, de los artistas intérpretes o } \\
\text { ejecutantes y de los productores de fonogramas; Convencidos } \\
\text { de que la protección de los productores de fonogramas contra } \\
\text { los actos referidos beneficiará también a los artistas intérpretes o } \\
\text { ejecutantes y a los autores cuyas interpretaciones y obras están } \\
\text { grabadas en dichos fonogramas; Reconociendo la importancia } \\
\text { de los trabajos efectuados en esta materia por la Organización } \\
\text { de las Naciones Unidas para la Educación, la Ciencia y la Cultura } \\
\text { y la Organización Mundial de la Propiedad Intelectual. }\end{array}$ \\
\hline $\begin{array}{l}\text { Convenio de Bruselas } \\
\text { para la protección de } \\
\text { los productores de } \\
\text { fonogramas contra } \\
\text { la reproducción no } \\
\text { autorizada de sus } \\
\text { fonogramas. }\end{array}$ & $\begin{array}{l}\text { Preocupados por la extensión e incremento de la reproducción } \\
\text { no autorizada de fonogramas y por el perjuicio resultante } \\
\text { para los intereses de los autores, de los artistas intérpretes o } \\
\text { ejecutantes y de los productores de fonogramas; Convencidos } \\
\text { de que la protección de los productores de fonogramas contra } \\
\text { los actos referidos beneficiará también a los artistas intérpretes o } \\
\text { ejecutantes y a los autores cuyas interpretaciones y obras están } \\
\text { grabadas en dichos fonogramas; Reconociendo la importancia } \\
\text { de los trabajos efectuados en esta materia por la Organización de } \\
\text { las Naciones Unidas para la Educación, la Ciencia y la Cultura y la } \\
\text { Organización Mundial de la Propiedad Intelectual; }\end{array}$ \\
\hline
\end{tabular}


Derecho a la información, bien público y bien privado:...

\begin{tabular}{|c|c|}
\hline $\begin{array}{l}\text { Tratado sobre el } \\
\text { Derecho de Marcas }\end{array}$ & $\begin{array}{l}\text { se entenderá por "registro de marcas" la recopilación de los } \\
\text { datos mantenida por una Oficina, que incluye el contenido de } \\
\text { todos los registros y todos los datos inscritos respecto de dichos } \\
\text { registros, cualquiera que sea el medio en que se almacene dicha } \\
\text { información; }\end{array}$ \\
\hline $\begin{array}{l}\text { Tratado de la OMPI } \\
\text { sobre Derecho de Autor }\end{array}$ & $\begin{array}{l}\text { El presente Tratado es un arreglo particular en el sentido del } \\
\text { Artículo } 20 \text { del Convenio de Berna para la Protección de las } \\
\text { Obras Literarias y Artísticas, en lo que respecta a las Partes } \\
\text { Contratantes que son países de la Unión establecida por dicho } \\
\text { Convenio. El presente Tratado no tendrá conexión con tratados } \\
\text { distintos del Convenio de Berna ni perjudicará ningún derecho u } \\
\text { obligación en virtud de cualquier otro tratado. }\end{array}$ \\
\hline $\begin{array}{l}\text { Decreto Promulgatorio } \\
\text { del Tratado de la } \\
\text { OMPI sobre derechos } \\
\text { de autor relativo a } \\
\text { las publicaciones en } \\
\text { Internet }\end{array}$ & $\begin{array}{l}\text { Instituye las pautas internacionales con la finalidad de impedir } \\
\text { el acceso no autorizado y la utilización indebida de las obras } \\
\text { disponibles en la red. Las facultades, estructura y disposiciones } \\
\text { del decreto, se enmarcan en que los autores dispondrán del } \\
\text { amparo jurídico en cada uno de los estados contratantes, en } \\
\text { contra de la distribución, alquiler comercial y comunicación al } \\
\text { público de sus obras en los entornos digitales. }\end{array}$ \\
\hline
\end{tabular}

La OMPI también otorga asistencia a los países para que puedan contar con un sólido sistema de propiedad intelectual. Este sistema proporciona las siguientes ventajas:

- Estimula el uso del talento inventivo y artístico

- Fomenta y preserva los recursos locales en materia de propiedad intelectual, como los conocimientos tradicionales y el folklore

- Es un incentivo para las inversiones al crear un marco estable en el que los inversionistas nacionales y extranjeros tienen la seguridad de que se respetarán sus derechos de propiedad intelectual. 


\section{Bienes públicos y bienes privados}

Los conceptos de bien público y bien privado se utilizan en el contexto de la economía y las finanzas públicas. Se define como bien privado aquel Bien que no puede ser consumido por más de una persona a la vez; cuando es consumido por una persona, todas las demás quedan excluidas de su consumo. Estos bienes son susceptibles de apropiación privada y tienen un precio en el mercado.

Un bien público es un bien que, incluso si se consume por una persona, sigue disponible para el consumo de otras personas.

Esta distinción se relaciona con el concepto de mercado, ya que la propia existencia de un mercado implica que el consumo de un bien sea excluyente, (además de otras características como el propio concepto de escasez, entendido en sentido amplio: no es posible un mercado para un bien infinito).

Generalmente es el mercado el que debe asignar los recursos para producir estos bienes privados, a la vez que se ha de encargar de su valoración y distribución. El mercado surge por tanto de la conjunción de personas interesadas en producir estos bienes, así como en personas interesadas en demandarlos, de tal forma que de ambos parámetros unidos obtenemos el precio y la cantidad producida de estos bienes, la forma de producirlos y en general, la distribución eficiente de los recursos de los que dispone la sociedad para conseguir la mayor satisfacción colectiva. 
Derecho a la información, bien público y bien privado:...

En el contexto de la información, el valor de esta es una de las ideas más difíciles de conceptualizar. Los investigadores han analizado este concepto con una gran variedad de vertientes, cada una complementa a la otra, así como aumenta la complejidad del concepto. La información puede ser una mercancía, un producto, un servicio o una experiencia. Además, su valor aumenta según el tipo, formato y calidad. El valor a veces es asignado en la forma que la información es empaquetada y distribuida; en otra vertiente el valor es inherente a su contenido a pesar de la forma en que es transmitida. También el valor de la información puede estar derivado del intercambio o su uso y pueden ser evaluado de forma normativa, realista o subjetiva.

Así la información es cara de producir, pero no de reproducir ya que se realizan fotocopias de los materiales; la información puede ser un bien público, privado, o un bien híbrido, dependiendo la perspectiva o del tipo de bien (público, privado o híbrido); el valor de la información puede aumentar o disminuir en función de su disponibilidad. La información es un bien unido a la experiencia. Su valor puede revelarse sólo después de su uso. El valor de la información es, en gran medida, subjetivo. La información se transmite principalmente por medio de la copia analógica y ahora digital. Por lo tanto, los derechos de propiedad intelectual, en muchas de las ocasiones, plantean un problema. 


\section{La naturaleza territorial del sistema de propiedad intelectual}

La propiedad intelectual deviene "territorial" porque el alcance es en su aplicación esencialmente geográfico, habiéndose definido por las restricciones o límites nacionales. Cada país determina para su propio territorio, e independientemente de cualquier otro país, lo que será protegido como propiedad intelectual y por cuánto tiempo, es decir, la existencia y duración de los beneficios de la protección. Por consiguiente, el hecho de que una persona pueda tener un derecho de propiedad intelectual válido y ejecutable en un país, no significa que pueda hacerlo valer necesariamente en otro. La naturaleza territorial de la propiedad intelectual podría ser explicada por su uso como instrumento de política económica y cultural de los gobiernos, pero sólo parcialmente. Es decir, de acuerdo con lo que sistematizó Savigny y que luego fue reconocido como el "orden público internacional”, como una limitación excepcional a la aplicación extraterritorial del derecho.

La propiedad intelectual se caracteriza por conceder derechos exclusivos, a través de monopolios establecidos para estimular a los creadores a obtener recompensa económica (concediendo licencias de explotación) al mismo tiempo de salvaguardar la integridad de sus trabajos originales e innovadores, así como su reputación. También de garantizar a los usuarios legítimos de material protegido a invertir en las innovaciones o creaciones, así como lanzarlas al mercado en 
Derecho a la información, bien público y bien privado:...

forma segura, ofreciéndoles una protección compensatoria por sus inversión y riesgo, y al público consumidor un acceso razonable a dichas creaciones, contenidos y productos.

Un régimen del Derecho Internacional Privado (DIPr) multilateral para la propiedad intelectual presupone que la mayoría de las legislaciones, han alcanzado cierto nivel de madurez en la materia, fenómeno iniciado en la posguerra y manifestado vigorosamente en los años setenta en el proceso de negociaciones comerciales multilaterales de las rondas del GATT (Acuerdo General sobre Aranceles Aduaneros y Comercio) y concluido en 1994, en el Acuerdo sobre los Aspectos de los Derechos de Propiedad Intelectual relacionados con el Comercio (Acuerdo sobre los ADPIC o, en inglés, TRIPS).

Cabe considerar, entonces, que el término "territorialidad" se utiliza con frecuencia en el campo de la propiedad intelectual para expresar la tendencia a elaborar el principio de que el tribunal que entiende en la causa no podrá aplicar otra legislación que no sea la suya, exacerbando expresiones "estatutarias" del derecho, originadas en la Edad Media como consecuencia del desmembramiento del Imperio Romano y denominadas "de la territorialidad", opuestas a los sistemas fundados en la personalidad.

El Acuerdo sobre los ADPIC dispone que el objetivo del trato nacional es la "protección" de la propiedad intelectual, y aclara en una nota que el término "protección" comprenderá los aspectos relativos a la existen- 
cia, adquisición, alcance, mantenimiento y observancia de los derechos de propiedad intelectual, así como los aspectos relativos al ejercicio de los derechos ..."

La existencia conjunta o separada del principio de territorialidad del derecho de autor y la naturaleza mundial de las redes digitales, plantea una ambigüedad, de carácter terminológico, pudiendo interpretarse la territorialidad como una simple vinculación de la que deriva la elección de la legislación aplicable (el lugar de publicación, el lugar de violación del derecho).

En este sentido, se plantean dificultades puesto que algunos consideran que por la universalidad de las redes digitales esos tipos de vinculación podrían pasan a ser artificiales, pero definitivamente compatibles con el conflicto de legislaciones.

La territorialidad de los derechos de propiedad intelectual, tienen un origen histórico como se ha señalado, tanto en el derecho de autor (privilegios de imprenta) y más aún en el Derecho de Patentes donde el orden público y las normas de jurídicas adquieren una relevancia mayor, pero siempre fundado en el derecho positivo.

\section{Consideraciones finales}

La globalización de la información, y por consiguiente la propiedad intelectual han traído cambios sustanciales en cómo se ha generalizado el acceso y uso de la información. Teniendo como consecuencia que a la información y a la propiedad intelectual se les vea 
Derecho a la información, bien público y bien privado:...

como un bien público y un bien privado, consecuencia de la competitividad globalizada y la liberación de diversos servicios de las tecnologías de información y comunicación.

La información se convierte en un bien privado, cuando tienen un valor agregado y se cobra la recuperación, ubicación e impresión del documento en cuestión, es un bien público, cuando se pone a disposición de los usuarios sin remuneración económica alguna y se hace visible sin ninguna restricción. En consecuencia la propiedad intelectual también se convierte en un público y privado, bajo el contexto antes expuesto.

Por ello, es importante especificar en la red, el uso de los textos completos, ya que puede darse el caso del uso libre y abierto sin restricciones (derecho público), un uso normalizado de los documentos y el pago de los derechos por la obtención de la obra (derecho privado), asimismo, habría que diferenciar el uso de estos documentos en las bibliotecas, referente a la reproducción parcial o total de la obra y la obligación de los usuarios de citar y dar los créditos respectivos de los documentos que analizan y consultan. También habría que definir los usos individuales y personales, entendiéndose éstos como el uso comercial de la obra y la reproducción con fines de lucro. 


\section{Bibliografía}

$<$ http://www.google.com.mx/search?q=HIST

ORIA+repositorios\&hl=es\&client=firefox-

a\&channel=s\&rls=org.mozilla:es-ES:official\&hs=

LBS\&sa=N\&tbs=tl:1\&tbo=u\&ei=QAJOS7-yAYjGlA-

fU-eSNDQ\&oi=timeline_result\&ct=title\&resnum

$=11 \&$ ved $=0 \mathrm{CCgQ} 5 \mathrm{wIwCg}>$

BARRIOS GARRIDO, Gabriela Et. Al. Internet y derecho en México. México: McGraw-Hill, 1998. 180 p.

BATTISTI, Michele. The future of copyright management. European perspective. En IFLA Journal 27(2):82-90, 2001.

BAUM, Erica. Argentina: derechos de autor en internet: un dilema no resuelto. En Revista Electrónica de Derecho Informático No. 27, Octubre de 2000 6p. < http://www.alfa-redi.org/revista/data/28-5. asp $>$ [ consultada: 10/10/02 ]

BERMÚDEZ, Guillermo. Biblioteca y derechos de autor en el nuevo mundo digital. En Revista Mexicana del Derecho de Autor. (7): 20-24. ene-mzo, 2003.

BIBLIOTECA DEL CONGRESO DE LOS ESTADOS UNIDOS. Introducción a los derechos de propiedad intelectual < http://www.lcweb.loc.gov/copyright/fls $>$ [ consultada: 13/06/02 ] 
Derecho a la información, bien público y bien privado:...

DICCIONARIO DE LA LENGUA ESPAÑOLA. Madrid: Espasa Calpe, 19922 Vols.

The Directory of Open access Repositories - Open-

DOAR < http://www.opendoar.org/ >

DSPACE http://www.dspace.org

FLORES, CUESTA, Gilda y Nancy Sánchez Tarrago. Los repositorios institucionales: análisis de la situación internacional y principios generales para cuba En Acimed Ciencias de la Información 16(6): $2<$ http://bvs.sld.cu/revistas/aci/vol16_6_07/ aci061207.htm > [Consultada: 04/05/09]

GÓMEZ DUEÑAS, Laureano F. Repositorios documentales y la iniciativa de archivos abiertos en Latinoamérica En did Textos universitarios de biblioteconomia i documentació 20, $2008<\mathrm{http}$ :// www.ub.es/bid/20gomez2.htm >

Hernández Pérez, Tony Et. Al. Open access: el papel de las bibliotecas en los repositorios institucionales de acceso abierto En Anales de Documentación 10, 2007. 200p.

MARKEY, Karen. Et. Al. Census of institucional repositories in the United Status: miracle Project research findings. Washington: Council on Library Information Resources, 2007. 181p. 
MENDEZ RODRÍGUEZ, Eva Ma. RDF: un modelo de metadatos flexible par alas bibliotecas digitales del próximo milenio En < http://www.bib.uc3m. es/ mendez/publicaciones/7jc99/rdf.htm $>$ [ Consultado: 31/10/01 ]

OEI. Declaración de Budapest: Declaración sobre la ciencia y el uso del saber científico < http://www. oei.es/salactsi/budapestdec.htm $>$ [Consultada :[ 06/01/10 ]

Open access and Institutional Repositories with EPrints $<$ http://www.eprints.org $>$

PINFIELD, S. Selfarchiving publications En International Yearbook of library and information management 2004-2005: scholarly publishing in an electronic era. London: Facet, 2004 20p. < http:// eprints.nottingham.ac.uk/142/1/IYLIM04.PDF > [ Consultada: 01/02/10 ]

RANKING WEB OF WORLD UNIVERSITIES < http:// repositories.webometrics.info/about_es.html >

Voutssás Márquez, Juan. Bibliotecas y publicaciones digitales. México: UNAM, CUIB, 2006. 338p. 



\title{
Información: un derecho y factor de desarrollo
}

\author{
José de Jesús Hernández Flores \\ Instituto de Investigaciones Estéticas \\ Universidad Nacional Autónoma de México \\ jjhf@servidor.unam.mx
}

El ser humano desea por naturaleza saber

Aristóteles

\section{Introducción}

G n México hemos celebrado recientemente los 200 $\triangle$ años de Independencia así como el centenario de la Revolución, por lo que vale la pena pensar y analizar algunos pendientes en materia de derecho y educación que se tienen con diversos sectores de la sociedad.

Jesús Silva Herzog (1892-1985) ya comentaba en su obra que el problema más grave del porfirismo se hallaba en la creciente miseria popular que se arrastraba desde 1870, donde el caos encontró eco debido a la carencia de leyes que promovieran la integración cultural e indígena al desarrollo nacional del momento. 
Derecho a la información, bien público y bien privado:...

México ha procurado atención especial por décadas a la educación básica, perdiendo de vista la importancia de brindar a la población una oportunidad de educación superior que le permita continuar con una formación profesional, han faltado apoyos e infraestructura que se encaminen a consolidar una ciencia y tecnología propias, que sean sustentables y que constituyan la base para un desarrollo continuo, así como garantizar un proceso de crecimiento y evolución acorde a los nuevos tiempos.

Tenemos universidades que deben ajustarse desafortunadamente a presupuestos raquíticos que las ha sumergido en una deficiencia, algunos se ha olvidado que en ellas se encuentra el progreso de los pueblos, parte de la preservación de la memoria cultural, solución a muchos de los problemas sociales, así como el avance de la civilización, todo ello se origina en las aulas, laboratorios y talleres que apoyan sus actividades académicas por medio de las bibliotecas como proveedoras de información, lo anterior es parte de la infraestructura en las universidades, tan necesaria en un mundo competitivo y globalizado, matizado por la modernidad, que se encuentra en constante evolución y movimiento.

\section{La información como un derecho}

Ya el filosofo francés Henri Bergson (1859-1941) decía; "Piensa como hombre de acción y actúa como hombre de pensamiento", el planteamiento sobre la acción y 
el pensamiento requiere de un firme derecho a la información, así como contar con los accesos necesarios que incidan y permitan avanzar o caminar hacia una autonomía de acción y pensamiento, con el fin de llegar a los objetivos propuestos en forma individual o colectiva.

En México, en la década de los años setenta, se presentó un gran interés por la investigación y el desarrollo, tanto como por la ciencia y la tecnología, el fenómeno se presentó en toda Latinoamérica; con ello surgieron centros de información como respuesta a la gran demanda de información en la región. Aun bajo las crisis recurrentes, en la sociedad y sus instituciones, en México se vivieron transformaciones económicas, científicas y tecnológicas, así como culturales, políticas y sociales.

En las últimas dos o tres décadas ha crecido el interés por a los derechos humanos, enmarcados por un pluralismo en aumento que demanda con urgencia una aceptación y mayor tolerancia en la sociedad, situación manejada en el ámbito académico por lo menos y que, en el discurso político también se exige.

En un Estado de Derecho, se debe garantizar el establecimiento de la libertad, podemos decir que representa la base para una verdadera democracia, además, implica una relación Estado-Sociedad en armonía, sana y sólida, en favor de una equidad para crear un ambiente que favorezca y fortalezca los derechos, contexto que requiere la autoridad con el fin de aplicar con liderazgo las normas, reglas y obligaciones en pro de una 
Derecho a la información, bien público y bien privado:...

sociedad más justa, que pueda ver que todo se encamina a consolidar libertades y los derechos ciudadanos.

Hemos vivido décadas y tiempos difíciles que han dejado pendientes, en materia de justicia, tenemos la falta de protección de la libertad personal, no se ha consolidado la libertad de expresión a través de los medios de comunicación, por lo que tenemos como prioridad garantizar el derecho de acceso a la información, entre otros.

Urge elevar la calidad en la educación, desde una visión democrática y que contribuya a limar prejuicios existentes por razones de edad, género, orientación sexual, grupo étnico, condición económica, pertenencia política o religiosa, que genere una conciencia para respetar los derechos de los diversos grupos que interactúan en nuestra sociedad, que por medio de la educación e información y no por la fuerza o imposición, se busquen soluciones a conflictos étnicos, así como hacer propuestas para frenar el incremento de la pobreza y disminuir la desigualdad social.

Consolidar el derecho a la información, permitirá sumarnos a compromisos globales que beneficien a todos, por ejemplo, un desarrollo sustentable con la protección del medio ambiente, regular el uso de los recursos naturales teniendo presente el resguardo de los ecosistemas, para ello los elementos indispensables serán los accesos a la información para su diseminación y así alcanzar objetivos, como resultado se tendrán estabilidad y paz social vital para el desarrollo nacional, una forma de lograrlo es que gobierno e instituciones tengan claros sus planes y programas. 
Algunas de las acciones requeridas son la transparencia en la toma de decisiones, por ejemplo, el fomentar una cultura de rendición de cuentas por la utilización de recursos públicos, así como notificar las acciones realizadas, de manera clara y oportuna.

Tenemos la necesidad de hacer y participar en una política dinámica, con sentido social, democrático e incluyente, basada en un marco de valores bajo el cual funcionen las instituciones. Otro factor importante será nuestra memoria histórica, así como la evolución que hemos vivido, con el firme propósito de evitar repetir nuevamente errores del pasado, medidas que coadyuven a mejorar el desempeño de las políticas públicas.

Un Estado de Derecho hace valer los derechos ciudadanos de acuerdo con ciertas normas para el buen funcionamiento de las mismas, fortaleciendo una cultura de obligaciones mutuas, obteniendo como resultado un activismo ciudadano y una consolidación institucional, todo encaminado a un desarrollo nacional en diversas áreas en que se interactúa; el marco que genere confianza en la población será la transparencia y propiciará el debate y el conocimiento de las ideas, o el planteamiento de necesidades en un ambiente de respeto para buscar soluciones con el consenso de la mayoría; consecuentemente se requiere de la ley que aplicada con criterios y juicios de equidad, veracidad y legalidad en las decisiones, lo que generara certeza y confianza. 
Derecho a la información, bien público y bien privado:...

Gobierno y sociedad se enfrentan al reto de aplicar acciones que nos encaminen a democratizar las instituciones, generen convencimiento con fundamento en un derecho de protección de la información y con garantía y aprecio por la libertad de expresión, desde una participación activa en asuntos de interés público con base a políticas establecidas. Abonando a la democracia la existencia de mayor respeto y libertad para ejercer nuestros derechos ciudadanos, factores primordiales para la realización plena de las personas.

Contamos con derechos y deberes en común, vínculos de vital importancia en la construcción de una nación sólida que basa su régimen jurídico en ellos, todo dentro de un marco legal y político, en donde el factor primordial es la información y se constituye en ser determinante para la interacción social, académica, política e industrial, independientemente de su presentación encuentra un vehículo ad boc en las bibliotecas, que se constituyen en garantes del derecho de acceso a la información. La disponibilidad de la información deben adecuarse en función a las demandas y necesidades de la sociedad, con la finalidad de facilitar su acceso o uso, ya sea para recibir o difundir lo que se produce y es de interés para la población.

Se debe garantizar, el manejo de información para uso personal o en proyectos colectivos, tanto en ámbitos de investigación científica, social o solo para fundamentar su participación o ejercer sus derechos ciudadanos, o si los usuarios desean informarse para deliberar sobre asuntos públicos, analizando la gestión 
y la toma de decisiones que le atañen, que se podría considerar como parte del debate público y participación ciudadana, así como la retroalimentación necesaria en la sociedad.

Las personas e instituciones tienen derecho a la información, al libre acceso, a consultar fuentes de información requeridas; en general se debe gozar de los beneficios de la información, un medio para asegurar la preservación cultural y una integración social. Vale la pena mencionar que existe la posibilidad de que se tiene legalmente que proteger el derecho al secreto profesional (derechos de autor) o a la reserva de fuentes (patentes), sin ver mermar nuestro derecho de acceso.

El acceso público a la información debe ser garantizado con diversidad de servicios, variedad de fuentes, contar con los medios tecnológicos necesarios para poder consultar y dar acceso, tener personal profesional, especializado para atender al usuario que desee acceder a la información ya sea para verificar, validar o fundamentar su opinión en las diversas áreas del conocimiento o simplemente estar actualizados sobre algún tema de su interés, sin importar su soporte.

El 28 de septiembre de 2003 se celebró, por primera ocasión, el "Día Internacional del Derecho a Saber", sobre el cual podemos decir que tiene estrecha relación con el derecho a buscar, recibir y difundir libremente información, empero en América Latina y el Caribe, por lo general no se respeta; la razón es la carencia de un marco legal que norme su aplicación, pues 
Derecho a la información, bien público y bien privado:...

en ocasiones el acceso depende de la discrecionalidad de los funcionarios públicos, quienes ocultan u obstaculizan el uso de la información a los ciudadanos, con pretextos ingenuos como si se tratara de un "secreto de Estado".

\section{Su importancia como factor de desarrollo}

Instituciones públicas y educativas involucradas con la investigación "en particular" tienen ante sí un escenario complejo ante las exigencias actuales por desarrollar ciencia y tecnología en universidades, a ello se suma la creciente composición multicultural de la sociedad, lo que se conjuga con el desarrollo global que presenta requerimientos de información cada vez más oportunos, veraces y de avanzada en diversas áreas de acuerdo al desarrollo regional; factores que obligan a tener presentes las responsabilidades académicas, profesionales y sociales de las instituciones.

Esto se debe a que, en muchas ocasiones, las alternativas que se buscan para solucionar algún problema en la sociedad, germinan en el sector educativo, la exploración se inicia en centros de innovación científica y tecnológica e incluso social o humanística.

Resulta necesaria la participación de la academia para encontrar soluciones apoyándose con la información, existente y muchas veces diseminada en las bibliotecas de universidades pertenecientes a una misma región, hoy en día las comunidades de investigadores 
bien informados, contribuyen a la solución de problemas en cualquier nación.

Es indispensable dar un sentido humanístico al trabajo de investigación y a la información, cuidar que no se conviertan en mercancía de los grandes capitales e intereses; para ello tenemos el arte y la cultura, factores que sirven como catalizadores indispensables para el desarrollo de la ciencia y tecnología, dando ese valor agregado por añadidura.

Con la disponibilidad de la sociedad se revalorará el uso de la información, su connotación social, a nivel local, regional y nacional, intrínsecamente se puede consolidar desde el derecho a la información, claro sin olvidar el valor económico que puede llegar a tener. La información se ha convertido en un bien de consumo cotidiano para casi todos los individuos, sociedades e instituciones, insustituible para la investigación, vital en el desarrollo de Ciencia y Tecnología, es indispensable para la construcción o diseño del futuro de una nación.

Dependiendo de quién sea el productor de la información o el dueño de los derechos de autor será el alcance de su cotización económica, puesto que la generación de información implica costos desde su elaboración (investigación), producción (editores e instituciones), hasta su distribución (nuevas tecnologías y bibliotecas), incluso su soporte físico en su presentación.

Actualmente se busca facilitar el acceso, difusión y uso, independientemente de su versión, ya sea impresa 
Derecho a la información, bien público y bien privado:...

o electrónica, en ello el rol de la biblioteca y del bibliotecario profesional es determinante.

Con la celebración del Bicentenario se tiene un compromiso con la cultura, con las tradiciones, con el potencial creativo e intelectual existente en la nación, tenemos la urgencia de evitar que los niveles de bienestar o seguridad se deterioren de manera irreversible, podemos crear y fortalecer una plataforma para el desarrollo nacional ante las oportunidades que presenta la situación global que vivimos; cabe señalar que contamos con un potencial representado por nuestros recursos humanos, naturales y económicos, que tenemos, por ello naciones como México, Argentina o Brasil, ya han sido miembros del G-20.

El G-20 es un foro mundial para la cooperación y consulta en asuntos relacionados con el sistema financiero internacional, se encarga de estudiar, revisar y promover la discusión, abarca cuestiones de política relacionados con la promoción de la estabilidad financiera internacional. Los miembros del G-20 se reúnen dos veces al año, a partir de 2011, las cumbres serán anuales.

Pertenecer al G-20 considera ciertas características, como cuestión financiera, nivel de desarrollo y potencial comercial e industrial, mismos que deben ser sustentados en sistemas alternos, uno y muy importante es contar con un sistema de acceso y flujo de información, que ayude implícitamente a la toma de decisiones, así como al fortalecimiento y desarrollo en ciencia y tecnología, a las universidades, apoyando la investiga- 
ción, en la actualidad se tiene un particular interés en Latinoamérica.

Tenemos gran potencial en las nuevas generaciones, debemos asumir el compromiso de formarlos intelectual y profesionalmente e integrarlos al ámbito productivo, siempre con un sentido humanístico, son parte del relevo generacional y deberán convertirse en los protagonistas del escenario mundial en el futuro inmediato, aprovechando y aplicando su potencial humano que representan al desarrollo.

\section{Conclusiones}

La información es en la actualidad un derecho fundamental, palanca de desarrollo y detonante de la renovación en la práctica docente e investigación en las universidades. No solo se trata de garantizar sino de fomentar su uso, y con ello inducir a las nuevas generaciones a la investigación; las bibliotecas al estar insertadas en instituciones de educación superior deben apoyar a las nuevas generaciones para que apliquen todo su potencial intelectual para, explotar la capacidad innovadora,en beneficio de nuestras sociedades.

Avanzar no será fácil, nos enfrentarnos constantemente a obstáculos como crisis, fuga de cerebros, falta de recursos económicos, falta de infraestructura, carencia de apoyos o estímulos, el camino es estrecho y con serios problemas, uno de los frutos será la consolidación de una ciencia y una tecnología propias, contri- 
Derecho a la información, bien público y bien privado:...

buir con información a la investigación, útil para la comunidad latinoamericana e internacional, dejar de ser solamente consumidores u observadores, convertirnos en protagonistas, aprovechar las oportunidades de desarrollo, sin dejar de considerar el valor del patrimonio cultural que tenemos.

El camino puede aligerarse, coordinando esfuerzos y recursos por medio de los sistemas bibliotecarios, organizando la información existente, procesarla teniendo en cuenta estándares internacionales en normalización, cumpliendo los autores con los niveles de producción, organización y calidad, como un valor agregado.

Factores como la autoría intelectual, ya sea individual o institucional, así como a los patrocinadores de la investigación, son factores académicos que coadyuvarán a que la información regional sea de calidad y con seriedad se considere en los organismos nacionales e internacionales responsables de indizar la producción intelectual, con el objetivo de que un mayor número de usuarios la utilicen en Latinoamérica para su beneficio, sacando a la ves mayor provecho a la investigación.

Tenemos la urgencia en la región de resolver problemáticas afines, parte de ello requiere consolidar un sistema efectivo de acceso a la información, que permita el acceso y flujo del conocimiento generado; Latinoamérica tiene factores en común, idioma, nivel de desarrollo, aspectos geográficos, grupos étnicos existentes que interactúan en nuestras sociedades. 
El derecho de acceso a la información va ligado al compromiso de rendir cuentas por recibir recursos públicos, no solo en dar a conocer números, sino ver los nuevos horizontes y la(s) estrategia(s) de como avanzar.

El derecho de acceso a la información tiene el propósito de hacer una sociedad justa y democrática, ejercer libremente nuestros derechos con un principio de no discriminación, facilitando la información almacenada y producida, una forma será consolidar el derecho de acceder a la información a los registros en poder de las entidades públicas, con el fin de dar sustento, a un equilibrio entre derechos y obligaciones.

Finalmente con la información podemos hacer historias transnacionales en el desarrollo latinoamericano, considerar que cada vez somos menos por lo que hemos o vamos olvidando.

\section{Bibliografía}

Bergson, Henri (2007). La evolución creadora. Buenos Aires, Cactus.

Fox, Jonathan; Haight, Libby. (2007). Derecho a saber: balance y perspectivas cívicas. México, Fundar. Centro de Análisis e Investigación.

The Group of Twenty Finance Ministers and Central Bank Governors (G-20). en: http:// en.wikipedia.org/wiki/G-20_major_economies (consulta: 20-agosto-2008). 
Derecho a la información, bien público y bien privado:...

López Cuenca, Alberto (Coord.) (2008). Propiedad Intelectual: nuevas tecnologías y libre acceso a la cultura. México, Universidad de las Américas, Puebla.

Luna Pla, Issa. (2009). Movimiento Social del Derecho de acceso a la información en México. México: Instituto de Investigaciones Jurídicas. (Serie Doctrina Jurídica, Núm. 471).

Mestre Delgado, Juan Francisco. El Derecho de acceso a archivos y registros administrativos: análisis del artículo 105 b de la constitución. Madrid, Civitas, 1998. 247 p. (2da. Ed.)

Naciones Unidad: http://www.un.org/es/ (consulta: 4-junio-2010)

Pérez Pintor, Héctor. (2004) Derecho a la información, acceso a la documentación administrativa $y$ al patrimonio cultural: un estudio comparado México-España. Morelia, Universidad Michoacana de San Nicolás de Hidalgo, Secretaría de Difusión y Extensión Universitaria.

Silva Herzog, Jesús, 1892-1985 (1953). Nueve estudios mexicanos. México: Imprenta Universitaria. (Colección Cultura Mexicana - 8)

Salazar Ugalde, Pedro. (2008). El Derecho de acceso a la información mexicana: razones, significados y consecuencias. México: UNAM, Instituto de 
Investigaciones Jurídicas, Instituto Federal de Acceso a la Información Pública.

Villanueva, Ernesto (2006). Derecho de acceso a la información en el mundo. México: H. Cámara de Diputados, UNAM, Instituto de Investigaciones Jurídicas, Porrúa.

Villanueva, Ernesto. (2001) Derecho de acceso a la información : visiones desde México y la experiencia comparada. México: Universidad Iberoamericana.

Villanueva, Ernesto (Coord.) (2006). Hacia un nuevo derecho de la información. México: Universidad Iberoamericana.

Voutssás Márquez, Juan (2006) Bibliotecas y publicaciones digitales. México : UNAM, Centro Universitario de Investigaciones Bibliotecológicas.

Voutssás Márquez, Juan (2007). Un modelo de planeación de bibliotecas digitales para México. México: UNAM, Centro Universitario de Investigaciones Bibliotecológicas. 



\title{
El derecho a la información como eje fundamental en las sociedades democráticas
}

\author{
Rosa María Martínez Rider* \\ Escuela de Ciencias de la Información \\ Universidad Autónoma de San Luis Potosí \\ rrider@uaslp.mx
}

La fuerza de toda democracia depende

de las virtudes de sus ciudadanos

Gilberto Guevara Niebla

\section{Derecho a la información}

$\mathrm{L}$

a democracia es un régimen político que tiene la fiigualdad de los derechos y en el respeto a la diferencia, es decir, en la pluralidad y la inclusión.

A lo largo de la historia se presentan los excesos y abusos de poder, la intolerancia, la discriminación, la xenofobia, donde se han manifestado los problemas del multiculturalismo, que surgen a partir de la mayo-

* Coautores: Rosa María López Martínez; Perla Itzamná Navarro Sánchez; Rodolfo Tovar Humara. Universidad Autónoma de San Luis Potosí. 
Derecho a la información, bien público y bien privado:...

ría que domina y las minorías que se sujetan, o por las minorías que responden violentamente para defender sus creencias, hasta su vida, en tanto se da la relación nosotros, los otros y no una nosotros y ellos con nosotros. De ahí la importancia de la formación ciudadana para buscar la calidad de vida de las sociedades.

La democracia se replantea en términos multiculturales para que se den soluciones a lo que Sartori ha criticado como una mayoría que toma todo y una minoría que pierde todo, ${ }^{1}$ reafirmando ésta idea, este problema es tan antiguo, que hasta la Biblia indica en Levítico 19:33 Cuando el extranjero morare con vosotros en vuestra tierra, no le oprimiréis. Asimismo, el tiempo ha demostrado el argumento de Mouffé, en el sentido de que "El problema no son los ideales de la democracia sino el hecho de que sus principios politicos están muy lejos de ser implementados, incluso en aquellas sociedades donde se dice sostenerlos". ${ }^{2}$

Por lo tanto, las agendas democráticas presentan un sinnúmero de desafíos, entre los que destaca el Derecho a la Información, definido por Carpizo y Villanueva como "un conjunto de normas jurídicas que regulan y tutelan las libertades, garantías, facultades y delimitaciones que ... [lo] ... integran" ${ }^{3}$ y debe ser entendido como un "derecho subjetivo... de interés público y

1 G. Sartori, p. 16.

2 Ch. Mouffé, Debates políticos contemporáneos, pp. 113-114.

3 J. Carpizo y Villanueva, E., p. 4.

4 S. López Ayllón, p. 172. 
social", ${ }^{4}$ al que debe tener acceso toda la ciudadanía, las mayorías y las minorías, pues es un "bien común... que debe perseguir el Estado... [en el que]... se deben crear ciertas condiciones materiales y espirituales", para construir nuevas relaciones y alternativas sociales, acordes con las necesidades y transformaciones del ser humano, de acuerdo a sus circunstancias.

\section{Bibliotecas y archivos en el Derecho a la Información}

Respecto a la información, Morales ${ }^{6}$ puntualiza tres aspectos trascendentes en el rescate de los derechos democráticos:

1.Considerar que la información y el conocimiento provienen tanto de los medios masivos como de "la generada por el lenguaje literario, científico y técnico de la literatura especializada"

2.La necesidad de reconceptualizar todos y cada uno de los componentes que integran el ciclo de la información.

3.Ser conscientes de que el uso de la información está en función "de la calidad, variedad de servicios, disponibilidad del Internet y las colecciones electrónicas"

Las unidades de información, además de su función y compromiso desde el punto de vista social, son ins-

5 F. Meneses Tello, et. al., p. 3.

6 E. Morales Campos, pp. 65, 105, 190. 
Derecho a la información, bien público y bien privado:...

tituciones que tienen una responsabilidad ética a través de las colecciones y los fondos que almacenan, que proporcionan a los usuarios y que resguardan. Deben proteger ciertos valores transversales como el multiculturalismo y el cuidado del medio ambiente, porque la libertad de un ciudadano informado "implica... el derecho, pero también el compromiso... capaz de dar realmente sustancia y realidad al derecho supremo de la autodeterminación del individuo". Entonces, el conocimiento y la información adquirida deben orientar, guíar, modificar y cambiar la calidad de vida de los sujetos y su entorno, no solamente ser un referente de los acontecimientos políticos, económicos, sociales o culturales, ni un discurso teórico sobre nuestros derechos, como si se fuera ajeno a estos, sino que debe traducirse en un beneficio individual y colectivo para el desarrollo social holístico, proporcionando las herramientas informativas, para mejorar la salud, la alimentación, entre otros asuntos.

El libro, los documentos y otras formas de expresión verbal o escrita, impresa, audiovisual, electrónica, digital o virtual, han influido y lo siguen haciendo, en los modelos socioculturales, para reafirmar los grupos hegemónicos o para proponer relaciones de pluralismo, mayor equidad y justicia social en los grupos multiculturales. Lozada reflexiona sobre el ciberespacio como un espacio público democrático, y expresa que: "Las perspectivas democratizadoras de la red van más

7 J. A. García Becerra, p. 775. 
allá de la discusión referida a la división social entre los que tienen y no tienen Internet, de la accesibilidad de todos", ${ }^{8}$ pues hay que analizar a fondo las asimetrías y los efectos de la globalización. Es necesario un análisis conceptual e ideológico de las redes sociales que se crean, de sus objetivos y sus fines.

Las limitantes del acceso a la información se asocian con varios aspectos, por ejemplo, la censura, el saqueo y la destrucción del patrimonio cultural, dentro del cual destaca el documental. La censura en las bibliotecas, en los medios de comunicación y en la industria editorial, prohíbe respectivamente, leer textos, difundir información o publicar. Báez indica que "Es un error frecuente atribuir las destrucciones de libros a hombres ignorantes, inconscientes... Cuanto más culto es un pueblo o un hombre, más dispuesto está a eliminar libros bajo la presión de mitos apocalípticos. Sobran los ejemplos de filósofos, eruditos y escritores que reivindican la biblioclastia", ${ }^{9}$ por lo tanto, también está directamente relacionada con la intelectualidad, las ideologías, particularmente con las políticas y las religiosas. Actualmente se ha expandido a las tecnologías de información y comunicación, creando grandes polémicas y debates.

Con relación a los archivos, en estos se encuentra la verdad histórica de los acontecimientos, sucesos y problemas sociales, razón por la cual se guardan celosamente, se utilizan con cautela y se destruyen

8 M. Lozada, s. p.

9 F. Báez, s. p. 
Derecho a la información, bien público y bien privado:...

cuando comprometen. Se han caracterizado históricamente por el ocultamiento, la discreción, la salvedad o la restricción en su acceso y consulta, por ejemplo, Lafuente cita que "El 44\% de los científicos dedicados a la genética reconocen la práctica de la ocultación de datos para defender su carrera o sus negocios." ${ }^{\prime 10}$ Esto tiene su origen en la competitividad económica, asociada con la gestión del conocimiento, que se almacena en diferentes tipos de archivos, desde las notas personales de trabajo, hasta los proyectos institucionales.

El bibliotecario y el archivista son parte de los actores responsables de impulsar el cumplimiento de los derechos cívicos, políticos, sociales y culturales. Mazzina opina que "La indiferencia cívica supone el desinterés del ciudadano por los asuntos políticos y por la conducción del Estado". ${ }^{11}$ Entonces, las bibliotecas y los archivos "constituyen también la base de la imaginación de nuevas posibilidades de ciudadanía, así como los campos en que se construyen las identidades de la relación social". ${ }^{12}$ La biblioteca pública en un régimen democrático tiene las funciones de proteger los derechos humanos, en especial los culturales; coadyuvar a disminuir los contrastes sociales, brindando información en igualdad de condiciones a todo el usuario que lo solicite y buscar a los que la requieren, brindándoles la oportunidad de mejorar sus condiciones de vida. Los

10 A. Lafuente, s. p.

11 C. Mazzina, s. p.

12 R. Alisdair, p. 211. 
archivos deben facilitar a los ciudadanos toda la información para involucrarse en las soluciones políticas, económicas y sociales, propiciando gestiones públicas transparentes y honestas.

Para ejercer el Derecho a la Información y coadyuvar en el desarrollo de las competencias ciudadanas, es fundamental examinar las diferencias entre las bibliotecas y los archivos.

Cuadro 1. Las diferencias entre las bibliotecas y los archivos

\begin{tabular}{|l|l|}
\hline \multicolumn{2}{|c|}{ DIFERENCIAS } \\
\hline \multicolumn{1}{|c|}{ Bibliotecas } & \multicolumn{1}{c|}{ Archivos } \\
\hline $\begin{array}{l}\text { Se originan como apoyo a la educación, la } \\
\text { información y la recreación. }\end{array}$ & $\begin{array}{l}\text { Nacen de las funciones en las diversas } \\
\text { instituciones sociales. }\end{array}$ \\
\hline $\begin{array}{l}\text { Construyen colecciones en base a las } \\
\text { necesidades de información de los } \\
\text { usuarios. }\end{array}$ & $\begin{array}{l}\text { Construyen fondos con las series, } \\
\text { subseries y secciones que se van } \\
\text { formando a partir de las diversas } \\
\text { actividades que las producen. }\end{array}$ \\
\hline $\begin{array}{l}\text { La descripción documental se hace por } \\
\text { piezas. }\end{array}$ & $\begin{array}{l}\text { La descripción documental se realiza } \\
\text { por series. }\end{array}$ \\
\hline $\begin{array}{l}\text { El libro tiene valor histórico, estético o } \\
\text { cultural. }\end{array}$ & $\begin{array}{l}\text { El documento tiene valor administrativo, } \\
\text { legal o contable. }\end{array}$ \\
\hline El libro tiene tiraje de varios ejemplares & El documento es único e irremplazable \\
\hline $\begin{array}{l}\text { El libro se descarta cuando se vuelve } \\
\text { obsoleto, no se consulta o está } \\
\text { maltratado. }\end{array}$ & $\begin{array}{l}\text { El documento pasa por criterios } \\
\text { de valoración para determinar su } \\
\text { permanencia o eliminación del archivo. }\end{array}$ \\
\hline $\begin{array}{l}\text { El libro está protegido por el respeto a } \\
\text { las creencias del usuario y el derecho } \\
\text { de autor. }\end{array}$ & $\begin{array}{l}\text { El documento tiene acceso restringido } \\
\text { cuando es reservado o confidencial. }\end{array}$ \\
\hline $\begin{array}{l}\text { El libro se da directamente al usuario o él } \\
\text { lo toma de la estantería. }\end{array}$ & $\begin{array}{l}\text { Las solicitudes de información y las } \\
\text { respuestas se dan a través de las } \\
\text { unidades de enlace. }\end{array}$ \\
\hline
\end{tabular}


Derecho a la información, bien público y bien privado:...

\begin{tabular}{|c|c|c|}
\hline $\begin{array}{c}\text { Problemas: } \\
\qquad \\
\bullet\end{array}$ & $\begin{array}{l}\text { Interferencia del bibliotecario } \\
\text { en las preferencias del lector } \\
\text { No hay los libros solicitados } \\
\text { por el usuario }\end{array}$ & $\begin{array}{cl}\text { Problemas: } & \\
\text { • } & \text { Archivos desorganizados } \\
\text { - } & \text { Delimitación entre lo } \\
& \text { público y lo privado } \\
\text { - } & \text { Negar información pública }\end{array}$ \\
\hline
\end{tabular}

La formación ciudadana se inculca a través de la educación democrática para la vida, definida como la capacidad de "Desarrollar al máximo las capacidades, realizar proyectos y mejorar continuamente en lo individual, familiar, laboral e intelectual, se requiere convertir a la educación en un proceso... y que el hecho educativo se dé durante toda la vida."13 Se relaciona con los derechos, las obligaciones y la convivencia social, en la cual, las bibliotecas y los archivos son apoyo fundamental para la inclusión y el involucramiento de los sujetos sociales.

El bibliotecólogo y el archivólogo tienen una función en tal formación (Fig. 1), para

Fig. 1 papel social y político de los profesionales de la información

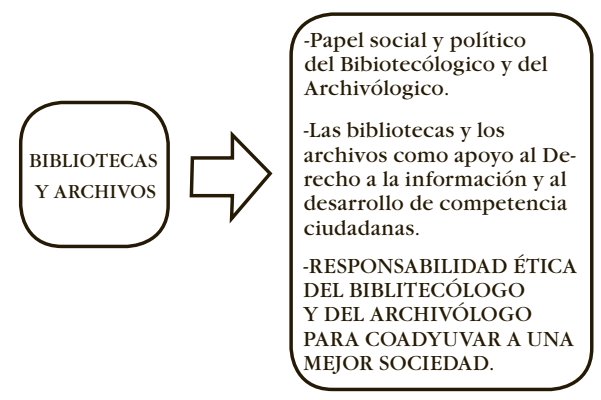

13 Guanajuato, Gobierno del Estado, s. p. 
contribuir a ejercer el derecho a la información de los ciudadanos, formando parte de los debates y propuestas políticas, que no están exentos de tensiones o desacuerdos, en aras de una mejor sociedad y de facilitar el desarrollo de competencias en sus espacios, que hoy se ven obstaculizados por "la privatización del espacio público ... la mercantilización y la militari-zación”. ${ }^{14}$

Los profesionales de la información requieren aplicar la siguiente tipología de competencias, además de las científicas, metodológicas, técnicas, éticas, axiológicas y comunicativas:

1.Ideológicas: con el objeto de identificar los proyectos de desarrollo para las bibliotecas o los archivos, desde diferentes ideologías políticas (por ejemplo, identificar las propuestas de los partidos políticos con relación a los sistemas públicos de información).

2.Sociales: con la finalidad de destacar el valor de la ciudadanía y analizar el flujo de la información en diversos sectores desprotegidos de la sociedad.

3.Culturales: con el propósito de fomentar el conocimiento, el respeto y la atención del multiculturalismo, el pluralismo cultural y la diversidad cultural.

4.Jurídicas: para interpretar la legislación en materia de información y documentación (por ejemplo, vigilar el cumplimiento de las leyes, reglamentos y normas de acceso o utilización).

14 R. Alisdair, Op. Cit., pp. 211-213. 
Derecho a la información, bien público y bien privado:...

Asimismo, en el Derecho a la Información, el bibliotecólogo y el archivólogo deben desplegar las siguientes pericias en los usuarios y los ciudadanos, poniendo en práctica tal derecho (Cuadro 2)

Cuadro 2. Competencias para la formación del ciudadano

\begin{tabular}{|l|l|}
\hline \multicolumn{1}{|c|}{ Competencia } & \multicolumn{1}{c|}{ Descripción } \\
\hline Identificar & $\begin{array}{l}\text { La información que requiere en función de su } \\
\text { objetivo personal o colectivo. }\end{array}$ \\
\hline Valorar & $\begin{array}{l}\text { La información como elemento fundamental del } \\
\text { desarrollo en la democracia, la pertenencia, la } \\
\text { solidaridad, los derechos humanos y la justicia } \\
\text { social. }\end{array}$ \\
\hline Consultar & $\begin{array}{l}\text { Datos, información, libros y documentos que } \\
\text { resuelvan su necesidad de información. }\end{array}$ \\
\hline Utilizar & $\begin{array}{l}\text { La información con honestidad, legalidad, } \\
\text { solidaridad, dialogo, participación, crítica y } \\
\text { apertura. }\end{array}$ \\
\hline Argumentar & $\begin{array}{l}\text { El uso de la información en la toma de } \\
\text { decisiones y en la resolución de problemas. }\end{array}$ \\
\hline Mejorar & Las habilidades informativas y digitales. \\
\hline Exigir & $\begin{array}{l}\text { Simetría social en todas sus dimensiones, } \\
\text { transparencia y rendición de cuentas. }\end{array}$ \\
\hline
\end{tabular}

El ciudadano informado debe visualizar nuevos escenarios mediante un trabajo previo del bibliotecólogo y el archivólogo, que contemple un sistema de información interdisciplinar, profesionales preocupados y 
comprometidos para abatir problemas como el analfabetismo o el grado de valor de un documento en sociedades desiguales.

\section{Conclusiones}

1.El profesional de la información se enfrenta a nuevos retos y desafíos para hacer de las bibliotecas y los archivos, centros de aprendizaje y de formación ciudadana, ante los problemas sociales que se agudizan en el siglo XXI.

2.El ciudadano debe ser actor dinámico en las transformaciones sociales y no contentarse con ser un agente de desarrollo económico, sino un ser humano con calidad de vida, ejerciendo su derecho a la información para coadyuvar en el cumplimiento de sus diversos intereses personales, laborales y sociales.

3.Este derecho implica la búsqueda de fuentes de financiamiento, recursos suficientes, una legislación que oriente las acciones y la toma de decisiones, que posicione a las unidades de información como una verdadera y real fuente de desarrollo social. 


\section{Bibliografía}

ACOSTA, Y. (1997) "Globalización e identidad latinoamericana" Cuadernos Americanos. no. 63

AÍNSA, F. (2004) "Un desafío impostergable: utopizar la democracia" Cuadernos Americanos. no. 103

ALISDAIR, R. (2001) "Los espacios del multiculturalismo y de la ciudadanía” Papeles de población no. 28

BÁEZ F. "Enfoques" http://www.lanacion.com.ar/nota.asp?nota_id=694690 (consultado el 18 de agosto de 2009)

CARPIZO MC GREGOR, J. y VILLANUEVA, E. "El derecho a la información en México" http://www. fidac.org.mx (Consultado el 20 de julio de 2010)

DEBATES POLÍTICOS contemporáneos. (1998) Buenfil, R. N. (coord.)México: Plaza y Valdez

DESANTES GUANTER, J. M. (1974) La información como derecho. Madrid: Nacional

GARCÍA BECERRA, J. A. El derecho a la información en México http://www.bibliojuridica.org/ libros/1/340/37.pdf (Consultado el 30 de julio de 2010) 
El derecho a la información como eje fundamental...

GUADARRAMA GONZÁlEZ，P. (2004) "El pensamiento de la integración latinoamericana ante la globalización" Cuadernos Americanos no. 103 México: UNAM

GUANAJUATO. GOBIERNO DEL ESTADO. "Una educación durante y para toda la vida." http://www. guanajuato.gob.mx/gestiones/romerohicks/ primero/unaeducacionparatodalavida/unaeducacionparatodalavida.htm (consultado el 23 de agosto de 2010)

LAFUENTE, A. "Secretismo en la ciencia" http:// www.madrimasd.org/blogs/tecnocidanos/2006/02/06/12969 (consultado el 5 de agosto de 2010).

LOZADA, M. (2001) "Política en red y democracia virtual: la cuestión de lo público" Estudios latinoamericanos sobre cultura y transformaciones sociales en tiempo de globalización 2. Daniel Mato (comp.), CLACSO.

MAZZINA, C. "La importancia de la formación ciudadana" http://www.iigov.org (Consultado el 26 de agosto de 2010)

MARTÍNEZ, M y ESTEBAN, F. (2005) Una propuesta de formación ciudadana para el EEES en Revista Española de Pedagogía, no. 230 
Derecho a la información, bien público y bien privado:...

MENESES TELLO, F. et. al. "Los servicios públicos bibliotecarios como bien público" 1er. Foro Social de Información, Documentación y Bibliotecas. Buenos Aires, 26-28 de agosto de 2004 http:// www.inforosocial.net/ponencias/eje01/36.pdf (Consultado el 2 de julio de 2010).

MORALES CAMPOS, E. (2003) Infodiversidad, globalización y derecho a la información. Buenos Aires: Sociedad de Investigaciones Bibliotecológicas

MORALES CAMPOS, E. (2001) La diversidad informativa latinoamericana en México. México: UNAM

SARTORI, G. (2003) ¿Qué es la democracia? México: Taurus

VILLANUEVA, E. (2003) Derecho de acceso a la información pública en Latinoamérica: estudio introductorio. México: UNAM

VILLANUEVA, E. y LUNA PLÁ, I., comps. (2004) Derecho mexicano de la información: derecho de acceso a la información pública, valoraciones iniciales. México: UNAM. 


\title{
La alfabetización informacional en la sociedad de los saberes compartidos
}

\author{
Alice Miranda Arguedas \\ Proyecto GUCAL \\ Universidad de Costa Rica-Universidad de Kassel \\ mirandaarguedas.alice@gmail.com
}

... el mundo está sujeto al conflicto de las interpretaciones; pero esta característica se convierte en la apertura de un borizonte de posibilidades para significar, resignificar y trasformar ese mundo.

Jacqueline García Fallas

\begin{abstract}
G n la actualidad, al término conocimiento se le ha dotado de una acepción particular. Desde la perspectiva tecnológica se le vincula con información y como una racionalidad técnica a la crítica del conocimiento. A la Era Digital se le asocia con la producción y distribución de enormes masas de información y conocimiento.

Las posibilidades de tratamiento de la información almacenada en gigantescas bases de datos, por medio de las nuevas tecnologías, constituye en sí un poderoso sistema de progreso del saber, tanto en las ciencias de la naturaleza y humanas como en las de la gestión y las ciencias sociales (David y Foray, 2003). Para estos autores
\end{abstract}


Derecho a la información, bien público y bien privado:...

El conocimiento debe distinguirse de la información. Poseer conocimientos, sea en la esfera que sea, es ser capaz de realizar actividades intelectuales o manuales. El conocimiento es por tanto fundamentalmente una capacidad cognoscitiva. La información, en cambio, es un conjunto de datos, estructurados y formateados pero inertes e inactivos hasta que no sean utilizados por los que tienen el conocimiento suficiente para interpretarlos y manipularlos.

Gigler (2004) agrega que la información no es sólo fuente de conocimiento, sino sobre todo, fuente de ampliación de libertades económicas, sociales, políticas, culturales. Son libertades singulares que pueden ser objeto de apertura, de ampliación del conocimiento del ser humano, de un mundo con memoria lúcida que no olvida la esclavitud, la pobreza, la agresión y, al hacer esa lectura histórica de manera objetiva, porque cuenta con la información para lograrlo, decodifica, interpreta y reconceptualiza sus falencias y sus aciertos. Por lo tanto, el conocimiento es fuente de desarrollo humano, social, cultural y también genera beneficios económicos. Alvin Toffler en su libro El cambio del poder (1990) se centra en defender que la información derivada en conocimiento es la espina dorsal del progreso.

Ahora bien, para que haya progreso todos deben disfrutar de él. Sin embargo, la sociedad está integrada por mundillos, algunos con exuberantes riquezas y derroches en exceso; otros frívolos, con ambiciones desmedidas y superfluos en sus necesidades; otros em- 
pobrecidos hasta la miseria, carentes de posibilidades de llenar la mínima necesidad; algunos inframundos que aterrorizan a cualquiera y ahí sobreviven. Lo extraño es cómo seres de la misma especie, con las mismas necesidades y posibilidades se han alejado tanto desde tiempos inmemoriales. Un grupo muy particular es el de los intelectuales, quienes se dedican a pensar y a planear un mundo con otras características, pero no logran impactar lo suficiente ni lo deseado, tal vez porque el conocimiento generado es poco divulgado.

Es evidente que no todas las personas ni todas las comunidades tienen igual acceso al saber y a las Tecnologías de Información y Comunicación (TIC). La brecha digital, producto del "verdadero progreso" que provocó la incursión de Internet en 1995, lo valora OCDE en relación con el acceso a las TIC, tomando como indicadores acceso a Internet y a las competencias para su uso. El modelo de desarrollo basado en la Sociedad de la Información se centró en la infraestructura, la accesibilidad y la usabilidad por todas las personas, en tres dimensiones: el comercio electrónico (e-economía o infonomía), el conocimiento (la biblioteca digital universal) y la gobernabilidad (e-administración) (Caridad y Marzal, 2006).

La Unesco (2003), en particular, ha adoptado el término "sociedad del conocimiento", o su variante, "sociedades del saber". Dentro de sus políticas institucionales ha promovido una reflexión en torno al tema, que busca incorporar una concepción más integral, no ligado solamente a la dimensión económica. Un matiz en 
Derecho a la información, bien público y bien privado:...

este debate, que solo concierne a los idiomas latinos, es la distinción entre "conocimiento" o "saber" (ambos en inglés se traducen como "knowledge"). La noción de "saberes" implica certitudes más precisas o prácticas, mientras que conocimiento abarca una comprensión más global o analítica. Por lo general, en este contexto se los utiliza indistintamente, si bien en español, al menos, conocimiento parece ser más usual.

Con el propósito de dar respuesta a los intereses de la Sociedad de la Información, Sociedad del Conocimiento o Sociedades del saber, las autoridades de gobierno crean espacios de diálogo, el más importante de ellos, la Cumbre Mundial de la Sociedad de la Información (CMSI)

La Cumbre Mundial de la Sociedad de la Información celebrada en Ginebra, en el 2003 y en Túnez, en el 2005, analiza, como documento base, la Declaración de Bolonia (19 jun.1999) resultado de la reunión mundial de los ministros de educación, la cual se ocupa de que la educación, el conocimiento, la información y la comunicación, esenciales para el progreso, la iniciativa y el bienestar de los seres humanos, sea de igual acceso y oportunidad para todos. Como primer paso se comprometieron a diagnosticar tres alfabetizaciones básicas: Alfabetización Informacional, Ciencias y Matemática.

En esas Cumbres Mundiales de la Sociedad de la Información, los gobernantes optan por mecanismos para evitar la ampliación de la brecha digital que se ha dado entre los países, los pueblos y las personas. 
La brecha digital se define como la separación que existe entre las personas (comunidades, estados, países...) que utilizan las TIC como una parte rutinaria de su vida diaria y aquellas que no tienen acceso a las mismas y que, aunque las tengan, no saben cómo utilizarlas (Serrano y Martínez, 2003). Los gobernantes han firmado acuerdos comprometiéndose a apoyar el desarrollo sostenible en la administración pública, los negocios, la educación y capacitación, la salud, el empleo, el medio ambiente, la agricultura y la ciencia, en el marco de las ciberestrategias nacionales (2004).

Las autoridades firmantes aseguraron que para el 2015, más de la mitad de los habitantes del planeta contarán con acceso a las TIC. Para avanzar en ello han establecido una serie de estrategias. Dos de ellas son: a. Creación de Centros Comunitarios de Inteligencia (CCI), con el propósito de que, en las comunidades más desprovistas de recursos, cuenten con laboratorios informáticos y con acceso a Internet, b. Creación o reorientación de sus políticas nacionales de desarrollo, para establecer entornos propicios y competitivos mediante el aseguramiento de la tenencia de infraestructura de TIC y para desarrollar nuevos servicios; así como prestar atención a las ciberestrategias que permitan acceso universal de conectividad a las TIC, en todas las instituciones públicas: escuelas, universidades, instituciones sanitarias, bibliotecas, oficinas de correos, centros comunitarios, museos, ... (CMSC, 2004).

Como plan de acción han ejecutado proyectos, tales como el Desarrollo y Selección de Competencias 
Derecho a la información, bien público y bien privado:...

(DESECO), bajo el liderazgo del Gobierno de Suiza; el Programa Tunning relacionado con la adquisición de competencias básicas y específicas, asignación de créditos acumulativos y transferibles a toda la educación formal e informal, definición de enfoques de aprendizaje didácticos y evaluativos y promoción de la calidad en la educación, promoviendo la autoevaluación y autorregulación.

Un breve perfil sobre la penetración de Internet en América Latina y el Caribe la ubica en la realidad ciberespacial mundial, según los datos actualizados al 30 de junio de 2010, por el World Internet Usage Population Statistics. La población mundial fue estimada en $6,845,609,960$ personas, de las cuales 1,966,514,816 son usuarios de Internet, lo cual significa que la penetración mundial de Internet fue establecida en $\mathbf{2 8 . 7 \%}$. Los internautas de América Latina y el Caribe son

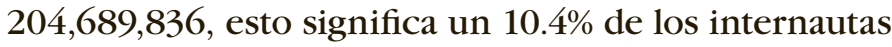
mundiales, con una penetración en la región, de 34.5\%

Según los resultados de The Global Information Technology Report 2009-2010, de los 133 países analizados a nivel mundial, los diez países que recibieron mejores evaluaciones en la región de América Latina y el Caribe son: Barbados (posición 35), Chile (40), Puerto Rico (45), Costa Rica (49), Uruguay (57), Panamá (58), Colombia (60), Brasil (61), Jamaica (66), República Dominicana (74).

En el cuadro siguiente se muestra la situación de América Latina y el Caribe en relación con la penetración de Internet. Se puede observar que ya 
tres países superan el $50 \%$ al que se comprometieron los gobernantes para el 2015. Argentina (64.4\%), Chile $(50.0 \%)$ y Uruguay (52.8\%). Los tres países con menor penetración son: Nicaragua (10\%), Bolivia (11.1\%) y Honduras (12\%).

\begin{tabular}{|c|c|c|c|c|c|}
\hline \multicolumn{6}{|c|}{ Penetración de Internet en América Latina } \\
\hline $\begin{array}{l}\text { PAÍSES / } \\
\text { REGIONES } \\
\text { AMÉRICA } \\
\text { LATINA }\end{array}$ & $\begin{array}{c}\text { Población } \\
\text { ( Est. 2010 ) }\end{array}$ & $\begin{array}{c}\text { Usuarios } \\
\text { de Internet, } \\
\text { últimos datos }\end{array}$ & $\begin{array}{l}\text { \% Población } \\
\text { ( Penetración ) }\end{array}$ & \begin{tabular}{|c|} 
User Growth \\
$(2000-$ \\
$2010)$
\end{tabular} & $\begin{array}{l}\% \text { Users } \\
\text { in Table }\end{array}$ \\
\hline Argentina & $41,343,201$ & $26,614,813$ & $64.4 \%$ & $964.6 \%$ & $13.3 \%$ \\
\hline Bolivia & $9,947,418$ & $1,102,500$ & $11.1 \%$ & $818.8 \%$ & $0.6 \%$ \\
\hline Brasil & $201,103,330$ & $75,943,600$ & $37.8 \%$ & $1,418.9 \%$ & $37.9 \%$ \\
\hline Chile & $16,746,491$ & $8,369,036$ & $50.0 \%$ & $376.2 \%$ & $4.2 \%$ \\
\hline Colombia & $44,205,293$ & $21,529,415$ & $48.7 \%$ & $2,352.1 \%$ & $10.8 \%$ \\
\hline Costa Rica & $4,516,220$ & $2,000,000$ & $44.3 \%$ & $700.0 \%$ & $1.0 \%$ \\
\hline Cuba & $11,477,459$ & $1,605,000$ & $14.0 \%$ & $2,575.0 \%$ & $0.8 \%$ \\
\hline $\begin{array}{l}\text { República } \\
\text { Dominicana }\end{array}$ & $9,823,821$ & $3,000,000$ & $30.5 \%$ & $5,354.5 \%$ & $1.5 \%$ \\
\hline Ecuador & $14,790,608$ & $2,359,710$ & $16.0 \%$ & $1,211.0 \%$ & $1.2 \%$ \\
\hline El Salvador & $6,052,064$ & 975,000 & $16.1 \%$ & $2,337.5 \%$ & $0.5 \%$ \\
\hline Guatemala & $13,550,440$ & $2,280,000$ & $16.8 \%$ & $3,407.7 \%$ & $1.1 \%$ \\
\hline Honduras & $7,989,415$ & 958,500 & $12.0 \%$ & $2,296.3 \%$ & $0.5 \%$ \\
\hline México & $112,468,855$ & $30,600,000$ & $27.2 \%$ & $1,028.2 \%$ & $15.3 \%$ \\
\hline Nicaragua & $5,995,928$ & 600,000 & $10.0 \%$ & $1,100.0 \%$ & $0.3 \%$ \\
\hline Panamá & $3,410,676$ & 959,900 & $28.1 \%$ & $2,033.1 \%$ & $0.5 \%$ \\
\hline Paraguay & $6,375,830$ & $1,000,000$ & $15.7 \%$ & $4,900.0 \%$ & $0.5 \%$ \\
\hline Perú & $29,907,003$ & $8,084,900$ & $27.0 \%$ & $223.4 \%$ & $4.0 \%$ \\
\hline Puerto Rico & $3,978,702$ & $1,000,000$ & $25.1 \%$ & $400.0 \%$ & $0.5 \%$ \\
\hline
\end{tabular}


Derecho a la información, bien público y bien privado:...

\begin{tabular}{|c|c|c|c|c|c|}
\hline Uruguay & $3,510,386$ & $1,855,000$ & $52.8 \%$ & $401.4 \%$ & $0.9 \%$ \\
\hline Venezuela & $27,223,228$ & $9,306,916$ & $34.2 \%$ & $879.7 \%$ & $4.7 \%$ \\
\hline DTAL & $574,416,368$ & $200,144,290$ & $34.8 \%$ & $1,024.9 \%$ & $100.0 \%$ \\
\hline \multicolumn{6}{|c|}{$\begin{array}{l}\text { NOTES: (1) Latin American Internet Usage and Population Statistics were updated for June } \\
\text { 30, 2010. (2) CLICK on each country name to see detailed data for individual countries } \\
\text { and regions. (3) Population numbers are based on data from the U.S. Census Bureau. (4) } \\
\text { The most recent usage comes mainly from data published by Nielsen-Online, ITU, and } \\
\text { trustworthy local sources. (5) Data on this site may be cited, giving the due credit and } \\
\text { establishing an active link back to Internet World Stats . (6) For definitions and help, see } \\
\text { the site surfing guide. Copyright @ } 0 \text { 2010, Miniwatts Marketing Group. All rights reserved. }\end{array}$} \\
\hline
\end{tabular}

Estos datos permiten comparar, cuantitativamente, las diferencias y similitudes entre los países latinoamericanos y del Caribe, con respecto al desarrollo tecnológico. Hay grandes diferencias en cuanto al acceso a Internet entre países muy cercanos geográficamente. Sin lugar a duda existe una amplia brecha digital. Y si se comparan las posibilidades de los ciudadanos de esos países, con los de los países del primer mundo, se encontraría con una brecha aún más amplia.

De igual forma, hay que prestar mucha atención a lo señalado por la Unesco (2005): "antes que los ordenadores y el acceso a Internet, la mayoría de las poblaciones del mundo necesitan de los libros, los manuales escolares y los maestros de los que carecen." O sea, la educación está antes que las TIC. Yo agregaría, no sólo de los maestros sino también de los bibliotecólogos que los alfabetizan informacionalmente, poniendo en sus manos la herramienta más valiosa: la Alfabetización Informacional, como competencia transversal para el lo- 
gro de la autonomía consciente, para que el ciudadano sea capaz de valorar la información que recibe, crear su propio criterio, tener independencia de juicio, sabiduría, sensatez. Esto, en parte, es lo que ha permitido alfabetizar a las personas; no obstante, el progreso de las personas y de los pueblos está estrechamente relacionado con el conocimiento que posean y, las TIC contribuyen a lograr el mayor acceso y velocidad a la transmisión de la información, compartir conocimiento por medio de las redes sociales, potenciar la creatividad y la innovación, pero con el acompañamiento de la educación.

McGarry (2003) señala que la alfabetización se entiende como la capacidad de leer, escribir entender la vida con un poder de apreciación crítica de aspectos implícitos en la cultura, normas éticas y del valor estético del texto.

La Alfabetización Informacional (ALFIN) apunta hacia un campo más profundo que descifrar signos y darles contenidos semánticos; amerita la articulación y complementariedad con el quehacer del individuo, para penetrar transversalmente en todos los actos del actuar ciudadano, quien debe ser capaz de reconocer cuándo necesita información y tener la babilidad para localizar, evaluar y utilizar efectivamente la información necesaria; pero, especialmente, tener la competencia para analizar, sintetizar y reflexionar sobre ella, para crear nuevo conocimiento y tomar decisiones inteligentes (OCDE, IFLA, ALA). Está estrechamente ligada con la información, la lectura y las TIC. 
Derecho a la información, bien público y bien privado:...

Las competencias en Alfabetización Informacional les permiten a los individuos saber cuándo y por qué necesitan información, dónde encontrarla, y cómo evaluarla, utilizarla y comunicarla de manera ética (CILIP).

En la Declaración de Praga (2003) Hacia una sociedad alfabetizada en información se dictan los principios de la Alfabetización Informacional y se señala qué se debe lograr de ella, en vez de conocimiento escolarizado. Establece siete pilares fundamentales para su logro: 1. Reconocer la necesidad de información; 2. Distinguir el modo por el cual la información puede ser accesada, 3. Construir estrategias para localizar la información, 4. Localizar y accesar la información; 5. Comparar y evaluar la información obtenida de diferentes fuentes de información; 6. Organizar, aplicar y comunicar la información a otros, de una manera apropiada a la circunstancia; 7. Sintetizar y cimentar, con la información existente, la contribución a la creación de nuevo conocimiento.

¿Qué implicaciones tiene no ser alfabetizado en información? ¿Cómo construyen identidades los ciudadanos del mundo real y los del mundo virtual o los de los dos mundos? ¿Con cuál tiempo o espacio se debe interpretar el mundo? ¿El del mundo físico o el del ciberespacio? ¿Se puede dialogar sobre pensamiento latinoamericano, sin incorporar la sociedad de los saberes compartidos?

Los grandes desafíos globales hacen necesarios, en los individuos, componentes cognitivos, operacionales y reflexivos, para convivir en grupos sociales pre- 
senciales o virtuales. La ALFIN permite al ser humano desarrollar esas competencias para resolver los problemas con información, de manera conveniente y las aplicaciones existentes de los dispositivos al servicio de la información y de los ciudadanos. Para Pimienta (2003), la:

"Sociedades de los saberes compartidos" está relacionado con pluralidad e indica que "Saber" es mejor que "conocimiento" porque está más anclado en el humano y en su subjetividad (ahí los saberes indígenas tendrían tanto peso como otros saberes).

Y "compartido" es lindo porque incluye "la comunicación” y la incluye, implícitamente, dentro de los conceptos de "solidaridad" y de "comunidades de aprendizaje" que nos importan sobremanera.

Hoy, las TIC, específicamente Internet, permiten la reflexión colectiva, compartida, con la creación de las redes sociales, con una visión de comunicación más flexible, brinda la oportunidad de lograr contacto con un mayor número de personas de una manera más ágil. Pero, la persona debe tener una posición consciente y crítica frente al tipo de información que consume y al grupo social con el que se asocie: analógico o virtual.

El progreso que ha facilitado Internet es sin precedentes y poco cuestionable. Supera cualquier otro medio o cualquier proyección imaginativa. Mientras la TV sólo ha tenido tres momentos importantes en casi siete décadas, Internet genera cambios dramáticos cada dos o tres años. Algunos de esos cambios se observan en 
Derecho a la información, bien público y bien privado:...

los avances de la Web 1.0, 2.0 y 3.0. La Web 1.0 era Internet en forma estática. La Web 2.0 es un cambio generacional. Es un espacio interactivo que permite a los usuarios crear y compartir su información. Ejemplos de mejoras son las redes sociales, los Wiki, los blogs. La Web 3.0 es una red semántica que permite perfilar los gustos de los internautas y dar respuestas más específicas de lo que se busca. Ejemplo, la geolocalización, que ya cuenta con tres millones de usuarios.

El dinamismo hiperactivo que provoca Internet se aprecia en los datos estadísticos que crecen día a día. La página de Google es vista 7.2 billones de veces al día y la visitan 620 millones de personas diariamente, algo monstruosamente extraordinario. El 95\% de los latinoamericanos con cuenta en Internet tienen, al menos, una cuenta en una red social; $52 \%$ son mujeres y $48 \%$ son hombres. 502000 costarricenses pertenecen a una red social; es decir, el $18.9 \%$ de la población total. Dedican 78 minutos diarios en tanto el promedio mundial es 52 minutos. El $17 \%$ lo accesa varias veces al día, 21\% al menos una vez al día, 30\% dos o tres veces por semana y el 16\% una vez a la semana. Ahí chatean, intercambian fotos y se relacionan con otras personas. Pero, ¿cuánto utilizan las redes sociales los mayores entusiastas de ellas, para aplicaciones educativas? Es muy prematuro aún para prejuiciar alcances o logros, hay que tomarse algún tiempo para estudiar su comportamiento, pero es importante invertir recursos en el uso de las redes sociales en la educación, para mejorar los países a través de ellas. 
Y si se presta atención a la celeridad, sin precedentes, del acceso y disponibilidad de información sobre la vida pública o privada, sobre lo cotidiano o lo científico, el asombro es aún mayor. Tan sólo digitar un nombre, una palabra, da respuestas que sorprenden al más erudito y al más visionario. Ante este panorama de desarrollo tan agresivo de información, pareciera que no es paralelo al crecimiento del conocimiento, entonces, ¿son suficientes las medidas que ofrece la Cumbre Mundial de la Sociedad de la Información? ¿Qué hacen las universidades al respecto? ¿Y las bibliotecas? ¿Y los bibliotecólogos?

Cómo se piensa, cómo se actúa, cómo se vive hoy, es una sinopsis de los saberes compartidos de la civilización que se refuerza aún más con el uso de las TIC. Ante esta realidad, los programas de formación de usuarios de las bibliotecas deben trascender la formación sobre el uso de los catálogos, los acervos, la elaboración de bibliografías, para enfatizar en programas de Alfabetización Informacional, aspectos relacionados con el uso ético de la información, capacitar para adoptar por una actitud consciente, crítica y analítica del uso de la información, así como a la interpretación de los nuevos formatos de reempaque de ella, tales como datos estadísticos, diagramas de flujo y mapas cartográficos, conceptuales y sinópticos ...

Es imperativo desarrollar programas de ALFIN, promover una América Latina y el Caribe digital, donde los conocimientos autóctonos o locales estén disponibles en Internet, para todos los ciudadanos y para el mundo entero. 
Se debe:

1.Promover sociedades analógicas y virtuales más integradas y participativas.

2.Favorecer a los marginados sociales con cursos sobre ALFIN para que formen parte de una sociedad más igualitaria.

3.Respetar la diversidad cultural, religiosa, social, política, de género, ...

4.Integrar en una sola sociedad pluralista, la información, el conocimiento, el saber para su uso ético y solidario.

\section{Bibliografía}

David, P. A. y Foray D. (2003), "Una Introducción a la Economía y a la Sociedad del Saber", Comercio Exterior, México.

Gigler, B. S. (2004) "Including the Excluded- Can ICTS empower poor communities? Towards an alternative evaluation framework based on the capability approach". Paper presented at the 4th International Conference on the Capability Approach, Sept. 2004, University of Pavia.

Pimienta, D. (2003) MISTICA: Sociedades de los saberes compartidos. Disponible en http://www.funredes.org/mistica/castellano/eme/produccion/ memoria8/0301.html Accesado 3 set. 2010. 
Serrano Santoyo, A. y Martínez, E. (2003). Brecha digital: mitos y realidades. México, Editorial Universitaria de la Universidad Autónoma de Baja California.

The Global Information Technology Report, 2009-2010

Torres, R. M. (11 jun. 2005) Sociedad de la información / Sociedad del conocimiento. isponible en http://www.ub.es/prometheus21/articulos/obsciberprome/socinfsoccon.pdf. Accesado 3 set. 2010.

UNESCO (2005). Hacia las sociedades del conocimiento. París: Ediciones UNESCO.

World Internet Usage Population Statistics (30 jun. 2010). Latin American Internet Usage and Population Statistics.

\begin{tabular}{|l|r|r|r|}
\hline \multicolumn{1}{|c|}{ Country } & $\begin{array}{c}\text { Total Users on } \\
\mathbf{3 / 1 / 2 0 1 0}\end{array}$ & $\begin{array}{c}\text { New Users in } \\
\text { February }\end{array}$ & $\begin{array}{c}\text { Monthly Growth } \\
\text { Rate }\end{array}$ \\
\hline Mexico & $8,545,020$ & 920,900 & $12.1 \%$ \\
\hline Argentina & $8,109,660$ & 379,940 & $4.9 \%$ \\
\hline Columbia & $8,140,200$ & 346,200 & $4.4 \%$ \\
\hline Brazil & $3,153,600$ & 283,680 & $9.9 \%$ \\
\hline Venezuala & $5,531,380$ & 249,780 & $47 \%$ \\
Peru & $1,761,420$ & 116,800 & $7,1 \%$ \\
Ecuador & 757,600 & 66,540 & $9.6 \%$ \\
Chile & $6,008,820$ & 45,860 & $0.8 \%$ \\
Costa Rica & 499,500 & 41,180 & $9 \%$ \\
\hline Uruquay & 685,700 & 40,800 & $6.3 \%$ \\
\hline
\end{tabular}

María del Mar en su ponencia "Posibles experiencias y tendencias de la Web 2.0" señala 
Derecho a la información, bien público y bien privado:...

\section{b) Sociedad del conocimiento}

La noción de "sociedad del conocimiento" (knowledge society) emergió hacia finales de los años 90; es empleada particularmente en medios académicos, como alternativa que ciertos prefieren a "sociedad de la información".

La Unesco, en particular, ha adoptado el término "sociedad del conocimiento", o su variante, "sociedades del saber", dentro de sus políticas institucionales. Ha desarrollado una reflexión en torno al tema, que busca incorporar una concepción más integral, no ligado solamente a la dimensión económica. Por ejemplo, Abdul Waheed Khan (subdirector general de la Unesco para la Comunicación y la Información), escribe (2003): "Information society is the building block for knowledge societies. Whereas I see the concept of 'information society' as linked to the idea of 'technological innovation', the concept of 'knowledge societies' includes a dimension of social, cultural, economical, political and institutional transformation, and a more pluralistic and developmental perspective. In my view, the concept of 'knowledge societies' is preferable to that of the 'information society' because it better captures the complexity and dynamism of the changes taking place. (...) the knowledge in question is important not only for economic growth but also for empowering and developing all sectors of society".

Un matiz en este debate, que solo concierne a los idiomas latinos, es la distinción entre "conocimiento" o "saber" (ambos en inglés se traducen como "knowled- 
ge"). La noción de "saberes" implica certezas más precisas o prácticas, mientras que conocimiento abarca una comprensión más global o analítica. Por lo general, en este contexto se los utiliza indistintamente, si bien en español, al menos, conocimiento parece ser más usual.

Página 2 de 9 Sociedad de la información / Sociedad del conocimiento 27/09/2005 http://www.vecam. org/edm/article.php3?id_article $=94$

\section{Bibliografía}

Pimienta, D. (2003) MISTICA: Sociedades de los saberes compartidos. Disponible en http://www. funredes.org/mistica/castellano/eme/produccion/memoria8/0301.html Accesado 3 set. 2010.

Torres, R. M. (11 jun. 2005) Sociedad de la información / Sociedad del conocimiento. Disponible en http://www.ub.es/prometheus21/articulos/obsciberprome/socinfsoccon.pdf. Accesado 3 set. 2010

Unesco (2005) Hacia las sociedades del conocimiento. Francia: Ediciones Unesco.

María del Mar en su ponencia "Posibles experiencias y tendencias de la Web 2.0" 



\title{
Apoyo bibliográfico que ofrecen las bibliotecas de la UNAM a sus estudiantes indígenas
}

\author{
Gabriela Olguín Martínez \\ Dirección General de Bibliotecas. \\ Universidad Nacional Autónoma de México \\ gabriela_olguin@dgb.unam.mx
}

$\mathrm{E}$ ste trabajo analiza el grado de apoyo que las bibliotecas de la UNAM proporcionan a sus estudiantes indígenas con lecturas en su lengua materna a fin de fortalecer su identidad y practicar la lectura de su lengua. Para ello nos hemos basado en un pequeño estudio que se llevó a cabo en el Seminario Información y Sociedad, impartido por la doctora Estela Morales Campos, dentro del Programa de Maestría en Bibliotecología y Estudios de la Información de la UNAM durante el primer semestre del año 2009.

La metodología empleada para la realización del estudio básicamente fue entrevistarnos con el doctor Carlos Zolla, docente del Programa Universitario México, Nación Multicultural (PUMC) de la UNAM, para conversar sobre sus experiencias personales con las comunidades indígenas, principalmente lo relacionado con los alumnos becarios de este Programa. Consultar 
Derecho a la información, bien público y bien privado:...

el sitio web del PUMC para analizar la información relacionada con los estudiantes indígenas. Detectar las lenguas maternas de los alumnos becarios del PUMC para ubicar los materiales bibliográficos en las bibliotecas seleccionadas. Leer 289 historias de vida de los becarios para conocer sus experiencias, necesidades e inquietudes personales.

La UNAM, dentro de las instituciones de educación superior en el país, tiene la gran responsabilidad de trabajar conjuntamente con el Gobierno Federal en los programas destinados para la población indígena. Motivo por el cual, el 2 de diciembre de 2004, siendo rector de la Universidad el doctor Juan Ramón de la Fuente, se creó el Programa Universitario México Nación Multicultural (PUMC), el cual cuenta con cinco áreas temáticas y operativas, dentro de las cuales está La docencia y la formación profesional en donde se integra el Sistema de Becas para Estudiantes Indígenas. Este sistema de becas apoya económicamente a estudiantes de pueblos indígenas originarios para su permanencia y culminación de estudios, fortaleciendo su identidad dentro de la sociedad mexicana. ${ }^{1}$ Es por ello que se tomó como muestra a los alumnos becarios del PUMC, dado que en la UNAM no se cuenta con un censo de estudiantes indígenas.

1 UNAM, Programa Universitario México, Nación Multicultiral. http://www.nacionmulticultural.unam.mx/Portal/Principal/ apaumc01.html [En linea][Consulta 13.03.2009]. 
Si bien, los estudiantes indígenas provienen de familias de culturas originarias, ellos ya son hispanohablantes, y recibieron su educación universitaria en español y sus soportes bibliográficos serán fundamentalmente escritos en esta lengua, sin embargo nos surgió una pregunta ¿qué tanto las bibliotecas a las que asisten estos jóvenes, los apoyan con lecturas en su lengua materna a fin de fortalecer su identidad y practicar la lectura de su lengua?

Con base en el número de alumnos inscritos en las diferentes escuelas de la UNAM se seleccionaron las bibliotecas de la Facultad de Derecho, la Facultad de Ingeniería, la Facultad de Estudios Superiores (FES) plantel Aragón, la Escuela Nacional de Enfermería y Obstetricia (ENEO) y la Biblioteca Central, para así determinar la cantidad y diversidad de materiales bibliográficos en lenguas indígenas que se ofrecen a la comunidad indígena de la UNAM.

Se incluye a la Biblioteca Central porque es una biblioteca que tiene un carácter universitario general. Es decir, está destinada a servir a la totalidad de la comunidad universitaria, como son alumnos, profesores, investigadores, personal administrativo, etcétera.

\section{Ubicación por plantel y autoadscripción étnica}

Hasta la convocatoria 2008, se reportaron 295 becarios, de los cuales 235 eran del nivel licenciatura, 25 del nivel posgrado y 35 correspondían al nivel bachi- 
Derecho a la información, bien público y bien privado:...

llerato. Al analizar la información de los alumnos por plantel nos percatamos que ellos eligen carreras que puedan ayudar a resolver los problemas que viven en sus comunidades, por ejemplo: en la Facultad de Derecho se encuentran inscritos 33 alumnos, en la Facultad de Ingeniería 29, en Enfermería y Obstetricia 19, en Arquitectura 13 y en Contaduría y Administración también $13 .^{2}$

La información antes mencionada concuerda con la que proporcionan los alumnos en sus historias de vida ${ }^{3}$ al manifestar por esta vía, los problemas económicos, sociales y políticos, así como el rezago educativo y discriminación que vivieron y que aún continúan afectando a sus comunidades, y para lo cual se están preparando académicamente; ya no solamente para mejorar su vida y la de su familia, sino para aportar con sus conocimientos al desarrollo de sus comunidades.

También se tuvo conocimiento, mediante sus historias de vida, que hay alumnos que desean preservar las costumbres de sus comunidades, como es el caso de aquellos que estudian música. Por ejemplo, la mayoría de ellos lo hacen por continuar la tradición familiar, ya que sus padres y abuelos también fueron músicos.

Igualmente, nos percatamos que la Facultad de Derecho y la Facultad de Ingeniería son las que tienen mayor población escolar indígena, con 33 y 29 alumnos respectivamente. ${ }^{4}$ En relación a la de Derecho, puede

2 op. cit.

3 op. cit

${ }^{4} \mathrm{Op}$. cit 
significar que estos alumnos deseen formarse académicamente para brindar ayuda en sus comunidades, ya sea a través del asesoramiento o defensa de los derechos más elementales como son: la salud, la educación, un empleo digno, entre otros. Referente a la de Ingeniería, nos indica que estos alumnos pretenden contribuir en la solución de problemas, como pueden ser los servicios y vías de comunicación; en tercer lugar tenemos a la FES Aragón, con 27 alumnos, de la cual no pudimos obtener información para conocer en qué carrera se encuentran inscritos los alumnos indígenas, ${ }^{5}$ sin embargo, especulamos que son las de mayor demanda como son derecho e ingeniería; en el cuarto sitio está la enfermería, con 19 alumnos, ${ }^{6}$ lo cual evidencia la carencia de este servicio en sus lugares de residencia, ya que en sus historias de vida expresan que algunos integrantes de sus comunidades, e incluso familiares, fallecieron debido a la falta de atención adecuada y oportuna; por último, están las de menor población, como son la Facultad de Odontología, con tres alumnos y la Escuela Nacional de Trabajo Social con un alumno ${ }^{7}$.

Cabe mencionar que tampoco pudimos obtener información para conocer en qué carrera se encuentran inscritos los alumnos indígenas de la FES Acatlán, la FES Cuautitlán, la FES Iztacala y la FES Zaragoza.

\footnotetext{
5 Op. cit.

6 Op. cit

7 op. cit
} 
La etnia nahua es la que mayor representación tiene en la UNAM, dado que cuenta con una población escolar de 60 alumnos, le siguen la mixteca con 56; la zapoteca con 50; la mixe y la otomí con 22; y en menor proporción, citamos la mazateca y la Triqui con 11 respectivamente. $^{8}$

\section{Apoyo bibliográfico}

Las bibliotecas de la UNAM conforman sus colecciones atendiendo, primordialmente, las necesidades de información requeridas en los planes de estudio, sin embargo algunas de ellas cuentan con materiales en lenguas indígenas.

A continuación se mencionarán los resultados de los materiales ubicados en las bibliotecas seleccionadas:

Escuela Nacional de Enfermería y Obstetricia (ENEO)

Las lenguas maternas de los estudiantes indígenas inscritos en la ENEO son nahua (2), otomí (1), mixteco (3), mazahua (3), maya (1), tzeltal (2), chinanteco (2), zapoteco (3) y mazateco (2). 9

En la biblioteca se localizaron 10 materiales, de los cuales ocho son libros (cinco en náhuatl, uno en mazateco, otro en tzeltal, más uno en mazahua) y los dos

8 Op. cit.

${ }^{9}$ Op. cit. 
restantes, son diccionarios en lengua náhuatl. En resumen, hay siete materiales en náhuatl, uno en mazateco, otro en mazahua y uno en tzeltal. Por consiguiente, los 19 alumnos adscritos a esta Escuela no tienen muchas opciones que los apoyen para practicar su lengua materna. A pesar de que en esta entidad se imparte una de las cuatro carreras de mayor demanda por los estudiantes indígenas.

Facultad de Estudios Superiores (FES), plantel Aragón

Las lenguas maternas de los estudiantes indígenas inscritos en esta Facultad son nahua (7), otomí (4), tepehua (1), totonaco (3), mixteco (5), zapoteco (2), triqui (3) y mazateco (2). ${ }^{10}$

En la biblioteca de esta entidad hay 41 materiales, de los cuales 35 son libros (20 en náhuatl, cuatro en mixteco, cuatro en zapoteco, uno en mazateco, otro en triqui, uno más en chinanteco, dos en tzotzil, uno en tzeltal y otro en ch'ol) y seis son diccionarios (uno en náhuatl, otro en purépecha, uno en tzotzil, otro en tzeltal y dos en maya). En resumen, observamos que de los 41 materiales disponibles, 21 están en náhuatl, cuatro en mixteco, otros cuatro en zapoteco, uno en mazateco, otro en triqui, uno en chinanteco, otro más en purépecha, tres en tzotzil, dos en tzeltal, otros dos en maya y uno en ch'ol.

${ }^{10}$ Op. cit. 
Derecho a la información, bien público y bien privado:...

Por lo tanto, los 27 alumnos inscritos, cuentan con mayor diversidad de materiales para practicar su lengua materna. Aunque observamos que esta biblioteca ha realizado un mayor esfuerzo, éste no ha sido suficiente para que todos sus alumnos indígenas tengan acceso a materiales en su lengua.

\section{Facultad de Derecho}

Las lenguas maternas de los estudiantes indígenas inscritos en esta Facultad son nahua (13), mazahua (1), mixe (2), mixteco (2), otomí (3), purépecha (1), teneek (1), tepehua (1), tlapaneco (1), totonaco (1), triqui (3), zapoteco (3) y zoque (1). ${ }^{11}$

En la biblioteca de esta facultad observamos que hay más materiales en lengua náhuatl, de los cuales 13 son libros y dos son diccionarios. Continuando con el desglose de la información, vemos que hay cinco libros, tanto en tzeltal como en maya, y en menor cantidad: dos libros en otomí, dos en chatino, uno en mixe, otro en mazahua y uno en tzotzil, así como dos diccionarios: uno en purépecha y otro en Popolaco. En total 34 materiales.

En la Facultad de Derecho se hallan 33 alumnos inscritos, quiénes no cuentan con diversidad de materiales bibliográficos en lenguas indígenas y lo poco que hay, es muy limitado.

11 op. cit. 
Considerando que en esta facultad se encuentra gran parte de la población de estudiantes indígenas, sería pertinente contar con mayor diversidad de materiales en lenguas indígenas.

\section{Facultad de Ingeniería}

Las lenguas maternas de los estudiantes indígenas inscritos en esta Facultad son amuzgo (1), ch'ol (1), mazateco (4), mixe (3), mixteco (4), nahua (2), otomí (3), popolaco (1), tepehua (1), tlapaneco (1), triqui (1), tzotzil (1) y zapoteco (6). ${ }^{12}$

Las carreras que se imparten en esta facultad son las de mayor demanda por los estudiantes de origen indígena, sin embargo, sólo hay cuatro materiales (dos libros en náhuatl y dos en maya).

En la Facultad de Ingeniería se encuentran inscritos 29 alumnos, por lo que sería conveniente que las bibliotecas de esta facultad se percataran de la existencia de estudiantes indígenas con la finalidad de apoyarlos con lecturas en su lengua.

\section{Biblioteca Central}

La Biblioteca Central atiende las necesidades de información de carácter general de su comunidad, por lo que posee mayor diversidad de materiales en lenguas indígenas.

${ }^{12} \mathrm{Op.cit}$. 
Derecho a la información, bien público y bien privado:...

Esta biblioteca cuenta con 187 materiales en lenguas indígenas, de los cuales 156 son libros (55 en náhuatl, dos en mixteco, cinco en zapoteco, cuatro en mixe, 13 en otomí, seis en mazateco, uno en triqui, cuatro en mazahua, siete en totonaca, cuatro en chinanteco, uno en tlapaneco, 11 en tzotzil, dos en tepehua, siete en tzeltal, 16 en maya, cuatro en zoque, tres en amuzgo, cinco en ch'ol y seis en huichol), así como 31 diccionarios (17 en náhuatl, uno en mixteco, otro en zapoteco, uno más en purépecha, dos en tzotzil, uno en tzeltal, siete en maya y uno en amuzgo). No obstante que esta biblioteca cuenta con una colección más completa, nos atreveríamos a especular que no todos los estudiantes indígenas dispondrían de materiales en su lengua materna.

Del mismo modo, observamos que esta biblioteca tiene 72 materiales en lengua náhuatl (39\%), lo cual es justificable si tomamos en cuenta que esta lengua se imparte en la UNAM por conducto de la Facultad de Filosofía y Letras, el Centro de Enseñanza de Lenguas Extranjeras y el Instituto de Investigaciones Filológicas.

\section{Producción editorial en lenguas indígenas}

Richard Uribe, subdirector de Libro y Desarrollo del Centro Regional para el Fomento del Libro en América Latina y el Caribe señala que "en términos generales, las editoriales comerciales en América Latina no han abordado la producción de títulos en lenguas indígenas por razones de mercado. La escasa producción edito- 
rial en lenguas indígenas está en el campo de políticas gubernamentales o en más aislados casos, obedeciendo a ediciones institucionales u organizaciones no gubernamentales". ${ }^{13}$ De lo cual se desprende varias situaciones, entre ellas:

- Las editoriales comerciales en América Latina no están interesadas en producir materiales en lenguas indígenas debido a las bajas tasas de alfabetización en lengua materna.

- Los ingresos de la población indígena son bajos.

- En muchas etnias la tradición oral es más importante que la escrita.

En entrevista el doctor Carlos Zolla comentó que la elaboración de materiales en lenguas indígenas exige cierto grado de especialización, lo que resulta complejo y costoso.

En el campo de las políticas gubernamentales, las instituciones educativas editan libros de texto para alfabetizar más que respetar la diversidad cultural, debido a la complejidad que representan las variantes lingüísticas.

13 Richard Uribe, "El idioma y el mercado del libro en América Latina". En III Seminario Interamerciano sobre la Gestión de las Lenguas: Las políticas lingüísticas en las Américas en un mundo multipolar- Actas. Edición a cargo de la Unión Latina, 2006. Disponible en http://dtil.unilat.org/tercer_seminario/actas/uribe_es.htm [En línea][Consulta 7-09-2010] 
Derecho a la información, bien público y bien privado:...

Por otra parte, en un artículo publicado por $\mathrm{El}$ espacio iberoamericano del libro 2008 expone los problemas de carácter metodológico para el registro de publicaciones en lenguas originarias debido a que la información consignada por los editores en la variable "lengua" es categorizada en el registro del ISBN de varios países como "otros idiomas", por lo que países, entre ellos México, reportaron muy pocos títulos (menos del 1\%). Situación de la cual podríamos deducir dos cuestiones: la primera, es que hay poca producción editorial en lenguas indígenas en México y segunda, que algunas instituciones u organizaciones sin fines de lucro que editan en lenguas indígenas no les interese registrar su producción editorial.

\section{Conclusiones}

- El PUMC de la UNAM resulta favorable para los jóvenes de procedencia indígena, porque les ayuda a impulsar su formación profesional, contribuir a la revaloración y fortalecimiento de su identidad, aporte y participación dentro de la sociedad mexicana.

- Las profesiones de Derecho e Ingeniería son las más demandadas por los estudiantes de origen indígena, situación que nos permite especular que ellos desean ayudar a resolver los problemas que se viven en sus comunidades, como pueden ser la falta de respeto a sus derechos o el implementar vías de comunicación. 
- La etnia nahua es la que mayor representación tiene, dado que es una de las que cuenta con mayor población escolar indígena en la UNAM.

- De acuerdo con los resultados obtenidos, la lengua donde hay más materiales en las bibliotecas muestra es el náhuatl, justificado en mayor medida por la impartición de la misma en algunas entidades académicas de la UNAM, más no por la existencia de estudiantes indígenas.

- En las colecciones de las bibliotecas seleccionadas se refleja la escasez de bibliografía en lenguas indígenas, principalmente en la Facultad de Ingeniería y en la Escuela Nacional de Enfermería y Obstetricia en donde hay dos y 10 materiales respectivamente.

- La escasez de materiales en lenguas indígenas nos permite señalar que las bibliotecas seleccionadas no cumplen con nuestro objetivo de apoyar a los estudiantes indígenas con lecturas en su lengua materna a fin de fortalecer su identidad y practicar la lectura de su lengua.

- La situación de descuido y falta de sensibilidad hacia las minorías se manifiesta notoriamente en los catálogos de las bibliotecas seleccionadas, dado que localizar un material en lengua indígena es complicado, salvo si tiene el nombre del autor o el título del material que se desea consultar o si se revisa el registro bibliográfico de algún material que se intuye está escrito en lengua indígena y después verificarlo físicamente, o que el registro bibliográ- 
Derecho a la información, bien público y bien privado:...

fico contenga una nota que indique que está escrito en lengua indígena.

- A pesar de que la producción editorial en lenguas indígenas es limitada, en comparación con la de el idioma inglés o español, sería conveniente que las bibliotecas de la UNAM hicieran un mayor esfuerzo por adquirir materiales en estas lenguas.

\section{Bibliografía}

Biblioteca "Antonio Caso". Facultad de Derecho, UNAM. Disponible en http://v880.derecho.unam. $\mathrm{mx} /$ web2/modules.php?name=academicos_biblioteca [En línea] [Consulta 31-05-2009].

Biblioteca "Antonio Dovalí Jaime". Facultad de Ingeniería, UNAM. Disponible en http://www.ingenieria.unam.mx/bibliotecas/catalogos.php [En línea] [Consulta 31-05-2009].

Biblioteca Central, UNAM. Disponible en http:// bc.unam.mx/[En línea] [Consulta 31-05-2009].

Biblioteca "Graciela Arroyo de Cordero". Escuela Nacional de Enfermería y Obstetricia (ENEO), UNAM. Disponible en http://132.248.141.62/ eneosite/servicioseducativos/biblioteca.php [En línea] [Consulta 31-05-2009].

Biblioteca "Jesús Reyes Heroles". Facultad de Estudios Superiores Aragón (FES), plantel Aragón, UNAM. 
Apoyo bibliográfico que ofrecen las bibliotecas de la UNAM...

Disponible en http://www.aragon.unam.mx/ servicios/biblioteca/[En línea] [Consulta 31-052009].

Constitución Política de los Estados Unidos Mexicanos. Disponible en http://www.ordenjuridico. gob.mx/Constitucion/cn16.pdf [En línea] [Consulta 31-05-2009].

Diario Oficial de la Federación, Catálogo de las Lenguas Indígenas Nacionales: Variantes Lingüísticas de México con sus autodenominaciones y referencias geoestadísticas, Enero 14, 2008, disponible en <http://www.cdi.gob.mx/lenguamaterna/catalogo_lenguas_indigenas_mexico_2008.pdf [En línea] [Consulta 31-05-2009].

El espacio iberoamericano del libro 2008. Disponible en http://www.abinia.org/nota-espacio.htm. [En línea] [Consulta 7-09-2010].

Una estrategia de investigación y educación superior para un mundo culturalmente diverso. Programa Universitario México, Nación Multicultural. México: UNAM, Coordinación de Humanidades, 2009. $50 \mathrm{p}$.

La migración México-Estados Unidos. México: Consejo Nacional de Población, 2009. 11-13 p. Disponible en <http://www.conapo.gob.mx/publicaciones/intensidadmig/cap01.pdf > [En línea] [Consulta 15-05-2009]. 
Derecho a la información, bien público y bien privado:...

Programa de Becas Educación Garantizada, disponible en <http://www.educaciongarantizada.df.gob. $\mathrm{mx} />$ [En línea] [Consulta 13-03-2009]

Programa Universitario México, Nación Multicultural, disponible en <http://www.nacionmulticultural.unam.mx/Portal/Principal/Pumc/pumc01. html> [En línea] [Consulta 16-03-2009].

Ramírez Velázquez, César Augusto. "La investigación de las necesidades de información en las comunidades indígenas: campo propicio para impulsar su desarrollo social", en Seminario Hispanomexicano de Investigación en Bibliotecología y Documentación (5: 2008: México, D.F.). Memoria del Quinto Seminario Hispano Mexicano de Investigación en Bibliotecología y Documentación, 9, 10 y 11 de abril de 2008/ comp. Filiberto Felipe Martínez Arellano.- México: UNAM, Centro Universitario de Investigaciones Bibliotecológicas, 2009. 391 p.

Rodríguez Gallardo, Adolfo. "Por qué una Biblioteca Central."Biblioteca Universitaria. Boletín Informativo de la Dirección General de Bibliotecas. Nueva Época. vol.4 no 1 enero junio 2001: p. 13-17.

Uribe, Richard. "El idioma y el mercado del libro en América Latina". En III Seminario Interamericano sobre la Gestión de las Lenguas: Las políticas lingüísticas en las Américas en un mundo mul- 
Apoyo bibliográfico que ofrecen las bibliotecas de la UNAM...

tipolar-Actas. Edición a cargo de la Unión Latina, 2006. Disponible en http://dtil.unilat.org/tercer_ seminario/actas/uribe_es.htm [En línea] [Consulta 7-09-2010]. 



\title{
La universidad pública y su compromiso social en la producción del conocimiento
}

\author{
Estela Morales Campos \\ Coordinadora de Humanidades \\ Centro Universitario de Investigaciones Bibliotecológicas \\ Universidad Nacional Autónoma de México \\ moce@unam.mx
}

\begin{abstract}
A lo largo de la historia, las universidades han ocu1 pado un espacio de ejercicio intelectual, así como de fomento del conocimiento y del saber; su existencia se justifica en la medida en que, de modo permanente, favorecen el desarrollo humano sostenible, lo cual repercute en el crecimiento científico y tecnológico, en la preservación e incremento de la cultura, así como en el bienestar social, y no sólo en el desarrollo económico, independientemente de sus consecuencias, sus causas y sus efectos. La educación y la investigación además de brindar formación académica a la juventud, también examinan, crean y recrean el conocimiento. Este proceso, en un sistema de educación superior como el de las universidades, se ve en la necesidad de corresponder con las aspiraciones de la sociedad civil.

Las comunidades universitarias (estudiantes, profesores, investigadores, egresados) y el sector social
\end{abstract}


Derecho a la información, bien público y bien privado:...

y productivo, asumen la responsabilidad de estimular una educación y una investigación de calidad, así como de promover la curiosidad de saber, de querer algo mejor de lo que tenemos. Actualmente, el conocimiento se produce, se acumula y se adquiere más rápido que nunca. El mundo se transforma aceleradamente: cambian las modas, las tecnologías se superan, las fronteras son políticas pero también virtuales, surgen nuevos paradigmas; en comparación a esta aceleración, los programas educativos y las estructuras institucionales reflejan cambios más lentos para incorporar aquellos que se dan fuera de las instituciones educativas.

Toda esa problemática la enfrentan, en mayor o en menor medida, las universidades públicas latinoamericanas, que han tenido que recorrer un largo y a veces accidentado camino de logros y adversidades en su afirmación e identidad. Sus respectivas trayectorias están llenas de tropiezos y sinsabores; sin embrago, su empeño en contribuir en la generación de conocimiento ha sido uno de los factores que más ha ayudado en su consolidación como instituciones comprometidas socialmente en cada uno de los países de la región que las alberga.

Este año, México conmemora dos acontecimientos que marcaron su historia y cambiaron el rumbo del país: doscientos años de la lucha por la Independencia política de España y cien de la Revolución que buscaba un cambio político, económico y social. Ambos movimientos armados propiciaron transformaciones, no sólo políticas, que impactaron en la vida del pueblo, en el 
campo y en la ciudad, en las aspiraciones de hombres y mujeres, en los familiares de los que murieron en la guerra, en los que vivieron para aprovechar mejores condiciones de vida, en los que conservaron sus privilegios y en los que, lamentablemente, mostraron una evolución casi imperceptible.

Los líderes y los ideólogos de estas dos grandes confrontaciones por un México mejor siempre buscaron que el pueblo, la gente más desprotegida, se hiciera de saberes y se adueñara del conocimiento que permitiera mejores condiciones de vida. Todos ellos sabían del poder del conocimiento y de la fuerza de la educación como las únicas vías de superar la explotación, la improvisación en la toma de decisiones, los índices de producción, la mala salud y la nula prevención de las enfermedades. Este asirse de conocimientos y saberes, en un inicio, no tenía como objetivo concentrarse en los grupos letrados, ya que en esas épocas, 1810 y 1910, sólo las clases privilegiadas estaban alfabetizadas y tenían las posibilidades económicas y sociales de acceder a la educación, de leer y, a través de las letras y la escuela, de llegar al conocimiento.

En 1910 concluyó una etapa de la vida del país, el Porfirismo, y se inició la Revolución Mexicana; en el mes de septiembre, todavía durante el gobierno de Porfirio Díaz, la sociedad mexicana asistió a un acontecimiento educativo y cultural de primer orden: la reapertura de la Universidad a través de la inauguración de la Universidad Nacional de México, ante el Presidente de la República, llevando a cabo el proyecto de Justo Sierra, Secretario de Instrucción Pública y Bellas Artes. 
Derecho a la información, bien público y bien privado:...

La Universidad Nacional de México tenía pocos meses de vida cuando inició la Revolución Mexicana, un movimiento que estableció vasos comunicantes con sus principios de origen y con los de un nuevo movimiento de gran trascendencia social; así, la Universidad interactuaría con la Revolución y se vería alimentada por ella.

Los principios sociales que le dieron origen a esa Universidad quedaron plasmados en el discurso pronunciado por Justo Sierra en la ceremonia de inauguración: la Universidad era considerada no sólo como una productora de ciencia, sino como una institución cercana al pueblo, donde el conocimiento generado y trasmitido debería permitir a la sociedad tomar parte más activa en el concierto humano; se indica claramente que el universitario será solidario con la problemática del país y trabajará en el campo de la acción para resolverla, además se reconoce que el conocimiento se adaptará a mejorar la realidad mexicana económica, social, demográfica, tecnológica y científica, a partir de la formación de un mexicano que piensa y a la vez es perceptivo a sus expresiones y sensibilidades, sus lenguas, sus culturas, la práctica de la libertad y la democracia, aceptando la diversidad que dio origen a México y a los mexicanos; pero, al mismo tiempo, Sierra reflexiona sobre el riesgo de consumir el conocimiento sin alimentarlo, sin actualizarlo ni innovarlo, tarea obligatoria de la Universidad y de la investigación científica que ésta deberá realizar e impulsar. La Universidad debe cultivar las artes, la estética, la cultura nacional, la fi- 
losofía, las letras, las humanidades y la búsqueda de la verdad con base en el método científico y en la ciencia. La Universidad Nacional, en su acto fundacional, tuvo su gran mandato social: "no es lícito al universitario pensar exclusivamente para sí mismo y que si se pueden olvidar a las puertas del laboratorio al espíritu y a la materia, no podemos, moralmente olvidarnos nunca ni de la humanidad ni de la Patria [...] La Universidad está encargada de la educación nacional en sus medios superiores e ideales [y] el Estado no podría, sin traicionar su encargo, imponer credo alguno y sí dejar a todos en absoluta libertad para profesar el que les imponga o la razón o la fe." 1

Si los orígenes de la Universidad privilegian su compromiso social, la Revolución Mexicana los ratifica y potencia; el contexto social en esos inicios mostraba un sector que se jactaba de ser letrado y "culto", con acceso a la educación, a la lectura y a ricas bibliotecas privadas; sin embargo, el acceso al bienestar era muy desigual, entre el campo y la ciudad, entre los letrados y los de cultura oral; por tal motivo, la Revolución planteaba que la educación llegara a todos los rincones del país a fin de facilitar los proyectos sociales, culturales y tecnológicos; de este modo, a una década de su creación, la Universidad Nacional llevaba un hilo conductor entre el mandato que le había conferido el Estado

1 Justo Sierra, "Discurso pronunciado en la Inauguración de la Universidad Nacional, el año de 1910", en: Justo Sierra, Prosas, México, UNAM, 2010, 5ª ed., p. 165-192. 
Derecho a la información, bien público y bien privado:...

en su creación y los objetivos que le había contagiado la Revolución, entre el pensamiento y la acción de Justo Sierra y los principios y programas del otro ideólogo de la Universidad, José Vasconcelos, quien promovió la creación tanto literaria, plástica y arquitectónica como social, científica y tecnológica, además del estudio de la economía, el derecho, la agricultura y la salud; conocimiento construido y estudiado en una Universidad al servicio del pueblo, ${ }^{2}$ y por lo tanto la institución adquiría otro compromiso, hacer llegar estos saberes al país, aun en sus rincones más alejados y deprimidos.

En estos primeros años de la Revolución, la Universidad Nacional fue una de sus joyas más valiosas entre las empresas educativas del país y, por lo tanto, la demanda social era muy fuerte; el pueblo no tenía la menor duda, como sucede hoy en 2010, de que la Universidad le pertenecía y que le respondería con la verdad y la solución adecuada para México y para los mexicanos.

La relación educación-libros-lectura fue el trinomio que estableció el programa gubernamental para superar el rezago de la población, y a este modelo seguirían los programas de la Universidad Nacional a la que el gobierno y su rector le asignaban una responsabilidad social hacia la ciudad donde tiene su sede y hacia el país, por lo que abría sus puertas a todo público; su principal objetivo, por supuesto, era la docencia y la investiga-

2 Enrique Krauze, "El evangelio según Vasconcelos", en: Caudillos culturales en la Revolución mexicana, México, Siglo XXI Edit., 1985, p. 104-110. 
ción que se realizaba en sus escuelas y, posteriormente, en sus facultades e institutos para sus estudiantes, sus profesores y sus investigadores; pero la Universidad Nacional, al tener también el objetivo de extender y difundir la cultura a los universitarios y a los mexicanos, abrió las puertas de sus bibliotecas, museos, teatros, exposiciones, conferencias, conciertos..., a fin de que todo aquel que lo deseara o tuviera curiosidad se pudiera acercar a la cultura en su concepción más amplia: la creación humana, en las artes, en las ciencias y la tecnología. ${ }^{3}$

Desde la creación de la Universidad Nacional hasta nuestros días, la constante de trasmitir y de construir conocimiento con un sentido social nos lleva a entender la vocación de los universitarios por considerar el conocimiento como un bien social, facilitando su acceso al conocimiento universal que requieren y al conocimiento que produce la Universidad.

Vivimos en una época de sociedades y sistemas complejos, inmersos en fenómenos que marcan la vida de las personas y las instituciones, y uno de ellos es el conocimiento como una fuente de riqueza que transforma al individuo, a la sociedad, al país, y que se vuelve parte del patrimonio de la humanidad, al igual que los recursos materiales y los productos del hombre, como pueden ser los bosques, los parques naturales, los edificios, las ciudades. Así, los productos del intelecto,

3 Enrique Krauze, "José Vasconcelos, la grandeza del caudillo", Letras Libres (México), núm. 24 (dic., 2000), p. 60-62. 
Derecho a la información, bien público y bien privado:...

la creación y la innovación se registran como conocimiento del hombre y tendrían que ser patrimonio de la humanidad y de cada uno de los pueblos que lo generan. Si no le otorgamos valor al conocimiento, éste será un producto que no le vamos a poder legar a las nuevas generaciones; pero lo más grave es que, al no otorgar valor al conocimiento, tampoco estaríamos estimulando su uso y, peor aún, no apoyaríamos su creación, producto de un sistema educativo y de investigación fuerte y de calidad. ${ }^{4}$

En este sentido, es importante analizar las iniciativas legales que atienden esos puntos de vista; tal es el caso de la Federal Research Public Access Act (FRPAA), que recientemente, en Estados Unidos, ha vuelto a entrar en el Congreso en fase de discusión. Dicha ley propone que la producción científica generada de proyectos financiados con fondos públicos de organismos de investigación federales que superen los 100 millones de dólares de presupuesto, cumpla con el requisito de estar disponible en acceso abierto. ${ }^{5}$

Por su parte, en América Latina, vale la pena mencionar los diversos movimientos de apoyo al acceso abierto al

4 Unesco, "La Unesco y la Sociedad de la Información para todos", París, Unesco, 1996. Estela Morales Campos, "Los retos que la Sociedad de la Información le presenta a la Universidad y sus Bibliotecas", Infodiversidad (Buenos Aires), vol. 8 (2005), p. 43-57.

5 The Scholarly Publishing and Academic Resources Coalition, "Federal Research Public Access Act (FRPAA)", http://www. arl.org/sparc/advocacy/frpaa/index.shtml 
conocimiento académico y científico, como la campaña que hoy por hoy realiza el Consejo Latinoamericano de Ciencias Sociales (CLACSO), cuyo propósito reside en extender el conocimiento entre sus centros miembros en lo concerniente al impacto del acceso abierto y de las bibliotecas y repositorios digitales con respecto a la visibilidad y accesibilidad de las investigaciones. A su vez, también con el objetivo de fortalecer estrategias que alientan el acceso abierto y la interoperabilidad entre los repositorios institucionales en América Latina, recientemente, del 18 al 24 de octubre pasado, se celebró, en el marco de la Semana del Acceso Abierto, el evento regional "Acceso abierto. Buenas prácticas en proyectos latinoamericanos", para mejorar las iniciativas institucionales y nacionales que se organizan en la región. De acuerdo con el sitio web de la Semana del Acceso Abierto, esta iniciativa constituyó una oportunidad dirigida a la comunidad académica y de investigación para que continúe aprendiendo sobre los beneficios potenciales del acceso abierto, para compartir lo que han aprendido con sus colegas, y para ayudar a inspirar una mayor participación en ayudar a hacer de esta propuesta una nueva norma en estudio y la investigación. ${ }^{6}$

Asimismo, no hay que olvidar las aportaciones que, en ese mismo sentido, ha realizado la Red de Revistas Científicas de América Latina y el Caribe, España y

6 Open Access Week (Octuber 18-24, 2010):

http://www.openaccessweek.org/ 
Derecho a la información, bien público y bien privado:...

Portugal (Redalyc). Este sistema de información es un proyecto impulsado por la Universidad Autónoma del Estado de México (UAEM), con el propósito de asistir en la difusión de la actividad científica editorial que se genera en y sobre Iberoamérica. La oferta específica de Redalyc se concentra en crear, diseñar y mantener una hemeroteca científica, disponible en línea y de libre acceso, ${ }^{7}$ la cual opera como punto de encuentro para todos aquellos interesados en reconstruir el conocimiento científico de y sobre Iberoamérica. Abierto al público desde el año 2002, este esfuerzo forma parte de una iniciativa derivada de un grupo de investigadores y editores preocupados por la poca visibilidad de los resultados de investigación generados en la región. Actualmente, Redalyc se ha logrado consolidar como un aparador donde se ofrece la más destacada producción científica de Iberomérica. ${ }^{8}$

Considerar el conocimiento un bien social, parte del patrimonio del hombre, es una premisa de la que deben partir las ciudades y los gobiernos, los profesores, los investigadores y las universidades. Ser un bien social, y no un bien sujeto a las leyes del mercado, no implica desconocer la autoría del creador, sólo facilita y propicia su uso, sobre todo en países y pueblos que

7 Red de Revistas Científicas de América Latina y el Caribe, España y Portugal. Sistema de Información Científica Redalyc: http://redalyc.uaemex.mx/

8 Redalyc, "Presentación": http://redalyc.uaemex.mx/redalyc/ media/principal/auxHemeroteca/presentacion.html 
no han desarrollado una actitud y una educación que busquen resolver los problemas de la vida a partir de la aplicación de conocimientos y saberes útiles.

Los países desarrollados y los que aspiran a serlo han puesto el énfasis en la educación superior como la opción para alcanzar el desarrollo económico, el desarrollo sustentable y el desarrollo humano; no obstante, algunos gobiernos lo han olvidado y privilegian el eje económico con demandas y soluciones que sólo funcionan para resolver necesidades inmediatas. $\mathrm{Y}$ aun con estas políticas económicas gubernamentales erróneas, la Universidad tiene la obligación de incentivar el uso del conocimiento en el aula, en el laboratorio y en la vida cotidiana, sobre todo en una época en la que el mundo desarrollado se asume como una Sociedad del Conocimiento.

La Universidad tiene la obligación y el compromiso de pugnar por políticas públicas y marcos jurídicos que privilegien la educación y la investigación como condiciones irremplazables para obtener el desarrollo y el acceso de forma equitativa a los bienes y derechos sociales.

El acceso al conocimiento deberá ser un derecho social de uso colectivo mediante las instituciones y medios que la sociedad y el Estado han creado para facilitar este acceso y uso.

Por eso en 2010, la Universidad Nacional vive una Revolución Intelectual, una Revolución para ingresar a la Sociedad del Conocimiento, en donde el centro de las políticas públicas del país debe estar ocupado por la 
Derecho a la información, bien público y bien privado:...

educación de calidad, pertinente y apoyada en el conocimiento que promueva el respeto al otro, al medio ambiente y a los valores sociales, para que los ciudadanos y los gobernantes se pongan al servicio de la sociedad y no aprovechen tal conocimiento para servirse de ella. 


\title{
La información como bien público: la responsabilidad social del bibliotecólogo
}

\author{
JaIme Ríos OrTega \\ Director del Centro Universitario de Investigaciones Bibliotecológicas \\ Universidad Nacional Autónoma de México \\ jrios@servidor.unam.mx
}

\section{Introducción}

Gs probable que la información en el siglo XXI, con Cantecedente en el siglo $\mathrm{xx}$, transite las siguientes décadas sin perder relevancia y, por el contrario, acreciente su carácter polisémico. También es un hecho que la democracia, sin ser el sistema de convivencia perfecto, ha dado mejores resultados a los seres humanos en el mundo. Estos dos conceptos se conjugan indisolublemente y se refuerzan en todo momento; su carácter tiende a ser universal y omnipresente. Junto a estas fuerzas de interacción social, también ha destacado desde hace siglos la institución denominada $b i$ blioteca, cuyo poder transformador de la información a conocimiento la ha hecho imprescindible. El bibliotecólogo se ha articulado a perspectivas sociales cada vez más amplias y ha trascendido los espacios físicos 
Derecho a la información, bien público y bien privado:...

hasta abarcar el creciente espacio virtual, el cual ha intensificado la capacidad de vinculación humana y repercute en todo aquello que es producto de la cultura. El bibliotecólogo, al igual que otros actores y constructores de las Sociedades del conocimiento, finca su intervención social a partir de valores cuyo sentido progresivo es civilizatorio y eminentemente humano; en tales dimensiones el conocimiento como bien público es materia de análisis del campo bibliotecológico y sus resultados deben orientar la participación de los practicantes de esta la disciplina hacia las esferas de la vida que nos son comunes.

\section{La información, el conocimiento y el contexto}

La ciencia moderna, en todos sentidos, es una de las creaciones culturales más impactantes. En los últimos tres siglos, además de las ideas y las diversas concepciones del hombre y del mundo que han transformado los diferentes órdenes sociales, la ciencia y sus aplicaciones han coadyuvado a crear entornos culturales, económicos y políticos que no admiten retroceso alguno. Sin embargo, en el mundo moderno coexisten los polos de desarrollo y los de pobreza. La desigualdad como característica distintiva es más exacerbada día con día y la ciencia, aun con sus aplicaciones, enfrenta severas limitaciones para mejorar la calidad de vida de millones de seres humanos. Mientras la ciencia y la cultura son alternativas esenciales para ampliar el sentido 
humano de la existencia, la pobreza denigra y lleva a la muerte, es decir, nos deja sin alternativa.

El término globalización, como valoración, ocupó las últimas dos décadas del siglo Xx y la primera del XXI, de ahí que la problematización de los términos justicia, pobreza, desigualdad, derechos económicos $y$ sociales, emerja con vigor al entenderlos como conceptos emergentes. De este modo, y en gran parte de su argumentación, las Sociedades del conocimiento presentan un escenario que es producto de la globalización y de los conceptos antes mencionados. En la visión de este tipo de Sociedades, el contexto de pobreza mundial y los resultados de la conjugación de brechas son el referente insoslayable aunque esto no se explicite totalmente.

No obstante es posible cuantificar las dimensiones, por ejemplo:

1.De acuerdo con cifras del Banco Mundial del 2010, una cuarta parte de la población de los países en desarrollo continúa viviendo con menos de 1,25 dólares al día. Al tiempo que 1.000 millones de personas carecen de agua potable; $1.600 \mathrm{mi}-$ llones, de electricidad, y 3.000 millones, de servicios de saneamiento adecuados la cuarta parte de todos los niños de países en desarrollo padecen malnutrición.

2.Brechas: a) económica, b) geográfica: asimetría entre el campo y las ciudades, c) poblacional, por edad y generaciones, d) de sexo y género, e) de 
Derecho a la información, bien público y bien privado:...

lengua, f) de educación y procedencia cultural, g) de empleo, h) de integridad física, i) cognitiva y j) digital.

Cada una de estas brechas contiene indicadores que al conjuntarlos e interpretarlos, sin duda, pueden presentar un panorama desolador. A pesar de ello, las Sociedades del conocimiento se presentan como una alternativa viable y se ha enfatizado que no se implica exclusivamente la información sino el conocimiento; que no se trata únicamente de un problema de conexión sino de educación. Así mismo se menciona que los retos que resumen el conflicto son, por una parte, el acceso a la información para todos, y por la otra el futuro de la libertad de expresión.

Es relevante destacar para el ámbito bibliotecológico algunos rasgos de este tipo de Sociedades, ya que el fin último no es la transferencia de información sino el desarrollo humano, así como la "humanización del proceso de mundialización”. Parte del éxito consistirá en transformar la información en conocimiento y que este sirva al desarrollo humano en general. Por eso resulta tan importante la capacidad de identificar, producir, tratar, transformar, difundir y utilizar la información, pues el objetivo es crear y aplicar los conocimientos nuevos para propiciar el mejoramiento humano.

Sin las capacidades anteriores no habría modo de distinguir entre la información en general respecto de la información que tiene valor social, la cual es la materia prima de la ciencia y el conocimiento avanza- 
dos. Se requiere, pues, de su apropiación a través de la educación y el trabajo de las comunidades epistémicas. La premisa que podría sustentar este argumento sería entonces la siguiente: la ciencia y el conocimiento original contribuirán al desarrollo humano, siempre y cuando éste se comparta y ayude a que las sociedades se conviertan en fuentes de tal desarrollo. Esta concepción del mejoramiento humano presupone el marco de los derechos universales del hombre, como condición necesaria para alcanzar los derechos económicos y sociales; y dentro de este conjunto de derechos destacan la libertad de expresión en sus diversas manifestaciones, los principios democráticos, la noción de justicia, la lucha contra la pobreza y el ideal del conocimiento compartido.

$\mathrm{Y}$ aquellos valores y principios que sustentan la factibilidad de alcanzar el ejercicio pleno de los derechos universales, así como económicos y sociales, son:

1.El acceso universal a la información

2.La libertad de expresión

3.La diversidad cultural y lingüística

4.La educación para todos

5.La educación a lo largo de la vida

Por lo anterior, la información con valor social es componente sustancial e imprescindible de las sociedades modernas cuyos ideales de progreso se centran en el bienestar humano. 
Derecho a la información, bien público y bien privado:...

\section{La información como bien público}

El interés de la bibliotecología por la información se focaliza en aquella que es socialmente valiosa. Es decir, no se preocupa por la información en su sentido más general puesto que quienes la requieren son seres humanos concretos. Por otra parte, la acumulación de información indiscriminada resulta caótica y por ello no sirve a ningún propósito. De lo anterior resulta que la valía de la información implica procesos de apropiación y reconocimiento social por parte de los individuos y las comunidades, y también su producción, descripción, clasificación y acceso, por parte de los bibliotecólogos. Lo anterior resulta entonces condición necesaria para la generación y la aplicación del conocimiento nuevo.

Dada su naturaleza acumulativa y comunitaria, el conocimiento científico y la cultura son bienes primarios, imprescindibles para el desarrollo social y personal. De igual modo, es importante destacar que lo anterior se define a partir de los sujetos que tal conocimiento y cultura producen, y las condiciones en que lo generan, así como el uso social que de él se hace. En consecuencia, tanto la información socialmente valiosa como la cultura, son bienes que permiten la satisfacción de necesidades de modo mediato o inmediato, pero también directa o indirectamente, y gran parte del valor que adquieren depende de si hubo necesidades satisfechas o problemas solucionados.

Toda vez que la información socialmente valiosa se ha generado se produce también la diferencia. Aun- 
que el conocimiento no culmine en su aplicación, sabemos que es susceptible de transformar un estado de cosas. Y el retroceso solo es posible si esta información no cuenta con registro, o bien si no pertenece a una memoria o archivo institucional e incluso personal. Sin embargo, iría contra la naturaleza de la empresa científica y cultural buscar deliberadamente una actuación retrógrada; empero, aun en tal escenario, sabríamos que la actuación es retrograda o bien que se trata de conocimiento obsoleto gracias a la existencia de la diferencia.

El conocimiento bibliotecológico ha creado instrumentos teóricos y operativos para organizar precisamente la diferencia. Sin dicha contribución desde la disciplina bibliotecológica, formularíamos hipótesis audaces que nos explicaran cómo es posible el enriquecimiento teórico o cognoscitivo de las disciplinas o los individuos sin la ayuda de la diferencia. Extensivamente, y por lo antes expuesto, uno de los atributos de la información valiosa consiste en que se trata de información diferenciada y sobre tal definición es posible tomar decisiones racionales y sensatas en todas las esferas de la vida humana.

Otra característica de la información como bien común reside en que, a pesar de su uso o consumo, no sufre merma alguna. Este bien común está codificado en fuentes de información las cuales se representan como bienes no individualizados y accesibles de forma general y han sido producidos o utilizados de forma transparente o participativa. La existencia de estos bienes, 
Derecho a la información, bien público y bien privado:...

por si sola, ya hace la diferencia, pero su aplicación y uso coadyuva a la transformación de los estados de cosas o de los sujetos.

Las prácticas sociales de apropiación de los bienes comunes, como el caso del conocimiento o la información, se realizan principalmente en la educación básica y secundaria, pero será en los diferentes procesos formativos que se llevan a cabo en la educación superior donde se concrete la práctica social de creación de nuevos bienes públicos gracias a la investigación original. Las comunidades que los producen trabajan con recursos públicos distribuidos a través del Estado y las instituciones que lo representan. El acceso a tales bienes públicos es una vía de devolución a la sociedad por la inversión hecha en la educación. Además, compartir el conocimiento es también una forma de asegurar la potencial aplicación, progreso y mejoramiento humano en el cual se ha centrado la perspectiva de las Sociedades del conocimiento.

\section{La responsabilidad social del bibliotecólogo}

Es importante diferenciar entre la responsabilidad social y la responsabilidad profesional del bibliotecólogo. Aunque cada una tiene rasgos propios, en la vida diaria las dos responsabilidades se conjugan. La primera de ellas destaca como una categoría de importancia inobjetable y de valor universal. No obstante, en la literatura especializada básicamente ha tratado el Código de ética profesional y el núcleo de valores en los que se 
sostiene. Se ha dejado, pues, de lado la categoría de responsabilidad social cuya perspectiva es imprescindible en la bibliotecología - cuya naturaleza es eminentemente social-, y por ello ambas responsabilidades deben conjuntarse y generar nuevos análisis.

Una de las premisas fundamentales del mundo moderno afirma que el mundo humano es producto de la interacción social y, por tanto, de seres autónomos y con capacidad de elección. Por ello, prácticamente no existe ninguna actividad de la esfera pública que no cuente con una persona o instancia que se haga cargo de la reparación de daños causados -incluso el mal "natural". La responsabilidad social se instaura en lo público, lo común y lo político y, en consecuencia, su compromiso abarca lo global, lo colectivo y lo social.

Por otra parte, para que la responsabilidad sea una acción integral debe ser:

- Dialógica

- Horizontal

- Intersubjetiva

La responsabilidad está acotada por el ámbito de interacción social donde opera, de tal modo que siempre se ejercita en nombre de algo y ante quien nos necesita. Uno de los principios que guía la responsabilidad es la capacidad de asumir que, con independencia de quien pueda ser el culpable, cualquier mal debe ser reparado. Además, en consonancia con lo anterior, el delito, la infracción o la falta no deben quedar impunes; el mal, incluido el natural, debe ser subsanado. 
Derecho a la información, bien público y bien privado:...

Con base en lo expuesto, y debido a que en la aplicación y uso del conocimiento bibliotecológico es factible afectar a los beneficiarios potenciales o reales del conocimiento e información requeridos, el bibliotecólogo, o bien, la institución que representa y en la cual se desempeña debe ser consciente acerca de la trascendencia de su función social, así como de la afectación que produce si por omisión, descuido o deliberadamente, genera daño alguno e impide el beneficio potencial o real de la información socialmente valiosa.

De diferente modo, el uso y la aplicación del conocimiento bibliotecológico está articulado al ejercicio de los derechos universales del hombre, así como a los derechos económicos y sociales de los seres humanos. Asimismo, el marco ético de actuación que asegure los beneficios de la información como bien público, opera con base en los valores y principios propios del ejercicio profesional, a saber:

- Asegurar el conocimiento a las generaciones futuras gracias a la preservación de los registros humanos.

- Ejercer la ética del servicio individual, comunitario, social como garante de políticas y procedimientos de las bibliotecas y los servicios de información.

- Garantizar y promover la libertad intelectual, la defensa de la libertad de expresión y el acceso a las fuentes de información.

- Aplicar el conocimiento avanzado en la organiza- 
ción y dirección de los servicios bibliotecarios.

- Fortalecer las capacidades y el amor por el aprendizaje para toda la vida.

- Asegurar la equidad de acceso a los registros del conocimiento e información.

- Asegurar la confidencialidad de los usuarios de la biblioteca y los servicios de información.

- Participar en los procesos educativos para garantizar la educación de los ciudadanos y el ejercicio de los derechos vigentes en la sociedad democrática.

En resumen, la responsabilidad social del bibliotecólogo, derivada del uso de la información como bien público, abarca la libertad, la prosperidad y el desarrollo de la sociedad y la persona. Los practicantes de la bibliotecología son constructores de las Sociedades del conocimiento, así como también participantes imprescindibles en los procesos de consolidación de la democracia. Transformar la información en un bien público requiere de capacidades cognoscitivas e informacionales, así como de acceso libre e ilimitado al conocimiento, el pensamiento, la cultura y la información. 
Derecho a la información, bien público y bien privado:...

\section{Obras consultadas}

Banco Mundial: Informe 2010. México: BM, 2010. Cruz, Manuel. Hacerse cargo: sobre responsabilidad e identidad personal. España: Paidós,1999.

Gorman, Michael. Our enduring values: Librariansbip in the 21st Century. US: ALA, 2000.

Los derechos económicos y sociales: una mirada desde la filosofía. Compiladora: Paulette Dieterlen. México: UNAM, Instituto de Investigaciones Filosóficas.

Hacia las sociedades del conocimiento: Informe mundial. París: Unesco, 1995. 


\title{
Gestión de la información en pueblos indígenas: una contextualización desde la experiencia
}

\author{
Florybeth SÁNChez EsPinOza \\ Escuela de Bibliotecología, Documentación e Información \\ Universidad Nacional / Heredia, Costa Rica
}

fanch@una.ac.cr

\section{Antecedentes}

Para emprender una contextualización del Proyecto FORTALECIMIENTO DEL DESARROLlO INTEGRAL DE LOS PUEBLOS INDÍGENAS BORUCA, REY CURRÉ Y Ó TÉRRABA A TRAVÉS DE LA GESTIÓN DE LA INFORMACIÓN 2009- 2011, es preciso devolverse al proyecto que dio origen a estas experiencias, como lo fue el proyecto CENTRO DE CONOCIMIENTO PARA GRUPOS ÉTNICOS INDÍGENAS CENTROAMERICANOS (GEIC). Es con éste último proyecto que la Escuela de Bibliotecología Documentación e Información (EBDI) incursiona en la temática indígena, específicamente en lo referente al componente información donde se empiezan a dar los primeros pasos y es insertado en el ámbito académico e investigativo de la Universidad Nacional. 
Derecho a la información, bien público y bien privado:...

El proyecto GEIC se definió en su momento con cinco objetivos:

- Crear un diagnóstico sobre/de información de Grupos Étnicos Indígenas Centroamericanos.

- Implementar una red a nivel centroamericano de unidades de información documental que apoyen el rescate, acceso y disponibilidad de la información documental sobre grupos étnicos indígenas.

- Organizar un centro de acopio de la información documental sobre grupos étnicos indígenas centroamericanos, que facilite la digitalización y generación de mega documentos en diferentes formatos y soportes sobre la producción cultural e intelectual de estos grupos (Base CEGE).

- Crear un portal sobre grupos étnicos indígenas centroamericanos que enlace a todos los organismos y promueva el acceso a esta información, facilitando espacios de reflexión y análisis sobre la cultura, costumbres y condiciones de vida de los grupos étnicos indígenas centroamericanos, con la participación de investigadores, especialistas y los integrantes de esos grupos, e impulsar la creación de bibliotecas especializadas dirigidas a grupos étnicos centroamericanos que contribuyan a la alfabetización.

- Impulsar la creación de bibliotecas especializadas dirigidas a grupos étnicos indígenas centroamericanos que contribuyan a la alfabetización, análisis e interpretación de su cultura y el entorno, forta- 
leciendo su identidad, propiciando la igualdad de oportunidades y potenciándolos como grupos en la región y en el mundo. (Miranda, 2002).

Según Miranda (2002), algunos de los problemas más significativos por los que se dio la iniciativa de crear el proyecto GEIC, fueron:

- Los pueblos indígenas no disponen de centros de información o documentación accesibles que les permita conocer su propia cultura y tradiciones.

- Esta ausencia de centros de conocimiento les dificulta recuperar su memoria histórica.

- Es necesario que estos centros se consoliden con base en las necesidades y demandas de la población indígena y su participación. El problema es que esto se desconoce y se requiere de estrategias que permitan ganar su confianza y apoyo.

El proyecto GEIC empezó sus gestiones a partir del 2004 con la participación de varias/os colegas y profesionales de otras disciplinas, las acciones que se pretendían con este proyecto son las siguientes:

- Un directorio de Instituciones que contengan la temática indígena.

- Una red de instituciones que contienen dicha temática a nivel nacional.

- Un portal (http://www.una.ac.cr/bibliotecologia/ grupos_etnicos/) que contiene los documentos y 
Derecho a la información, bien público y bien privado:...

la memoria del proyecto a través del tiempo de ejecución.

- La gestión de unidades de información en territorios indígenas, específicamente Talamanca.

En el 2005 se reformula el proyecto GEIC con el fin de alcanzar las metas que hasta el momento no se habían logrado, quedando el proyecto con una vigencia de tres años más (2006 al 2008) y siempre con los objetivos que le dieron origen más otros dos nuevos:

- Elaborar un diagnóstico sobre las necesidades básicas de las comunidades indígenas para desarrollar servicios de información que contribuyan a la resolución de dichas necesidades.

- Proponer metodologías que permitan el rescate cultural y la recopilación de la memoria histórica de las comunidades.

Con GEIC se involucraron tres áreas del campo de la gestión de la información como lo fueron:

1. El acceso abierto a la información de y sobre los grupos étnicos indígenas centroamericanos. Para esto se hizo necesario el monitoreo permanente de todas aquellas organizaciones regionales que contuvieran esta información, en qué formatos y cómo la ofrecían. A partir de este diagnóstico se posibilitó la participación de esas organizaciones en una red de cooperación cuya finalidad fue po- 
tenciar el libre acceso a la información Los objetivos 1 y 2 del proyecto correspondieron a esta área.

2. La gestión de información involucró actividades de recolección, procesamiento, almacenamiento, búsqueda, recuperación y difusión de la información. Para ello el proyecto definió los objetivos 3 y 4 logrando alcanzar cada una de estas instancias del proceso y concretando productos en una base de datos de 4712 registros y un enlace para su acceso a través de un portal ubicado en la página de la Escuela de Bibliotecología y Documentación.

3. El uso de la información y generación de nueva información como fin principal de los procesos de gestión de la información contemplados en este proyecto, planteó la necesidad de desarrollar habilidades informacionales en las comunidades indígenas que favorecieran el uso de la información. Informe final centro de conocimiento para grupos étnicos indígenas centroamericanos (2009).

\section{Proyecto de fortalecimiento del desarrollo integral de los pueblos indígenas Boruca, Rey Curré y o Térraba a través de la gestión de la información 2009- 2011.}

La ejecución de la reformulación del proyecto GEIC termina en diciembre del 2008, producto de las experiencias y gestiones que se dieron en GEIC es que se escribe el proyecto FORTALECIMIENTO DEL DESARROLLO INTEGRAL DE LOS PUEBLOS INDÍGENAS BORUCA, REY CURRÉ 
Derecho a la información, bien público y bien privado:...

Y Ó TÉRRABA A TRAVÉS DE LA GESTIÓN DE LA INFORMACIÓN 2009- 2011.

Es preciso para empezar a hablar del proyecto Fortalecimiento..., definir lo que se entiende como gestión de la información, según la literatura consultada se detalla "como un conjunto de actividades y prácticas orientadas a la adquisición más eficiente de las habilidades asociadas con un conocimiento y su correcta utilización, con el propósito de obtener los mejores resultados en el desarrollo de las actividades de una determinada organización" (Aja Quiroga, L., 2002). Para el proyecto Fortalecimiento la gestión se ha seguido con este norte, que es el de realizar actividades y practicas con los y las indígenas para ayudarles en el fomento de habilidades y destrezas para el uso del conocimiento y la organización de la información.

Como se retomará más adelante en lo correspondiente a la gestión, el proyecto fortalecimiento ha tenido que escribir y reescribirse lo que ya estaba en papel, y la razón de esta situación es muy sencilla , para trabajar con esta población es necesario hacerlo desde la experiencia, desde la cotidianidad de ellos/as y a partir de sus necesidades informacionales, no se puede llegar a estas comunidades con escritos hechos en piedra y con investigaciones hechas a la medida de los y las investigadores y de sus necesidades de información, ya que con estas poblaciones el papel dice qué se debe hacer pero la experiencia con ellos/as dice otra cosa.

Por lo tanto, el proyecto "Fortalecimiento..." empieza a dar sus primeros pasos en julio del 2009 a partir 
de un diagnóstico elaborado el año anterior en el territorio de Boruca al sur del país, donde se le solicita a la comunidad sus impresiones y expectativas en lo referente a la creación de una Biblioteca Comunitaria en dicho territorio. Cabe resaltar que este proyecto se escribió a partir de la experiencia de GEIC y con él se decide delimitar el campo de acción a tres territorios del sur de Costa Rica como lo son Boruca, Térraba y Rey Curré, tres territorios en donde el planteamiento era llegar a ganarse la confianza de las personas y empezar a trabajar desde la gestión de la información y a partir de las necesidades de cada territorio, respetando su cosmovisión (sus creencias, tradiciones, espacios y todo lo referente a su cultura).

El Proyecto Fortalecimiento se emprende con cuatro objetivos:

- Continuar con la actualización de la página web del proyecto GEIC.

- Gestionar la instalación de un servicio de información

- Identificar el interés por la implementación de otra unidad de información en un territorio indígena aledaño a Boruca (Térraba o Rey Curré).

- Determinar las necesidades de capacitación de los colegios de secundaria con respecto a la alfabetización informacional en bibliotecología.

Con el primer objetivo, Fortalecimiento, se apropia de la actualización de la página web de GEIC, debido a 
Derecho a la información, bien público y bien privado:...

la importancia, al impacto y al esfuerzo que ha tenido en los años anteriores, por lo que se avoca a gestionar las tareas y actividades pertinentes.

Con el objetivo dos, "Gestionar la instalación de un servicio de información", es donde este proyecto emprende su quehacer en la comunidad de Boruca con:

- Reuniones en la comunidad, casa por casa, conversando con las personas, compartiendo ideas, anécdotas para llegar a ganarse la confianza de las personas y empezar a trabajar desde la gestión de la información.

- Llegar con planteamientos a partir de las necesidades de cada territorio, respetando su cosmovisión (sus creencias, tradiciones, espacios y todo lo referente a su cultura).

- Presentación del proyecto a las personas que la misma comunidad ha decidido, en el caso de Boruca al gobierno local, la Asociación de Desarrollo y al consejo de la Cooperativa.

- La Junta Directiva de la Cooperativa de Boruca (Coopebrunca), así como la Asociación de Desarrollo Integral de este territorio indígena; resuelven impulsar la apertura de una Biblioteca comunitaria

- Paralelamente se forma un comité de biblioteca, en el cual se dan numerosos cambios en sus representantes debido al mismo cambio que existe en las asociaciones de desarrollo cada cierto tiempo 
En dicha comunidad se realizan varias actividades para conocer las necesidades y la opinión de la comunidad:

- Reuniones con el comité de biblioteca.

- Reuniones con instituciones de educación (Escuela y Colegio).

- Participación en eventos de la comunidad, (bingos, actividades del colegio y de la comunidad).

- Elaboración, aplicación y sistematización de 116 cuestionarios, pasados casa por casa en territorio Boruca.

- Talleres.

- Capacitaciones.

- Divulgación del proyecto (Radio de la comunidad, afiches, panfletos, participación de eventos).

La comunidad de Boruca se visita mes a mes y se programan las reuniones con el comité de biblioteca con la finalidad de:

- Realizar las gestiones de búsqueda de lugares posibles que albergarían la biblioteca,

- Establecer servicios hechos a la medida por y para ellos/as.

- Recomendar el mobiliario y el equipo entre otras cosas asignar las tareas especificas al comité para avanzar en la gestión. 
Derecho a la información, bien público y bien privado:...

Después de casi un año de estar gestionando en el territorio de Boruca, la Junta de Desarrollo decide no continuar con las gestiones ya que no se demuestra el interés de las personas que conforman el Comité por lo que se continúa con las gestiones desde el Liceo de la comunidad.

De igual forma en el Liceo se empezó con reuniones con el Director y la Junta de Desarrollo para lograr el aval. Una vez se obtuvo el compromiso por parte de ambas instancias (Liceo y EBDI), se emprenden las siguientes gestiones:

- Búsqueda de lugares posibles que albergarían la biblioteca.

- Servicios hechos a la medida por y para ellos/as.

- Se recomiendan mobiliario y el equipo entre otras cosas.

- Se le asignan tareas especificas al comité para avanzaren la gestión.

- Se traslada la colección de documentos del Liceo, a la EBDI, con el aval tanto de la junta como del director para el tratamiento técnico de la información.

- Se crea una base de datos y se ingresan los documentos para normalizar y entregarles los documentos procesados y digitados en una base de datos.

- Posteriormente, se emprende la capacitación al bibliotecario empírico realizando actividades y practicas para ayudar en el fomento de habilidades y 
destrezas para el uso del conocimiento y la organización de la información.

- Se concientiza y sensibiliza al bibliotecario para que empiece a dar servicios a la medida, o sea para las necesidades detectadas en el Liceo.

- Se realizan actividades desde la coordinación de fomento y divulgación del proyecto, con el objetivo de dar a conocerlo y a la vez de solicitar material y equipo para la biblioteca.

La Gestión en el Liceo de Boruca se quedó en el paso anterior, ya que el lugar donde se tenía previsto que se albergara la biblioteca, debía ser debidamente acondicionado, este proceso se ha postergado por las múltiples necesidades que tiene el Liceo; la Junta de Educación ha tenido que destinar los recursos que tenía para adaptar el rancho asignado a la biblioteca, para techar el comedor y solucionar problemas de inundaciones en el mismo, razones muy válidas que han pospuesto indefinidamente el traslado del acervo y que la biblioteca trabaje como tal, ya que en el lugar que está no tiene espacio ni mobiliario para dar servicios adecuados.

En el objetivo tres, Identificar el interés por la implementación de otra Unidad de información en un territorio indígena aledaño a Boruca (Térraba o Rey Curré) se aborda paralelamente a los otros objetivos, ya que mientras se está gestionando en un territorio, se empieza de cero con el otro territorio. Para el logro de este objetivo se realizó lo siguiente: 
Derecho a la información, bien público y bien privado:...

- Se emprende de nuevo la gestión visitando el territorio, casa por casa, conociendo las personas, invitándoles a conocer del proyecto.

- Si demuestran interés y al tener un grupo significativo se les convoca para explicarles la idea del proyecto.

- Se les expone y se les invita a pensarlo y consultarlo en la comunidad.

- Se empieza a repetir las experiencias del territorio anterior, abordado de distinta manera, siempre respetando las ideas y las necesidades de cada comunidad porque son diferentes.

Con el cuarto objetivo "Determinar las necesidades de capacitación de los colegios de secundaria con respecto a la alfabetización informacional en bibliotecología" se visitaron varios colegios, pero sólo en dos se logró ejecutar los talleres (Liceo de Térraba y Boruca). Para este proceso, se solicita el aval del director/a, se le presenta el proyecto y específicamente este objetivo. Una vez proporcionados los permisos, se empiezan las reuniones con los/as estudiantes de IV y V año, para determinar las necesidades y expectativas que tienen para el ingreso a las Universidades Estatales. En dichas reuniones se les invitó a un taller y se les dio un espacio para conocer sus expectativas de información.

En la ejecución del taller:

- Se aclaran dudas. 
- Se les brinda información con ejemplos y con el uso de las TIC del funcionamiento de la Universidad Nacional, las carreras que se imparten.

- Se les dio especial énfasis a la Facultad de Filosofía y Letras, específicamente a las carreras de la Escuela de Bibliotecología.

- Se trabajó en grupos con la información compartida.

- Por último, se les invita a compartir la información que escogieron y se cierra con una plenaria en donde las ejecutantes reafirman y aclaran dudas.

Anteriormente señalé que en este proyecto se han tenido que escribir y reescribir las actividades, además de analizar lo que ya estaba en papel y de alguna forma adaptarlo, ya que en territorio indígena la teoría puede decir una cosa pero el día a día con estos grupos de personas y sus necesidades dicen otra y el proyecto debe ser lo suficientemente amplio para reescribirse y repensarse con el fin de construir poco a poco juntos y juntas esta historia, además se deben crear nuevas actividades para llenar expectativas o en algunos casos solicitudes, así como también y una de las cosas mas importantes, ir ganándose la credibilidad con acciones y actividades donde ellos/as son los/as protagonistas. Lo anterior porque al estar en tierra indígena surgen nuevas ideas, proyectos, actividades que de alguna manera se ven ligadas y debe aprovecharse el momento y las circunstancias y es donde aparece el reescribir el proyecto. 
Lo anterior significa que:

- Visitas a otros territorios como Salitre, su comunidad, Colegio, han dado valor agregado a este proyecto ya que se ha participado con el grupo de quintos años dándoles charlas, en las escuelas del circuito 12, al que pertenece Salitre.

- Otro valor agregado que ha tenido este proyecto es la entrega de cerca de 2.500 documentos productos de la gestión de donación, en 10 escuelas aproximadamente que pertenecen a Boruca y a Térraba. Y otros tantas al circuito 12 de Salitre, para que estas personas que son el futuro de nuestro país y que algunos/as de ellos/as tendrán en sus manos la toma de decisiones, tengan acceso a la lectura, además de contribuir de alguna forma a que tengan más conocimiento, mejoren la ortografía, despierten la imaginación y desarrollen el pensamiento y en poco tiempo contar con más niños y niñas amantes de la lectura.

- Se está trabajando en la elaboración de un taller de técnicas de lectura, primero con docentes y luego en noviembre con los niños y niñas representantes de las escuelas de este circuito.

- En varios momentos de este proyecto se ha gestionado la donación de materiales tanto en Buenos Aires como en San José y Heredia.

- Además se han visitado instituciones como Bancos en donde se ha expuesto el proyecto y a la vez se ha solicitado donaciones para las bibliotecas de Boruca y Térraba. 
- Otro valor agregado, es la gestión desde ARADIKES, (Asociación Regional Indígena del Diques), en esta asociación se están gestionando desde dos actividades:

a. con el objetivo de plantearles el proyecto para que se estudiara la posibilidad de crear una biblioteca Indígena dentro de las instalaciones, ya que por ser una asociación indígena, es el lugar en donde llegan las representaciones de todos los grupos indígenas existentes en Costa Rica,

b. bajo la iniciativa del proyecto se está trabajando desde la conformación de una base de datos creada con el fin de reunir en forma digital (repositorio) todos los documentos, para que todas las personas tengan acceso a esta información.

- Lo anterior se está gestionando desde el curso de control bibliográfico que se imparte en la EBDI en el segundo ciclo, al finalizar este ciclo quedará una base de datos con aproximadamente 544 documentos a texto completo y con acceso en línea.

Otra actividad importante de resaltar es la divulgación del proyecto de la siguiente forma: 
Derecho a la información, bien público y bien privado:...

- Primero en los mismos territorios, tanto los que conforman en proyecto como los que se visitan.

- El semanario Campus de la UNA.

- Página WEB de GEIC.

- Página del Proyecto de Fortalecimiento.

- Por medio de la red que se conformó con el Proyecto GEIC.

- ARADIKES.

- Reuniones y talleres asistidas.

- Estudiantes.

- Colegio de Bibliotecarias/os.

- conare.

- UNA/ Pueblos Indígenas.

- EBDI.

Por último, para finalizar con esta contextualización desde la experiencia, están las gestiones y la creación de la biblioteca de la Comunidad de Térraba. En este territorio se empezó a gestionar en febrero del 2010, en donde se realizaron las mismas actividades que se mencionaron anteriormente, en donde a continuación solo mencionare algunas para no repetir:

- Reuniones en la comunidad, casa por casa, conversando con las personas, compartiendo ideas, anécdotas para llegar a ganarse la confianza de las personas y empezar a trabajar desde la gestión de la información.

- Llegar con planteamientos a partir de las necesidades de cada territorio, respetando su cosmovisión 
(sus creencias, tradiciones, espacios y todo lo referente a su cultura).

- Presentación del proyecto a las personas que la misma comunidad a decidido.

- La Asociación Indígena Comunitaria del Térraba (Aict) es quien resuelve impulsar la apertura de una Biblioteca comunitaria.

- Se traslada la colección de documentos, recopilados en territorio indígena a la EBDI, con el aval tanto de la asociación, para el tratamiento técnico de la información.

- Se entrega el acervo y una base de datos con cerca de 400 documentos, además se trabaja con el comité en el acomodo, de este y la manipulación de la base de datos.

- Posteriormente se emprende la capacitación a varias personas de la comunidad para ayudar en el fomento de habilidades y destrezas para el uso del conocimiento y la organización de la información.

- Se concientiza y sensibiliza al comité para que empiece a dar servicios a la medida.

- Divulgación del proyecto (afiches, panfletos, participación de eventos).

Como resultado final se tiene a partir de octubre del 2010, un espacio para la biblioteca que alberga un estante creado y diseñado por la misma comunidad, (hecho en madera, recogida y sacada de la montaña por ellos/as mismos/as) que aloja este acervo, además se es- 
Derecho a la información, bien público y bien privado:...

tá trabajando en la capacitación de estas personas y en un diagnóstico de necesidades de información.

En este proceso se ha trabajado como se mencionó anteriormente, consultando a la comunidad, dándoles las destrezas y acompañándoles, siempre a su ritmo, sin apresurar ni imponer, lo que ha dado como resultado un trabajo en equipo, dando frutos, una biblioteca, la primera en territorio indígena, dando servicios mínimos, tales como:

- Servicio a sala.

- Búsquedas y apoyo documental.

- Narraciones de cuentos.

- Talleres y capacitaciones.

Paralelamente a lo anterior se construyen talleres (dos) en el Colegio de Térraba con la comunidad estudiantil de cuarto y quinto año, en un acompañamiento para la vida, o sea desde principios de este año se les ha acompañado, buscándoles información de carreras, becas, alojamiento, entre otras y además apoyándoles con la información que necesitan para la toma de sus decisiones.

\section{Conclusiones}

Como conclusión es necesario decir que es un trabajo muy gratificante y a la vez desgastante, ya que el acompañamiento, el compartir lo cotidiano, hacen que una se sensibilice y pretenda casi una utopía, que es, 
no regresar de estos territorios sin haber logrado una biblioteca en cada uno de ellos, ofreciendo servicios; pretensión que no está al alcance de la gestión del proyecto, por diferentes factores como, tiempo, recursos, prioridades, entre otras, y es que el compartir con estas comunidades se aprende mucho de sus saberes y formas de pensar; de sus necesidades y en la cotidianidad aparecen ideas, actividades, solicitudes que no dependen de la gestión de ejecución del proyecto, sino de muchas otras cosas, tomas de decisiones a tiempo, gobiernos locales, falta de recursos económicos, humanos, infraestructura, sensibilización, por mencionar algunos ejemplos.

Otra conclusión tiene que ver con el diseño e implantación de servicios de documentación e información para usuarios/as indígenas que no es de ninguna manera, una tarea fácil. Las dificultades tienen que ver principalmente con la carencia de recursos económicos, medios de comunicación y nuevas tecnologías.

\section{Referencias bibliográficas}

Aja, L. ( 2002). "Gestión de información, gestión del conocimiento y gestión de la calidad en las organizaciones": http://bvs.sld.cu/revistas/aci/ vol10_5_02/aci04502.htm (Consultado el 20 de octubre, 2010) 
Derecho a la información, bien público y bien privado:...

Miranda, A. (2002). Guía para la formulación de proyectos de extensión. Heredia, UNA.

Sánchez, F. (2009). Proyecto Fortalecimiento del desarrollo integral de los pueblos indígenas Boruca, Rey Curré y ó Térraba a través de la gestión de la información 2009-2011. Heredia, UNA.

Universidad Nacional, Costa Rica. Escuela de Bibliotecología, Documentación e Información. (2009). Informe final centro de conocimiento para grupos étnicos indígenas centroamericanos. Heredia, UNA. 


\title{
El derecho a la información desde la perspectiva costarricense: un bien de carácter público
}

\author{
Rosario Solano Murillo y José Pablo Meza Pérez \\ Programa de Bibliotecología \\ Escuela de Ciencias Sociales y Humanidades / \\ Universidad Estatal a Distancia (UNED), Costa Rica \\ rosolano@uned.ac.cr
}

\section{Introducción}

1 iniciar una disertación referente al derecho a la
información como un bien de carácter público, y
al referirnos al caso particular de Costa Rica, conviene
ubicar en primera instancia el espíritu democrático de
nuestro país, el respeto a la libre expresión del indivi-
duo y la infodiversidad que nos distinguen, aunado al
compromiso social de nuestra profesión por fomentar
la accesibilidad a la información.
Como lo señala Morales Campos (2003), "la infodi-
versidad es un fenómeno manifestado con mayor auge
en el proceso de globalización, el incremento del uso
intensivo de las tecnologías de la información, la explo-
sión de la información, el aumento exponencial de la
capacidad de comunicación y el factor de inclusión so-
cial de la pluraridad y la diversidad cultural de los pue- 
Derecho a la información, bien público y bien privado:...

blos"; siendo este último tema de gran preocupación como elemento medular al definir una política nacional de información, que conlleve aparejado el derecho a la información como un bien público de la sociedad, en general.

En esta época de constantes transformaciones en todos los ámbitos, pero en especial en la producción de bienes y servicios debido a la enorme cantidad de información que se produce y de los medios tecnológicos mediante los que ésta se disemina, la sociedad se ha visto en la necesidad de establecer normas que ordenen y a la vez favorezcan el uso de estos recursos con el afán de hacer valer el derecho a la información, de manera permanente e inalienable para el ciudadano.

Para cumplir con este cometido es necesario que el Estado enmarque y regule los alcances del derecho a la información considerando aspectos jurídicos y políticos, para lo que se requiere de manera obligada del establecimiento de políticas nacionales de información. Bajo esta perspectiva acceder a la información debe contemplarse desde su perspectiva como bien público y como bien privado: acceso comunitario y acceso individual.

\section{El derecho a la información}

En forma sinóptica López López y Morillo Caldero (2003), identifican los antecedentes más lejanos del derecho a la información en el pensamiento filosófico de las Revoluciones Francesas y Americana. En sus 
El derecho a la información desde la perspectiva costarricense: ...

inicios, el derecho a la información mantuvo un vínculo con la libertad de expresión, manifestada en la $D e$ claración del Buen Pueblo de Virginia de 1776. Este principio también se encuentra presente en el artículo 11 de la Declaración de los Derechos del Hombre y del Ciudadano de1789. Desde el Renacimiento, en que dio inicio una visión menos teológica y más cosmogónica de la naturaleza humana, pero en especial a partir de la Ilustración, el ser humano sintió la necesidad de otorgar de manera más concreta un espíritu filosófico y universal a sus vivencias cotidianas, de modo que concordó en su necesidad de ordenar y ejemplificar sus derechos mediante la manifestación de declaraciones o cartas universales.

Posterior a esa transformación de la filosofía de la historia $\mathrm{y}$, más recientemente en el siglo $\mathrm{xx}$, como producto del vacío encontrado en el respeto de los derechos humanos sobre todo a raíz de los conflictos vividos durante la Segunda Guerra Mundial y de la falta de un organismo que regulara e hiciera valer esos derechos se crean las Naciones Unidas cuya intención primordial en sus inicios fue la instauración de la Declaración Universal de los Derechos Humanos (1948).

Como señala Villalobos Quirós (2000), esta Declaración consagra en su artículo 19 el derecho a la información como un derecho humano que a la letra dice:

Todo individuo tiene derecho a la libertad de opinión y de expresión; este derecho incluye el de no ser molestado a causa de sus opiniones, el de investigar y reci- 
Derecho a la información, bien público y bien privado:...

bir informaciones y opiniones, y el de difundirlas, sin limitación de fronteras, por cualquier medio de expresión. (Declaración Universal de los Derechos Humanos, 1948. Art 19.)

El advenimiento de una nueva visión y otro concepción del mundo forjó en nuestro continente la necesidad de unir esfuerzos y establecer lazos de amistad en búsqueda de la protección ciudadana y territorial. Así se creó la Organización de Estados Americanos, consolidando, entre otras razones, la formación de un foro político para el diálogo multilateral y la toma conjunta de decisiones, el como fortalecer la paz, apoyar el desarrollo social, consolidar la democracia y promover los derechos humanos.

Bajo esta perspectiva, la OEA suscribió en 1969 la Convención Americana sobre Derechos Humanos, que entró en vigor a partir de 1978 . En un contexto inmediato siempre referido a América Latina, la Convención Americana sobre Derechos Humanos o Pacto de San José de Costa Rica, garantiza las libertades de pensamiento y expresión como fundamento para el respeto al derecho de información en el ámbito regional y que en su artículo 13 , revela:

Toda persona tiene derecho a la libertad de pensamiento y de expresión. Este derecho comprende la libertad de buscar, recibir y difundir informaciones e ideas de toda índole, sin consideración de fronteras, ya sea oral- 
El derecho a la información desde la perspectiva costarricense: ...

mente, por escrito o en forma impresa o artística, o por cualquier otro procedimiento de su elección. (Convención Americana sobre Derechos Humanos, 1969, p. 5).

El alcance de esta Convención es amplio y trasciende el ámbito nacional de cada país miembro, para situarse en el marco de la producción, la publicación y la difusión de la información a nivel regional. Como tal, la información es un derecho extraterritorial y garantiza su difusión por diferentes medios de comunicación, más allá del medio impreso y en consecuencia no puede ser sujeto de la censura. Aunque expresamente no se mencionan los medios electrónicos, su interpretación es bastante general como para incluirlos para comunicar información.

Otro de los justificantes por los cuales el derecho a la información juega un papel importante es el valor económico. Los procesos de industrialización mundial iniciados desde el siglo XIX, la transformación de los medios de intercambio económico, aunado a la creación de los primeros ordenadores y la generación exponencial de la información, ha favorecido la aparición de un tercer sector de la economía que se refiere a la esfera de los servicios y, particularmente, aquellos ligados a la comunicación de datos e información.

La información y el conocimiento, como elementos de este sector de la economía, tienen un valor en su contexto histórico y social. La esfera de servicios en la sociedad actual resulta compleja, según datos de Meza Pérez (2009), representa cerca $46 \%$ del producto inter- 
Derecho a la información, bien público y bien privado:...

no bruto de la Unión Europea y de manera semejante lo es para en otros hemisferios del planeta; tener la capacidad de utilizar, comunicar y controlar la información resulta un bien codiciado.

Para Soler (2001) no es casual que diez compañías de telecomunicaciones controlen $86 \%$ del mercado de las comunicaciones. Otro dato importante de contemplar es que el $96 \%$ de las patentes están en manos de los países industrializados.

En esencia, la información y el conocimiento facilitan un posicionamiento determinante para generar valor y poder, el primero, como base para la generación del conocimiento y la información objetiva, para la conformación de datos estructurados y la generación de nueva información y nuevo conocimiento que le de valor agregado al producto.

Además de los factores aquí reseñados, el derecho a la información es un elemento que impulsa la transferencia de tecnología, la innovación y la investigación, impacte en forma directa al desarrollo nacional y al bienestar y calidad de vida de las personas. El derecho a la información, debe estar necesariamente enmarcado en las políticas nacionales de información así como ser obligatorias y esenciales por parte del gobierno de cada país.

Al ser la información el insumo primordial del desarrollo de los países, y de los avances en el plano investigativo, la implementación de las políticas nacionales es una tarea importante para el gremio de especialistas en este campo. Su impulso y consolidación deben ser 
El derecho a la información desde la perspectiva costarricense: ...

un compromiso constante y enérgico. Además, resulta una estrategia para potenciar el valor de la información y como elemento de desarrollo e instrumento para preservar el patrimonio histórico, científico, social, así como la diversidad cultural de una nación.

\section{Legislación costarricense}

En la actualidad, la firma de tratados de libre comercio ha generado la necesidad de la actualización en los temas relativos a derechos de autor, propiedad intelectual, reproducción, difusión, marco de acción, así como el uso y protección de datos y de fuentes de información. Ante esta perspectiva, lo cierto es que las legislaciones nacionales se ven obligadas a actualizarse, y armonizarse, a fin de estar acordes con los tiempos y con las circunstancias, de tal manera se busca eliminar las discordancias y buscar asimetrías entre las diferentes legislaciones de cada país, entre sí y con respecto a la normativa internacional. Para este cumplimiento, en Costa Rica, se creó el 12 de octubre de 2000, la Ley, n. 8039, o Ley de Procedimientos de Observancia de los Derechos de Propiedad Intelectual; dicha Ley cumple con los requisitos exigidos por la Organización Mundial del Comercio, de la que Costa Rica forma parte. Más recientemente, el 3 de mayo de 2010, se publicó el decreto de Reforma al Reglamento de la Ley de Autores en el cual se señalan las principales modificaciones a la legislación costarricense a fin de hacerla concordar con los compromisos adquiridos 
Derecho a la información, bien público y bien privado:...

mediante la firma del Tratado de Libre Comercio entre Estados Unidos Centroamérica y República Dominicana (CAFTA, por sus siglas en inglés) y con los convenios suscritos con la Organización Mundial para la Propiedad Intelectual (OMPI). Señala la modificación del reglamento derechos de autor en sus considerandos las siguientes reformas, en sus artículos $2^{\circ}$ y $7^{\circ}$ :

Que la Ley n. 8686, de 21 de noviembre de 2008 reformó, adicionó y derogó una importante cantidad de normas en materia de derechos de autor y derechos conexos afectando la Ley sobre Derechos de Autor y Derechos Conexos n. ${ }^{\circ}$ 6683, de 14 de octubre de 1982, derogando los artículos 3 y 61 de esa Ley, adecuando la normativa interna a los compromisos que el país adquirió en esa materia específicamente en el Capítulo XV del Tratado de Libre Comercio.

La Ley n. 8622 de 21 de instrumentos internacionales relacionados en las anteriores consideraciones, ratificados y consecuentes todos con la legislación nacional, no afectan, limitan, excluyen o disminuyen la protección que la ley costarricense le reconoce y concede a los autores y compositores, ni afecta la esfera moral o patrimonial de los derechos de autor sobre sus obras literarias o artísticas originales, ni el pleno ejercicio de esos derechos. (Reglamento Ley sobre Derechos de Autor y leyes conexas n. 36014-MP-COMEX-J. p. 3).

Estas modificaciones a la legislación costarricense en algunos aspectos han logrado mayor apertura en aspectos que tradicionalmente eran sumamente res- 
El derecho a la información desde la perspectiva costarricense: ...

trictivos y rígidos. Esta reforma del Reglamento de la Ley sobre Derechos de Autor y Derechos Conexos, es importante ya que regula y esclarece la figura de la comunicación pública en su artículo 3, inciso 4, el cual estable los alcances y limitaciones en materia de derechos de autor definiéndola como,

El acto mediante el cual la obra literaria o artística protegida se pone al alcance del público, por cualquier medio o procedimiento que no consista en la distribución de ejemplares, de forma que pueda ser recibida o percibida por las personas a cambio de una contraprestación o ventaja económica. Todo el proceso necesario y conducente a que la obra se ponga al alcance del público con ese propósito constituye comunicación pública. (Reglamento Ley de Derechos de Autor y Derechos Conexos, p. 42).

Las reformas en otros aspectos son más restrictivas en especial, lo referido con la protección de datos de investigación, patentes, especialmente de productos químicos y medicamentos. Aumentando los años de reserva para la divulgación de los datos o prescripción de la cobertura de la reserva de explotación.

\section{Accesibilidad y uso de tecnologías de la información en Costa Rica}

La brecha digital es otro de los factores que inciden en la participación para ejercer el derecho a la infor- 
Derecho a la información, bien público y bien privado:...

mación, y beneficiarse de las Tecnologías de la In-formación y la Comunicación, TIC. Según lo anota Meza Pérez (2009), el indicador Networked Readiness Index (NRI) o índice de capacidad de acceso a la red que evalúa 68 variables con base en tres criterios: a)entorno favorable normativo, infraestructura y clima de negocios para desarrollar las TIC. b)Nivel de disponibilidad y uso de las TIC y c)Uso real de las TIC. (Meza p., 2009. p. 5).

Al cotejar estos parámetros con la realidad costarricense, se evidencia que Costa Rica mantiene una posición intermedia dentro de la evaluación de 122 países. A nivel regional ocupa posiciones de privilegio para dar un salto cualitativo y cuantitativo. Un enfoque estratégico para este avance es la cobertura de telefonía celular cercana a un $80 \%$, así como un 93\% de electrificación en todo el territorio nacional, condiciones de infraestructura que le son muy favorables para considerar un avance significativo. La siguiente tabla ilustra cómo el indicador NRI, ubica a los países centroamericanos y a República Dominicana, dentro de la disposición de conectividad para el bienio 2006-2007:

Tabla n. 1: The Networked Readiness Index 2006-2007 rankings Países de Centroamérica, Panamá y República Dominicana

\begin{tabular}{|c|c|c|}
\hline Posición & País & índice NRI \\
\hline 56 & Costa Rica & 3.77 \\
\hline 61 & El Salvador & 3.66 \\
\hline 65 & Panamá & 3.58 \\
\hline
\end{tabular}


El derecho a la información desde la perspectiva costarricense: ...

\begin{tabular}{|c|c|c|}
\hline 66 & República Dominicana & 3.56 \\
\hline 79 & Guatemala & 3.41 \\
\hline 94 & Honduras & 3.09 \\
\hline 103 & Nicaragua & 2.95 \\
\hline
\end{tabular}

Fuente: The Networked Readiness Index 2006-2007 rankings (2008). Consultado el 11 de junio, 2008 Disponible en: http://www.weforum.org/pdf/gitr/ rankings2007.pdf

\section{La conectividad}

La conectividad a la red Internet es un factor que incide directamente con el derecho a la información y su accesibilidad. Recientemente, la Sala Constitucional, emitió un fallo y declaró el acceso a Internet como un derecho fundamental de los ciudadanos que obliga a promover y garantizar en forma universal la democratización del uso y accesibilidad a las nuevas tecnologías de información y comunicación.

Sobre este criterio, Miguel González, director ejecutivo de la Cámara de Infocomunicación y Tecnología, manifestó: "Se puede decir que con esta resolución Costa Rica ha consolidado su modelo de competencia con inclusión social" (Fallo de la Sala Constitucional: Acceso a Internet es un derecho fundamental, p. 10).

El más reciente informe anual "Hacia la Sociedad de la Información y el Conocimiento en Costa Rica, 2009”, del Programa de la Sociedad de la Información y el Conocimiento, (PROSIC) de la Universidad de Costa Rica, señala citando a su vez como fuente de datos al Minis- 
Derecho a la información, bien público y bien privado:...

terio de Ciencia y Tecnología, año 2008 afirma, que la red de información más utilizada para la transferencia de datos e información en Costa Rica entre las instituciones del sector público, académico, organizaciones sin fines de lucro (OSFL) y organismos internacionales, en el período del 2008 al 2009, es mayoritariamente, Internet. De manera ilustrativa, el siguiente gráfico, muestra numéricamente estos registros:

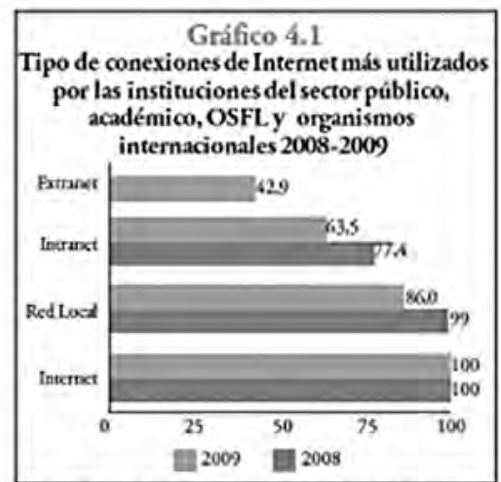

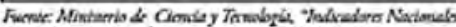

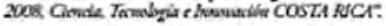

Concretamente estos datos dan evidencia de cómo el sector público, académico, organizaciones sin fines de lucro y organismos internacionales en Costa Rica, predomina el uso de Internet en forma pública para difundir información, un bien de dominio público. De manera más amplia se consignan los usos dados a la red de Internet, como se expone en el siguiente gráfico: 
El derecho a la información desde la perspectiva costarricense: ...

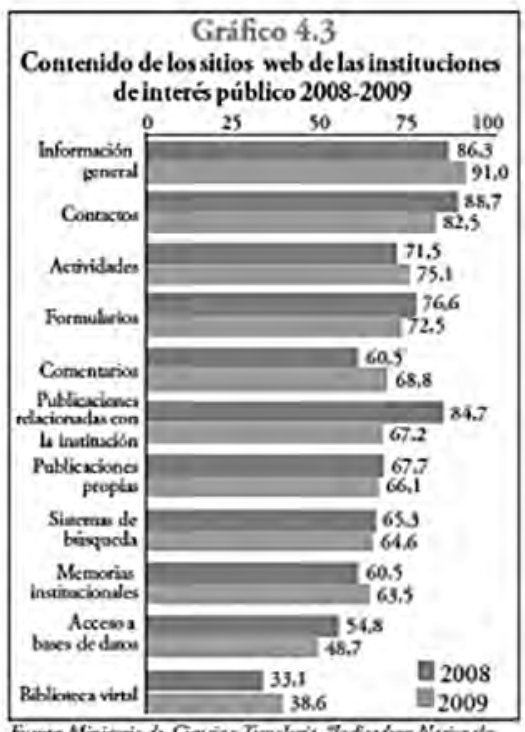

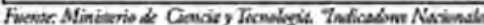

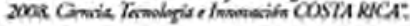

Estos números evidencian un comportamiento que permite establecer algunos nichos de acción para los especialistas en ciencias de la información, como lo son el facilitar el acceso a la producción autóctona institucional y el desarrollo de bibliotecas virtuales, rubro que entre los años 2008 y 2009, muestra una tendencia de crecimiento de un $5.4 \%$.

También, los principales usos y la utilización de páginas web, que realiza el sector empresarial mediante el uso de Internet se muestran en el siguiente gráfico: 


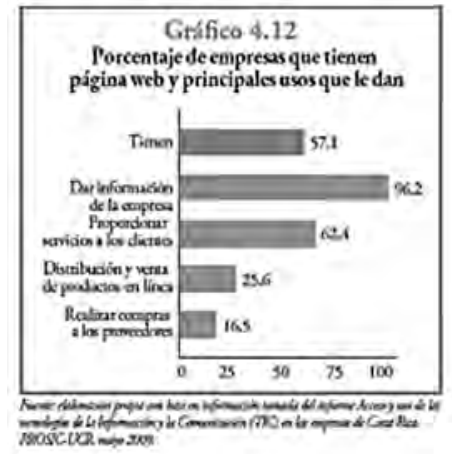

La innovación en el empleo de las tecnologías de información y comunicación es cambiante y se manifiesta en nuevos fenómenos comunicativos. El auge de las redes sociales se ha convertido en un mecanismo muy efectivo de comunicación con los clientes y proveedores. Hoy, muchas de las empresas, organizaciones e instituciones públicas dedican parte del tiempo laboral, en atender sus perfiles en las redes sociales como Facebook, Twitter, hi5 y otras. Es un nuevo fenómeno presente hasta en comunidades de profesionales que mantienen contactos y trabajos colaborativos en formas tan novedosas como los colegios invisibles o redes del conocimiento.

Hasta este momento hemos analizado la capacidad de producción y comunicación de dos actores principales, las organizaciones y los sectores empresariales que por su naturaleza se han logrado posicionar en la red de Internet. Sin embargo, ahora nos abocaremos a 
conocer el acceso a las tecnologías de la información que realiza el ciudadano costarricense.

Las aristas y alcances del derecho a la información son bastantes extensos pero en el contexto de la sociedad de la información y del conocimiento, el ciudadano requiere de un marco jurídico que le sustente para ejercer ese derecho, accediendo al uso de las tecnologías de información y comunicación. En el último quinquenio, el ciudadano medio ha incrementado en forma importante el acceso a diferentes recursos de las tecnologías, evidenciando como país un gran esfuerzo por integrarse a este nuevo reto de la sociedad.

De manera ilustrativa, el siguiente gráfico detalla la variación en la tenencia de las diferentes TIC en las viviendas en el quinquenio 2005-2009:

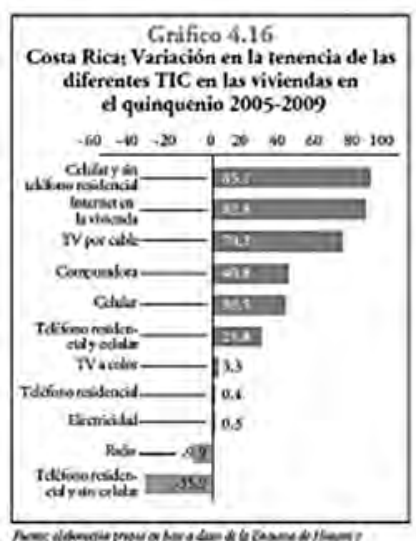

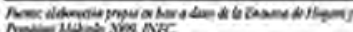


Porcentualmente, un $85.1 \%$ tiene un acceso a la telefonía celular y se ha incrementado en $82.8 \%$ el acceso de Internet en la viviendas. Otro dato importante de resaltar es que la tenencia de computadoras en los hogares costarricenses en el quinquenio 2005-2009, se ha incrementado en un $40.8 \%$.

Otra dato significativo y de gran importancia para nuestra sociedad es la disparidad en el acceso a las tecnologías de la información y la comunicación, según los diferentes estratos socioeconómicos. Los informes del Estado de la Nación, en varios años han señalado la injusta distribución del ingreso en Costa Rica y esto se refleja también en las oportunidades de acceder a recursos tecnológicos por parte del ciudadano costarricense (XV Informe Estado de la Nación, 2010).

Según informes aportados por la "Encuesta de hogares y propósitos múltiples, 2009”, presentado en el siguiente gráfico, evidencia el porcentaje de viviendas con tenencia de diferentes TIC, en contraposición con la tasa de crecimiento en el quinquenio 2005-2009 (por quintil de ingreso): 
El derecho a la información desde la perspectiva costarricense: ...

\begin{tabular}{|c|c|c|c|c|c|c|c|c|c|c|}
\hline \multicolumn{11}{|c|}{ 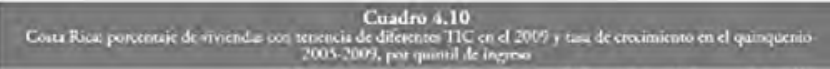 } \\
\hline \multirow[b]{2}{*}{ IIC } & \multicolumn{2}{|c|}{ Quintalt } & \multicolumn{2}{|c|}{ Quentil II } & \multicolumn{2}{|c|}{ Quisent III } & \multicolumn{2}{|c|}{ Qument IV } & \multicolumn{2}{|c|}{ Quimat V } \\
\hline & 2000 & Thes & $200 \%)$ & Tas & 2009 & Trod & 2009 & Thes & 2009 & Twa \\
\hline Radio & 685 & $-12,6$ & 74,2 & $-13,2$ & 78,9 & $-8,1$ & 82,5 & -8.7 & 84.9 & -7.5 \\
\hline TV a colar & 917 & 10.3 & 95,5 & 36 & 96,5 & 1.3 & 95,1 & 20 & 97.7 & -0.5 \\
\hline Teldoeso raidencial & 50.0 & 15,2 & 60,4 & -15 & 663 & $-1,1$ & 71,2 & -5.0 & 79.9 & $-4,2$ \\
\hline Celular & 46.9 & 176,1 & 59,1 & 724 & 71,6 & 466 & 80.5 & 23.7 & 89.3 & 71 \\
\hline TV por calle & 187 & 326,2 & 26,5 & 185.4 & 36,7 & 131.6 & 46,8 & 76.5 & 64.7 & $21 \lambda$ \\
\hline Compuesdirs & 16,9 & 169.9 & 24,2 & 965 & 3,0 & 1006 & 479 & 36,3 & 70,7 & 19.2 \\
\hline Internet en La vivienda & 3.1 & 655,2 & 7.5 & 319.3 & 12,7 & 217,4 & 22,0 & 91.1 & 47.7 & 50.5 \\
\hline Tel residencid y in celuler & 25,0 & 20.0 & $2 \alpha, 5$ & -35.6 & 17.1 & .05 .5 & 13.3 & -12.1 & 6,6 & -16.5 \\
\hline Celular y sia teldfono res. & 219 & 188,5 & 23,2 & 113,1 & 22,4 & 72,1 & 22.7 & 71.9 & 16,1 & 320 \\
\hline Takfoes fer.y colutir & 25,0 & 166.1 & 35.9 & 34.0 & 49.2 & 37.8 & 57.5 & 11.7 & 73.2 & 3.1 \\
\hline
\end{tabular}

El cuadro anterior muestra la desigualdad de accesos de los recursos tecnológicos por estrato o "percentiles" de ingreso económico. Destacándose que en los "percentiles" más altos la tenencia de celulares, telefonía fija, computadoras e Internet es significativamente, mayor. Este dato representa un reto como país para cumplir con el objetivo de lograr una inclusión social de todos los ciudadanos en forma igualitaria de acceso y oportunidades a los servicios y por ende, a la sociedad de la información.

También existen diferencias geográficas importantes, la cobertura de servicios no es igual en todo el país y está concentrada en la región central. Según muestra en el siguiente gráfico: 


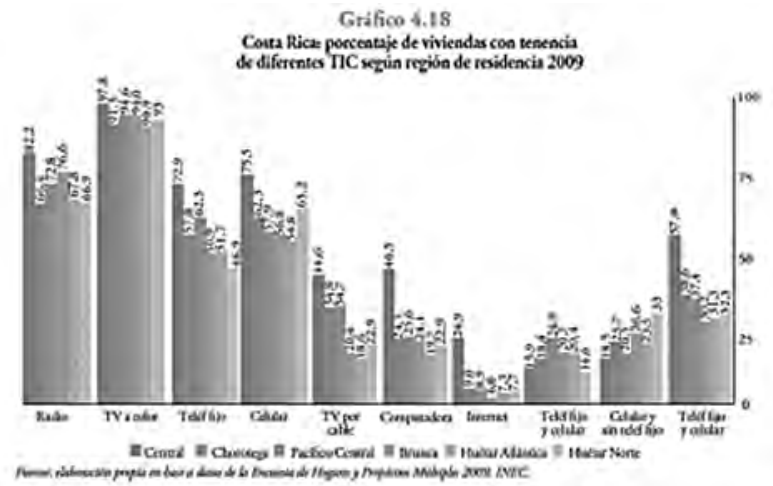

Geográficamente, el Gran Área Metropolitana, concentra de manera significativa el mayor acceso a computadoras e Internet en los hogares costarricenses, poniendo en desventaja al resto del país. Lógicamente, esta situación evidencia una disparidad en la conectividad, accesibilidad y uso de las tecnologías.

Los datos sobre la cobertura de Internet varían de acuerdo con diferentes estudios, sin embargo, se puede inferir que rondan aproximádamente al 40\% de la población, según fuentes periodísticas recientes (Fallo de la Sala Constitucional: Acceso a Internet es un derecho fundamental, p. 10). Los ciudadanos costarricenses acceden a Internet desde, su hogar, cafés Internet, lugares de estudio o trabajo. Como se muestra en el gráfico siguiente, elaborado con base a un estudio de CID-Gallup contratado por RACSA en el año 2009: 
El derecho a la información desde la perspectiva costarricense: ...

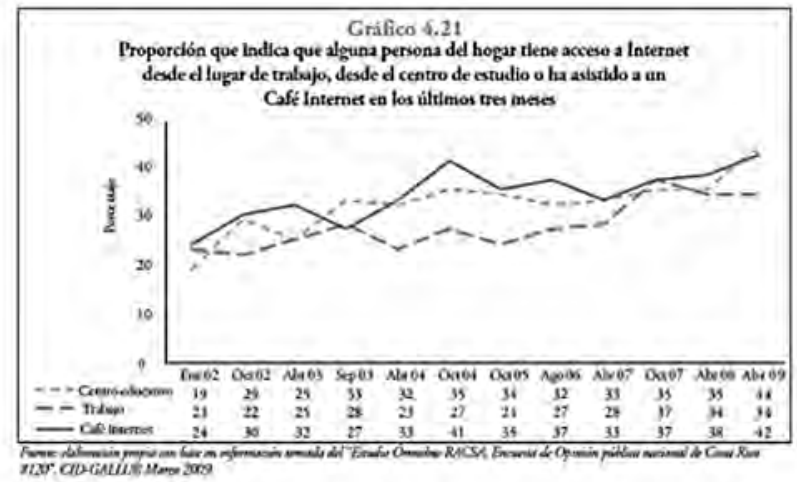

\section{A manera de conclusión}

La necesidad de enmarcar jurídica y políticamente el uso de la información, y los derechos que le asisten, a todo ser humano en su accesibilidad han representado un proceso a lo largo del tiempo. El carácter universal al derecho a la información es un derecho manifiesto que ha contado con el apoyo decidido de organismos de trascendencia mundial y regional, como las Naciones Unidas y la Organización de Estados Americanos.

En el caso particular de Costa Rica, los argumentos expuestos sobre la contextualización del desarrollo del derecho de la información, las modificaciones jurídicas recientes, el fallo de la Sala Constitucional, los amplios márgenes de cobertura del significado de "comunicación pública" y las descripción de algunos elementos importantes de la realidad nacional han sido elemen- 
Derecho a la información, bien público y bien privado:...

tos propiciatorios para permitir la democratización en el uso y accesibilidad de los recursos de información. Sin embargo, la disparidad en los ingresos económicos y la capacidad de cobertura de las telecomunicaciones, es una tarea que está aún a mitad del camino.

El estado costarricense según el criterio emanado de la Sala Constitucional garantiza la universalidad del acceso a Internet sin exclusiones, como un derecho fundamental. Sin embargo, la realidad costarricense representa un reto para los profesionales de la información a fin de lograr la democratización del acceso a la información, libremente. Las barreras socioeconómicas y geográficas no pueden ser una limitante para el desarrollo de productos de información, pero se convierten en una condición o variable a considerar.

El Informe anual (2009) del Programa de la Sociedad de la Información y el Conocimiento (PROSIC), resalta un componente de mucha importancia sobre el papel de las bibliotecas virtuales su conceptualización y su impulso. "Con relación a los sistemas de organización del conocimiento, en la investigación realizada encontramos debilitada esta importante área, pues aún la mayoría de las bibliotecas y centros especializados no implementan cambios sustanciales" (Prosic. 2009. p. 232)

Los retos de la sociedad de la información se encuentran ligados a la gestión, difusión y libre acceso al patrimonio histórico, científico y cultural de una nación. La infordiversidad es un bien público que se debe preservar. Las bibliotecas, en sus múltiples formas, siempre han sido celosas guardines de sus acervos 
El derecho a la información desde la perspectiva costarricense: ...

y con el patrimonio documental digital no puede ser diferente.

El articular acciones de una política nacional de información es una buena estrategia para empoderar el momento histórico de la sociedad costarricense y potenciar las ventajas legales que nos ofrece el marco jurídico, así como minimizar las barreras económicas y geográficas.

Como país se han desarrollado importantes acciones para implementar una Política Nacional de Información, que articule las acciones del estado y recientemente se pueden identificar las siguientes acciones:

-El proyecto gobierno digital que en su etapa inicial fue integrado por una directriz presidencial que obligaba a todas las instituciones del estado a poner en funcionamiento una página web de información para todos los ciudadanos.

- La Unidad de Información del Ministerio de Economía Industria y Comercio (MEIC) después de un proceso iniciado en año 2005 y del trabajo conjunto de especialistas en las ciencias de la información, ha realizado una labor importante en el ámbito de la administración pública al establecer las directrices que debe seguir la gestión documental institucional.

- La labor implementada por el Ministerio de Cultura y el sistema Nacional de Bibliotecas, al digitalizar parte de su patrimonio documental y disponerlo mediante su página web. 
- Pero el trabajo más sistemático en la conformación de una política nacional de información es la labor liderada por el Ministerio de Agricultura y fruto del trabajo de las unidades de información del subsector de agrícola en el año 2010, proponen una Política Nacional de información Documental para el Sector Agropecuario, con lineamientos específicos.

Finalmente, podemos concluir que el derecho a la información en el caso costarricense es un bien público, garantizado con respaldo jurídico en la normativa vigente. Los procesos de actualización de ésta, después de la ratificación de instrumentos comerciales y jurídicos internacionales, han permitido armonizar los conceptos legales y posiblemente representa uno de los mayores impactos para sustentar la aplicabilidad del concepto de comunicación pública, que en consecuencia, otorga un marco de seguridad jurídica importante para ejercer como ciudadanos el derecho a informarse y ser informado.

\section{Bibliografía}

Arce Gómez, C, ed. (2007). Ley sobre Derechos de Autor y Derechos Conexos y su Reglamento. San José, C. R.: Editorial Universidad Estatal a Distancia. 
El derecho a la información desde la perspectiva costarricense: ...

Castro Bonilla, A. (2006). Derecho de autor y nuevas tecnologías. San José, C. R.: Editorial Universidad Estatal a Distancia.

(2010). Reglamento Ley sobre Derechos de Autor y Derechos Conexos y leyes conexas. N. 36014-MP-COMEX-J. San José, C.R. Imprenta Nacional.

Instituto Nacional de Estadística y Censos. (2009). Encuesta de hogares y propósitos múltiples 2009. San José, C. R.: INEC.

López López, P. y Morillo Caldera, M.J. (2003). "Derecho a la información y democracia en el marco de la globalización neoliberal: bibliotecas, archivos y medios de comunicación de masas". Revista General de Información y Documentación. 13, núm. 297-131.

Meza Pérez, J. P. (2009). Operacionalización de una red virtual de conocimiento para los productores documentales e investigadores en administración pública y finanzas para Centroamérica, Panamá y República Dominicana. San José: Universidad de Costa Rica, Escuela de Bibliotecología. (Tesis de Posgrado).

Morales, E. (1999) "El derecho a la información y las políticas de Información en América Latina". 65th IFLA Conference. Bangkok, Thailand: IFLA. 
Derecho a la información, bien público y bien privado:...

Programa de la Sociedad de la Información y el Conocimiento. (2009). Acceso y uso de las tecnologías de la información y la comunicación en las empresas de Costa Rica, mayo 2009. San José, C. R.: PROSIC- Universidad de Costa Rica.

Informe anual. San José, C.R.: PROSIC- Universidad de Costa Rica.

XV Informe del Estado de la Nación. (2010). San José, C. R.: Programa Estado dela Nación.

Soler, F. (2001). Mundialización, globalización y sistema capitalista. Valencia, España: Universidad de Valencia.

Villalobos Quirós, E. (2000). El Derecho a la Información. San José, C. R.: Editorial Universidad Estatal a Distancia.

\section{Enlaces electrónicos}

Convención Americana Sobre Derechos Humanos (1969). OEA. Washington. Consultado 22 de setiembre, 2010. Disponible en: http://www. oas.org/juridico/spanish/tratados/b-32.html

Costa Rica. Leyes y Decretos. (2000). Ley de Procedimientos y Observancia de la Propiedad Intelectual. Consultado 22 de setiembre, 2010. Disponible en bttp://www.webdelambiente.com/ legislacion/Leyes/8039\%20Ley\%20Procedimien- 
El derecho a la información desde la perspectiva costarricense: ...

tos $\% 20$ de $\% 20$ Derechos $\% 20$ de $\% 20$ Propiedad $\% 20$ Intelectual.pdf

Costa Rica. Leyes y Decretos. (2010). Políticas de Información Documental para el Sector Agropecuario Costarricense. (26 de febrero). La Gaceta Digital: Diario Oficial, n. 40. Disponible en http://historico.gaceta.go.cr/pub/2010/02/26/ COMP_26_02_2010.pdf

Declaración Universal de los Derechos Humanos. (1948) Naciones Unidas. Consultado 22 de setiembre, 2010. Disponible en: http://www. un.org/es/documents/udhr/

González, M. (2010). Fallo de la Sala Constitucional: Acceso a Internet es un derecho fundamental ( 6 de octubre) La Nación. Consultado el 6 de octubre, 2010. Disponible en http://www.nacion.com/201008/ElPais/NotasSecundarias/E Pais2514038.aspx

The Networked Readiness Index 2006-2007 rankings. (2008). Consultado el 11 de junio, 2008. Disponible http://www.weforum.org/pdf/gitr/ rankings2007.pdf

Sala Constitucional. (2010). Fallo de la Sala Constitucional: Acceso a Internet es un derecho fundamental (6 de octubre) La Nación. Consultado el 6 de octubre, 2010. Disponible en http://www. nacion.com/201008/ElPais/NotasSecundarias/ElPais2514038.Aspx. 

Derecho a la información, bien público y bien privado: acceso comunitario $y$ acceso individual. Coordinación editorial, Zindy E. Rodríguez Tamayo. Revisión especializada, Homero Quezada Pacheco. Formación editorial, Christopher Barrueta Álvarez. Centro Universitario de Investigaciones Bibliotecológicas/UNAM. México D.F. julio de 2011. 